\title{
Diels-Alder Approach for the Construction of Halogenated, ortho-Nitro Biaryl Templates and Application to the Total Synthesis of anti-HIV Agent Siamenol.
}

Michael R. Naffziger, Bradley O. Ashburn, Johanna R. Perkins and Rich G. Carter*

Department of Chemistry, Oregon State University, Corvallis, OR 97331.

Electronic Supplementary Information: Experimental 
General. Infrared spectra were recorded neat unless otherwise indicated and are reported in $\mathrm{cm}^{-1}$. ${ }^{1} \mathrm{H}$ NMR spectra were recorded in deuterated solvents and are reported in ppm relative to tetramethylsilane and referenced internally to the residually protonated solvent. ${ }^{13} \mathrm{C}$ NMR spectra were recorded in deuterated solvents and are reported in ppm relative to tetramethylsilane and referenced internally to the residually protonated solvent.

Routine monitoring of reactions was performed using EM Science DC-Alufolien silica gel, aluminum-backed TLC plates. Flash chromatography was performed with the indicated eluents on EM Science Gedurian 230-400 mesh silica gel.

Air and/or moisture sensitive reactions were performed under usual inert atmosphere conditions. Reactions requiring anhydrous conditions were performed under a blanket of argon, in glassware dried in an oven at $120^{\circ} \mathrm{C}$ or by flame, then cooled under argon. Dry DMF, THF, DCM, and PhMe were obtained via a solvent purification system. All other solvents and commercially available reagents were either purified via literature procedures or used without further purification.

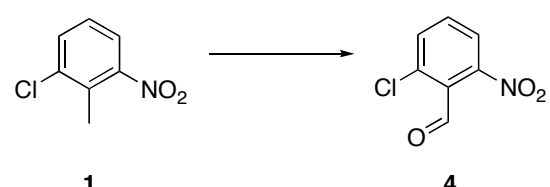

Aldehyde 4: To a stirred solution of $1(18.53 \mathrm{~g}, 108.0 \mathrm{mmol})$ in dry DMF $(240 \mathrm{~mL})$ was added $N, N$-dimethylformamide dimethyl acetal (DMF•DMA) $(39.5 \mathrm{~g}, 44.0 \mathrm{~mL}, 331 \mathrm{mmol})$. After heating at $140^{\circ} \mathrm{C}$ for $16 \mathrm{~h}$, the dark red solution was cooled to $0^{\circ} \mathrm{C}$ and added slowly, over $1 \mathrm{~h}$ via cannula, to a rapidly stirred solution of $\mathrm{NaIO}_{4}(83.0 \mathrm{~g}, 388.0 \mathrm{mmol})$ in $\mathrm{H}_{2} \mathrm{O}(291 \mathrm{~mL})$ and $\mathrm{DMF}(77 \mathrm{~mL})$ at $0^{\circ} \mathrm{C}$. The reaction flask was washed with $\mathrm{DMF}(20 \mathrm{~mL})$ at $0^{\circ} \mathrm{C}$ and added to $\mathrm{NaIO}_{4}$ mixture. The reaction was stirred at $0^{\circ} \mathrm{C}$ for $2 \mathrm{~h}$ then allowed to warm to rt. After an additional $6 \mathrm{~h}$, the orange solution was filtered and rinsed with $\mathrm{PhMe} / \mathrm{EtOAc}(1: 1,200 \mathrm{~mL})$. The filtrate was then washed with $\mathrm{H}_{2} \mathrm{O}(3 \times 150 \mathrm{~mL})$ and sat. aq. $\mathrm{NaCl}(3 \times 150 \mathrm{~mL})$. The dried $\left(\mathrm{MgSO}_{4}\right)$ extract was concentrated in vacuo to a dark red oil, and hexanes $(40 \mathrm{~mL})$ were added. Solids were isolated and recrystalized in PhMe to give the known aldehyde $\mathbf{4}^{1}$ (17.23 g, $92.88 \mathrm{mmol}, 86 \%) .{ }^{1} \mathrm{H}$ NMR $\left(400 \mathrm{MHz}, \mathrm{CDCl}_{3}\right) \delta 10.42(\mathrm{~s}, 1 \mathrm{H}), 8.01(\mathrm{dd}, J=1.0,8.2 \mathrm{~Hz}, 1 \mathrm{H}), 7.79$ $(\mathrm{dd}, J=1.0,8.1 \mathrm{~Hz}, 1 \mathrm{H}), 7.65(\mathrm{t}, J=8.1 \mathrm{~Hz}, 1 \mathrm{H}) ;{ }^{13} \mathrm{C} \mathrm{NMR}\left(100 \mathrm{MHz}, \mathrm{CDCl}_{3}\right) \delta 188.6,148.4,138.6$, $132.9,132.4,123.4,121.9$.

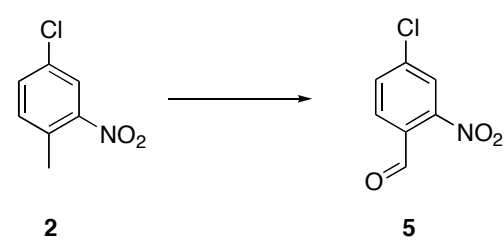

Aldehyde 5: ${ }^{2}$ To a stirred solution of $2(5.248 \mathrm{~g}, 30.59 \mathrm{mmol})$ in dry DMF $(172 \mathrm{~mL})$ was added $N, N$-dimethylformamide dimethyl acetal (DMF•DMA) $(13.7 \mathrm{~g}, 12.0 \mathrm{~mL}, 88.5 \mathrm{mmol})$. After heating at $140^{\circ} \mathrm{C}$ for $16 \mathrm{~h}$, the dark red solution was cooled to $0^{\circ} \mathrm{C}$ and added slowly, over 20 min via cannula, to a rapidly stirred solution of $\mathrm{NaIO}_{4}(18.7 \mathrm{~g}, 87.4 \mathrm{mmol})$ in $\mathrm{H}_{2} \mathrm{O}(69 \mathrm{~mL})$ and $\mathrm{DMF}(23 \mathrm{~mL})$ at $0^{\circ} \mathrm{C}$. The reaction flask was washed with $\mathrm{DMF}(20 \mathrm{~mL})$ at $0^{\circ} \mathrm{C}$ and added to $\mathrm{NaIO}_{4}$ mixture. The reaction was stirred at $0^{\circ} \mathrm{C}$ for $30 \mathrm{~min}$ then allowed to warm to rt. After an additional $4 \mathrm{~h}$, the orange solution was filtered and rinsed with $\mathrm{PhMe}(200 \mathrm{~mL})$. The filtrate was then washed with $\mathrm{H}_{2} \mathrm{O}(2 \times 200 \mathrm{~mL})$ and sat. aq. $\mathrm{NaCl}(2 \mathrm{x}$ $100 \mathrm{~mL})$. The dried $\left(\mathrm{MgSO}_{4}\right)$ extract was filtered, concentrated in vacuo to a dark red oil, and purified by flash chromatography over silica gel, eluting with $20-50 \%$ EtOAc / Hexanes to give known aldehyde $\mathbf{5}^{3}$ (4.737 g, $25.53 \mathrm{mmol}, 84 \%) .{ }^{1} \mathrm{H}$ NMR (400 MHz, $\left.\mathrm{CDCl}_{3}\right) \delta 10.41$ (s, 1H), 8.13 (d, J=2.0 Hz, 1H), 7.97 
$(\mathrm{dd}, J=8.3 \mathrm{~Hz}, 1 \mathrm{H}), 7.78(\mathrm{dd}, J=2.0,8.3 \mathrm{~Hz}, 1 \mathrm{H}) ;{ }^{13} \mathrm{C} \mathrm{NMR}\left(100 \mathrm{MHz}, \mathrm{CDCl}_{3}\right) \delta 186.9,150.1,140.2$, $134.2,130.9,129.3,124.8$.

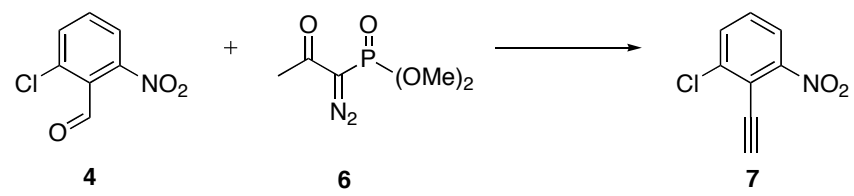

Acetylene 7: To a stirred solution of $4(16.64 \mathrm{~g}, 89.67 \mathrm{mmol}), \mathrm{K}_{2} \mathrm{CO}_{3}(25.14 \mathrm{~g}, 181.9 \mathrm{mmol})$, and $\mathrm{MeOH}(1.34 \mathrm{~L})$ was added diazophosphonate $\mathbf{6}^{4}(24.33 \mathrm{~g}, 208.7 \mathrm{mmol})$ at $\mathrm{rt}$. After $4 \mathrm{~h}$, the solution was quenched with sat. aq. $\mathrm{NaHCO}_{3}(500 \mathrm{~mL})$ and concentrated in vacuo to remove the $\mathrm{MeOH}$. The solution was diluted with EtOAc $(700 \mathrm{~mL})$ and washed with $\mathrm{H}_{2} \mathrm{O}(3 \times 200 \mathrm{~mL})$, and sat. aq. $\mathrm{NaCl}(2 \times 150 \mathrm{~mL})$. The dried $\left(\mathrm{MgSO}_{4}\right)$ extract was concentrated in vacuo and purified by flash chromatography over silica gel, eluting with $1 \%$ EtOAc / Hexanes, to give $7(13.84 \mathrm{~g}, 76.22 \mathrm{mmol}, 85 \%)$ as a pale yellow solid. MP 94$95^{\circ} \mathrm{C}$; IR (thin film) $3286,1521,1351,808,756,736,681 \mathrm{~cm}^{-1} ;{ }^{1} \mathrm{H} \mathrm{NMR}\left(400 \mathrm{MHz}, \mathrm{CDCl}_{3}\right) \delta 7.92$ (dd, $J$ $=8.2,1.1 \mathrm{~Hz}, 1 \mathrm{H}), 7.74(\mathrm{dd}, J=8.2,1.1 \mathrm{~Hz}, 1 \mathrm{H}), 7.47(\mathrm{t}, J=8.2,1 \mathrm{H}), 3.86(\mathrm{~s}, 1 \mathrm{H}) ;{ }^{13} \mathrm{C} \mathrm{NMR}(100 \mathrm{MHz}$, $\left.\mathrm{CDCl}_{3}\right) \delta 139.8,134.0,129.6,123.1,117.6,109.9,91.7,75.3$; HRMS (CI+) calcd. for $\mathrm{C}_{8} \mathrm{H}_{5} \mathrm{NO}_{2} \mathrm{Cl}(\mathrm{M}+\mathrm{H})$ 182.0009 , found 182.0005 .
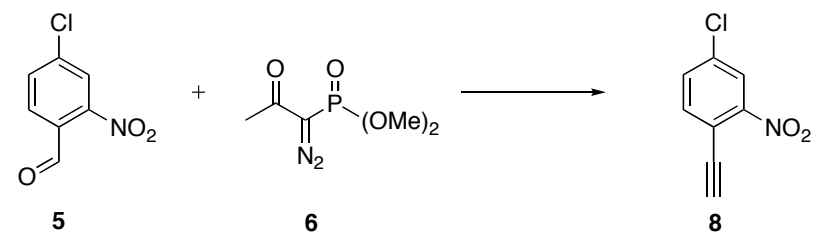

Acetylene 8: To a stirred solution of 5 (3.667 g, $19.76 \mathrm{mmol}), \mathrm{K}_{2} \mathrm{CO}_{3}(5.510 \mathrm{~g}, 39.87 \mathrm{mmol})$, and $\mathrm{MeOH}(330 \mathrm{~mL})$ was added diazophosphonate $6^{4}(5.168 \mathrm{~g}, 26.90 \mathrm{mmol})$ at $\mathrm{rt}$. After $4 \mathrm{~h}$, the solution was quenched with sat. aq. $\mathrm{NaHCO}_{3}(200 \mathrm{~mL})$ and concentrated in vacuo to remove the $\mathrm{MeOH}$. The solution was diluted with EtOAc $(200 \mathrm{~mL})$ and washed with $\mathrm{H}_{2} \mathrm{O}(3 \times 50 \mathrm{~mL})$, and sat. aq. $\mathrm{NaCl}(2 \times 50 \mathrm{~mL})$. The dried $\left(\mathrm{MgSO}_{4}\right)$ extract was concentrated in vacuo and purified by flash chromatography over silica gel, eluting with $1 \%$ EtOAc / Hexanes, to give $8(2.870 \mathrm{~g}, 15.81 \mathrm{mmol}, 81 \%)$ as a pale yellow solid. MP 68 $70^{\circ} \mathrm{C}$; IR (thin film) $3285,1555,1528,1345,891,840,791,761 \mathrm{~cm}^{-1} ;{ }^{1} \mathrm{H}$ NMR $\left(400 \mathrm{MHz}, \mathrm{CDCl}_{3}\right) \delta 8.09$ $(\mathrm{d}, J=2.0 \mathrm{~Hz}, 1 \mathrm{H}), 7.67(\mathrm{dd}, J=8.4 \mathrm{~Hz}, 1 \mathrm{H}), 7.60(\mathrm{dd}, J=8.4,2.0,1 \mathrm{H}), 3.59(\mathrm{~s}, 1 \mathrm{H}) ;{ }^{13} \mathrm{C}$ NMR $(75 \mathrm{MHz}$, $\left.\mathrm{CDCl}_{3}\right) \delta 150.5,136.4,135.3,133.1,124.9,115.9,86.3,77.6$; HRMS $(\mathrm{CI}+)$ calcd. for $\mathrm{C}_{8} \mathrm{H}_{5} \mathrm{NO}_{2}{ }^{37} \mathrm{Cl}(\mathrm{M}+\mathrm{H})$ 183.9979, found 183.9980 .

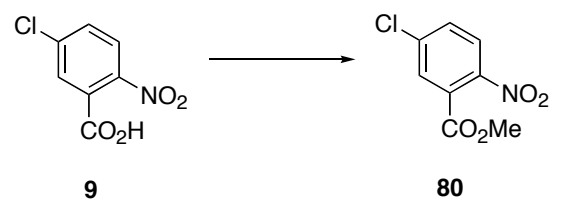

Methyl ester 80: To a stirred solution of $9(9.393 \mathrm{~g}, 46.60 \mathrm{mmol})$ in dry DMF $(155 \mathrm{~mL})$ at $0^{\circ} \mathrm{C}$ was added $\mathrm{K}_{2} \mathrm{CO}_{3}(13.23 \mathrm{~g}, 95.72 \mathrm{mmol})$ and $\mathrm{MeI}(19.38 \mathrm{~g}, 8.5 \mathrm{~mL}, 136.5 \mathrm{mmol})$ and warmed to $40^{\circ} \mathrm{C}$. After $1 \mathrm{~h}$, the solution was cooled to rt and diluted with EtOAc $(115 \mathrm{~mL})$. The solution was washed with $\mathrm{H}_{2} \mathrm{O}(3 \times 100 \mathrm{~mL})$, and sat. aq. $\mathrm{NaCl}(3 \times 100 \mathrm{~mL})$. The dried $\left(\mathrm{Na}_{2} \mathrm{SO}_{4}\right)$ extract was concentrated in vacuo and purified via flash chromatography over silica gel, eluting with 40-60\% EtOAc / Hexanes, to give the known methyl ester $\mathbf{8 0}^{\mathbf{5}}(9.244 \mathrm{~g}, 42.87 \mathrm{mmol}, 92 \%)$ as a pale yellow solid. ${ }^{1} \mathrm{H}$ NMR $\left(400 \mathrm{MHz}, \mathrm{CDCl}_{3}\right) \delta$ $7.95(\mathrm{~d}, J=8.7 \mathrm{~Hz}, 1 \mathrm{H}), 7.73(\mathrm{~d}, J=2.3 \mathrm{~Hz}, 1 \mathrm{H}), 7.63(\mathrm{dd}, J=8.7,2.3 \mathrm{~Hz}, 1 \mathrm{H}), 3.98(\mathrm{~s}, 3 \mathrm{H}) ;{ }^{13} \mathrm{C}$ NMR $\left(100 \mathrm{MHz}, \mathrm{CDCl}_{3}\right) \delta 164.7,146.1,139.7,131.6,129.8,129.4,125.5,53.6$. 


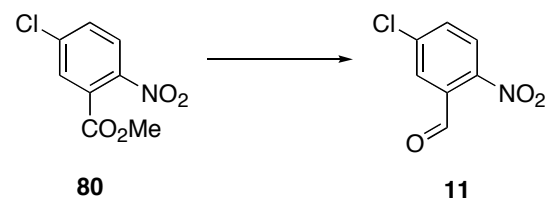

Aldehyde 11: To a stirred solution of $\mathbf{8 0}(8.20 \mathrm{~g}, 38.0 \mathrm{mmol})$ and dry $\mathrm{CH}_{2} \mathrm{Cl}_{2}(205 \mathrm{~mL})$ was added DIBAL-H (48.0 mL, $48.0 \mathrm{mmol}, 1.0 \mathrm{M}$ in $\left.\mathrm{CH}_{2} \mathrm{Cl}_{2}\right)$ at $-78^{\circ} \mathrm{C}$. After $45 \mathrm{~min}, \mathrm{MeOH}(20 \mathrm{~mL})$ was added and the solution was allowed to warm to rt. Next, aq. sodium tartrate $(200 \mathrm{~mL}, 10 \% \mathrm{w} / \mathrm{v})$ was added and the suspension was left to stir vigorously until a bilayer was distinct. The solution was diluted with $\mathrm{CH}_{2} \mathrm{Cl}_{2}$ $(100 \mathrm{~mL})$ and washed with $\mathrm{H}_{2} \mathrm{O}(2 \times 100 \mathrm{~mL})$, sat. aq. $\mathrm{NaCl}(2 \times 100 \mathrm{~mL})$. The dried $\left(\mathrm{Na}_{2} \mathrm{SO}_{4}\right)$ extract was purified via flash chromatography over silica gel, eluting with 20-50\% EtOAc / Hexanes to give the known aldehyde $13^{6}$ (6.80 g, $\left.36.7 \mathrm{mmol}, 97 \%\right)$. ${ }^{1} \mathrm{H}$ NMR (400 MHz, $\left.\mathrm{CDCl}_{3}\right) \delta 10.46(\mathrm{~s}, 1 \mathrm{H}), 8.15(\mathrm{~d}, J=8.7 \mathrm{~Hz}$, $1 \mathrm{H}), 7.94(\mathrm{~d}, J=2.3 \mathrm{~Hz}, 1 \mathrm{H}), 7.74(\mathrm{dd}, J=2.4,8.7 \mathrm{~Hz}, 1 \mathrm{H}) ;{ }^{13} \mathrm{C} \mathrm{NMR}\left(100 \mathrm{MHz}, \mathrm{CDCl}_{3}\right) \delta 187.0,147.5$, $141.0,133.5,132.7,129.4,126.2$.

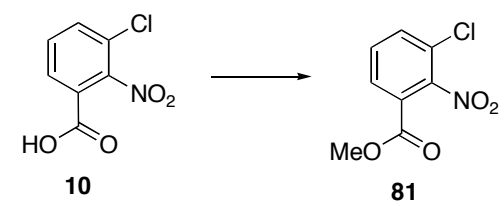

Methyl ester 81: To a stirred solution of $\mathbf{1 0}(5.01 \mathrm{~g}, 24.9 \mathrm{mmol}), \mathrm{K}_{2} \mathrm{CO}_{3}(10.3 \mathrm{~g}, 74.7 \mathrm{mmol})$, and DMF $(25 \mathrm{~mL})$ was added MeI $(3.10 \mathrm{~mL}, 7.07 \mathrm{~g}, 49.8 \mathrm{mmol})$. The reaction mixture was heated to $40^{\circ} \mathrm{C}$. After $1 \mathrm{~h}$, the reaction was quenched with $\mathrm{H}_{2} \mathrm{O}(30 \mathrm{~mL})$, diluted with EtOAc $(50 \mathrm{~mL})$, and washed with $\mathrm{H}_{2} \mathrm{O}(20 \mathrm{~mL})$ and sat. aq. $\mathrm{NaCl}(20 \mathrm{~mL})$. The dried extract $\left(\mathrm{MgSO}_{4}\right)$ was concentrated in vacuo to give known ester $\mathbf{8 1}^{7}$ (5.31 g, $\left.24.6 \mathrm{mmol}, 99 \%\right)$ as a white crystalline solid. MP $101-103^{\circ} \mathrm{C}$; ${ }^{1} \mathrm{H}$ NMR (300 $\left.\mathrm{MHz}, \mathrm{CDCl}_{3}\right) \delta 8.01(\mathrm{dd} J=1.2,7.8 \mathrm{~Hz}, 1 \mathrm{H}), 7.74(\mathrm{dd}, J=1.2,8.1 \mathrm{~Hz}, 1 \mathrm{H}), 7.55(\mathrm{dd}, J=7.8,8.1 \mathrm{~Hz}, 1 \mathrm{H})$, $3.94(\mathrm{~s}, 3 \mathrm{H}),{ }^{13} \mathrm{C} \mathrm{NMR}\left(100 \mathrm{MHz}, \mathrm{CDCl}_{3}\right) \delta 162.6,148.4,134.8,130.7,129.7,126.4,124.5,53.4$.

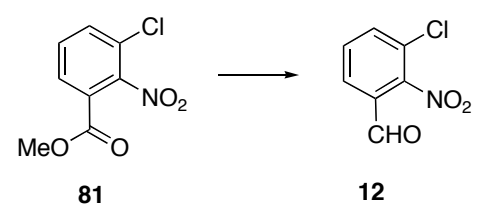

Aldehyde 12: To a stirred solution of $\mathbf{8 1}(2.91 \mathrm{~g}, 13.5 \mathrm{mmol})$ and $\mathrm{CH}_{2} \mathrm{Cl}_{2}(134 \mathrm{~mL})$ at $-78^{\circ} \mathrm{C}$ was added DIBAL-H $\left(16.0 \mathrm{~mL}, 16.0 \mathrm{mmol}, 1.0 \mathrm{M}\right.$ in $\left.\mathrm{CH}_{2} \mathrm{Cl}_{2}\right)$ over $15 \mathrm{~min}$. After an additional $10 \mathrm{~min}$, the reaction was quenched with $\mathrm{MeOH}(1.0 \mathrm{~mL})$ and warmed to rt. Next, a solution of aq. sodium potassium tartrate $(190 \mathrm{~mL}, 10 \% \mathrm{w} / \mathrm{v})$ was added and vigorously stirred. After $4 \mathrm{~h}$, the reaction mixture was diluted with $\mathrm{CH}_{2} \mathrm{Cl}_{2}(50 \mathrm{~mL})$ and washed with $\mathrm{H}_{2} \mathrm{O}(3 \times 100 \mathrm{~mL})$ and sat. aq. $\mathrm{NaCl}(100 \mathrm{~mL})$. The dried extract $\left(\mathrm{MgSO}_{4}\right)$ was concentrated in vacuo and purified by recrystallization with EtOAc / Hexanes (1:3) to give known aldehyde $\mathbf{1 2}^{8}(2.32 \mathrm{~g}, 12.7 \mathrm{mmol}, 94 \%)$ as a white crystalline solid. ${ }^{1} \mathrm{H}$ NMR $\left(400 \mathrm{MHz}, \mathrm{CDCl}_{3}\right) \delta$ $9.90(\mathrm{~s}, 1 \mathrm{H}), 7.92(\mathrm{dd}, J=1.4,7.7 \mathrm{~Hz}, 1 \mathrm{H}), 7.80(\mathrm{dd}, J=1.4,8.1 \mathrm{~Hz}, 1 \mathrm{H}), 7.67(\mathrm{dd}, J=7.7,8.1 \mathrm{~Hz}, 1 \mathrm{H})$; ${ }^{13} \mathrm{C}$ NMR (100 MHz, $\left.\mathrm{CDCl}_{3}\right) \delta 186.0,148.1$ 136.0, 131.7, 130.1, 128.5, 126.6.

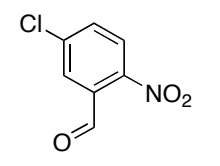

11

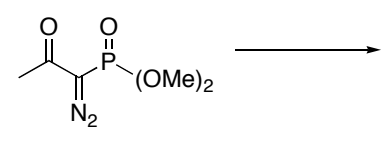

6

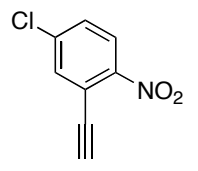

13

Acetylene 13: To a stirred solution of $11(3.694 \mathrm{~g}, 19.90 \mathrm{mmol}), \mathrm{K}_{2} \mathrm{CO}_{3}(5.528 \mathrm{~g}, 40.00 \mathrm{mmol})$, and dry $\mathrm{MeOH}(350 \mathrm{~mL})$ was added diazophosphonate $\mathbf{6}^{4}(5.088 \mathrm{~g}, 26.48 \mathrm{mmol})$ at $\mathrm{rt}$. After $4 \mathrm{~h}$, the 
solution was quenched with sat. aq. $\mathrm{NaHCO}_{3}(200 \mathrm{~mL})$ and concentrated in vacuo to remove the $\mathrm{MeOH}$. The solution was diluted with EtOAc $(300 \mathrm{~mL})$ and washed with $\mathrm{H}_{2} \mathrm{O}(3 \mathrm{x} 100 \mathrm{~mL})$, and sat. aq. $\mathrm{NaCl}(2 \mathrm{x}$ $100 \mathrm{~mL})$. The dried $\left(\mathrm{MgSO}_{4}\right)$ extract was concentrated in vacuo and purified by flash chromatography over silica gel, eluting with 1\% EtOAc / Hexanes, to give 13 (2.891 g, $15.92 \mathrm{mmol}, 80 \%)$ as a pale yellow solid. MP $70-73^{\circ} \mathrm{C}$; IR (thin film) 3286, 2112, 1599, 1559, 1516, 883, 834, $753 \mathrm{~cm}^{-1} ;{ }^{1} \mathrm{H}$ NMR (300 MHz, $\left.\mathrm{CDCl}_{3}\right) \delta 8.04(\mathrm{~d}, J=8.7 \mathrm{~Hz}, 1 \mathrm{H}), 7.68(\mathrm{~d}, J=2.3 \mathrm{~Hz}, 1 \mathrm{H}), 7.49(\mathrm{dd}, J=8.7,2.3 \mathrm{~Hz}, 1 \mathrm{H}), 3.60(\mathrm{~s}, 1 \mathrm{H})$; ${ }^{13} \mathrm{C} \mathrm{NMR}\left(75 \mathrm{MHz}, \mathrm{CDCl}_{3}\right) \delta 148.5,139.5,135.2,129.6,126.0,119.2,86.6,77.5 ; \mathrm{HRMS}$ (CI+) calcd. for $\mathrm{C}_{8} \mathrm{H}_{5} \mathrm{NO}_{2}{ }^{37} \mathrm{Cl}(\mathrm{M}+\mathrm{H}) 183.9979$, found 183.9977 .

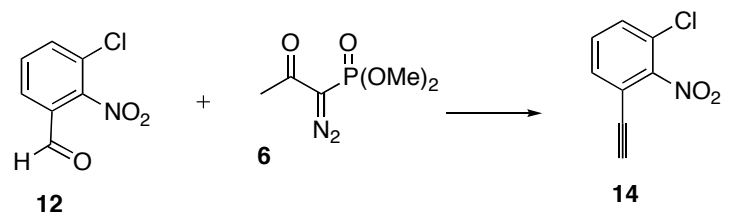

Acetylene 14: To a stirred solution of 12 (1.02 g, $5.59 \mathrm{mmol}), \mathrm{K}_{2} \mathrm{CO}_{3}(1.54 \mathrm{~g}, 11.1 \mathrm{mmol})$, and $\mathrm{MeOH}(56.0 \mathrm{~mL})$ was added diazophosphonate reagent $6^{4}(1.39 \mathrm{~g}, 1.07 \mathrm{~mL}, 7.26 \mathrm{mmol})$ at $\mathrm{rt}$. After $2 \mathrm{~h}$, the reaction was quenched with aq. $\mathrm{NaHCO}_{3}(60 \mathrm{~mL}, 5 \% \mathrm{w} / \mathrm{v})$, and the $\mathrm{MeOH}$ was removed in vacuo. The reaction mixture was diluted with EtOAc $(30 \mathrm{~mL})$ and washed with aq. $\mathrm{NaHCO}_{3}(25 \mathrm{~mL}, 5 \% \mathrm{w} / \mathrm{v}), \mathrm{H}_{2} \mathrm{O}(25$ $\mathrm{mL})$, and sat. aq. $\mathrm{NaCl}(20 \mathrm{~mL})$. The dried extract $\left(\mathrm{MgSO}_{4}\right)$ was concentrated in vacuo and purified by chromatography over silica gel, eluting with 5 - 20\% EtOAc / Hexanes, to give 14 (1.01 g, $4.94 \mathrm{mmol}$, $88 \%$ ) as a pale yellow solid. MP $42-43^{\circ} \mathrm{C}$; IR (neat) $3289,3072,1549 \mathrm{~cm}^{-1} ;{ }^{1} \mathrm{H}$ NMR $\left(300 \mathrm{MHz}, \mathrm{CDCl}_{3}\right) \delta$ $7.56(\mathrm{dd}, J=1.4,7.9 \mathrm{~Hz}, 1 \mathrm{H}), 7.54(\mathrm{dd}, J=1.4,7.9 \mathrm{~Hz}, 1 \mathrm{H}), 7.44(\mathrm{dd}, J=7.9,7.9 \mathrm{~Hz}, 1 \mathrm{H}), 3.35(\mathrm{~s}, 1 \mathrm{H})$; ${ }^{13} \mathrm{C} \mathrm{NMR}\left(100 \mathrm{MHz}, \mathrm{CDCl}_{3}\right) \delta 151.6,132.0,131.0,130.7,125.4,117.1,85.1,75.8$; HRMS (CI+) calcd. for $\mathrm{C}_{8} \mathrm{H}_{4} \mathrm{NO}_{2} \mathrm{Cl}(\mathrm{M}+\mathrm{H})$ 182.0009, found 182.0001 .

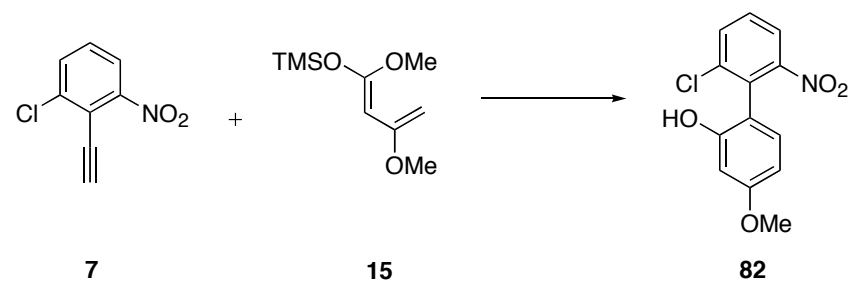

Phenol 82: To a pressure vessel containing 7 (1.739 g, $9.578 \mathrm{mmol})$ and $\mathrm{PhMe}(20 \mathrm{~mL})$ was added diene $15^{9}(8.423 \mathrm{~g}, 41.63 \mathrm{mmol})$ at $\mathrm{rt}$. The mixture was heated at $80^{\circ} \mathrm{C}$. After $24 \mathrm{~h}$, the reaction was cooled to $0^{\circ} \mathrm{C}$ and DABCO $(4.414 \mathrm{~g}, 39.35 \mathrm{mmol})$ was added and gradually warmed to $40^{\circ} \mathrm{C}$ over $30 \mathrm{~min}$. After $1 \mathrm{~h}$ at $40^{\circ} \mathrm{C}$, the brown mixture was cooled to $\mathrm{rt}$ and quenched with aq. $\mathrm{HCl}(1 \mathrm{M}) \mathrm{until} \mathrm{pH}=2$, diluted with EtOAc $(100 \mathrm{~mL})$, washed with $\mathrm{H}_{2} \mathrm{O}(50 \mathrm{~mL})$, and sat. aq. $\mathrm{NaCl}(2 \times 50 \mathrm{~mL})$. The dried $\left(\mathrm{Na}_{2} \mathrm{SO}_{4}\right)$ extract was concentrated in vacuo and purified via flash chromatography over silica, eluting with 0-20\% EtOAc / Hexanes to give 82 (1.795 g, $6.417 \mathrm{mmol}, 67 \%)$ as a yellow solid. MP 134-135 ${ }^{\circ} \mathrm{C}$; IR (thin film) 3423, 1620, 1529, 1444, $1356 \mathrm{~cm}^{-1} ;{ }^{1} \mathrm{H}$ NMR $\left(300 \mathrm{MHz}, \mathrm{CDCl}_{3}\right) \delta 7.78(\mathrm{dd}, J=8.1,1.0 \mathrm{~Hz}, 1 \mathrm{H})$, $7.73(\mathrm{dd}, J=8.1,1.0, \mathrm{~Hz}, 1 \mathrm{H}), 7.46(\mathrm{t}, J=8.1,1 \mathrm{H}), 7.00(\mathrm{~d}, 8.5 \mathrm{~Hz}, 1 \mathrm{H}), 6.58(\mathrm{dd}, J=8.5,2.4 \mathrm{~Hz}, 1 \mathrm{H})$, $6.49(\mathrm{~d}, J=2.4 \mathrm{~Hz}, 1 \mathrm{H}), 5.05(\mathrm{~s}, 1 \mathrm{H}), 3.82(\mathrm{~s}, 3 \mathrm{H}) ;{ }^{13} \mathrm{C} \mathrm{NMR}\left(100 \mathrm{MHz}, \mathrm{CDCl}_{3}\right) \delta 161.8,154.2,152.2$, 137.6, 134.0, 131.3, 131.2, 129.6, 122.6, 114.2, 107.1, 102.5, 55.8; HRMS (CI+) calcd. for $\mathrm{C}_{13} \mathrm{H}_{10} \mathrm{NO}_{4} \mathrm{Cl}$ $(\mathrm{M}+)$ 279.0298, found 279.0304. 


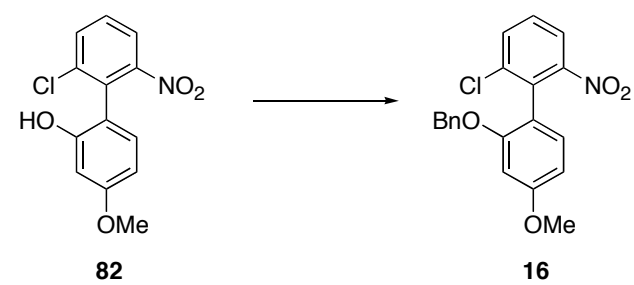

Chloride 16: To a stirred solution of 82 (1.245 g, $4.500 \mathrm{mmol})$ and dry DMF (22.0 mL) was added $\mathrm{NaH}$ (397.2 $\mathrm{mg}, 9.93 \mathrm{mmol}, 60 \%$ dispersion in mineral oil) at $0^{\circ} \mathrm{C}$. To this dark red solution was added $\mathrm{BnBr}(7.76 \mathrm{~g}, 5.40 \mathrm{~mL}, 45.4 \mathrm{mmol})$. After $10 \mathrm{~min}$, the yellow solution was quenched with sat. aq. $\mathrm{NH}_{4} \mathrm{Cl}(100 \mathrm{~mL})$, diluted with EtOAc $(150 \mathrm{~mL})$, washed with $\mathrm{H}_{2} \mathrm{O}(50 \mathrm{~mL})$, and sat. aq. $\mathrm{NaCl}(2 \times 100$ $\mathrm{mL})$. The dried $\left(\mathrm{MgSO}_{4}\right)$ extract was concentrated in vacuo and purified by flash chromatography over silica gel, eluting with 0-10\% $\mathrm{Et}_{2} \mathrm{O} /$ Hexanes to give 16 (1.582 g, $\left.4.277 \mathrm{mmol}, 95 \%\right)$ as a bright yellow crystalline solid. MP 99-100 ${ }^{\circ} \mathrm{C}$; IR (thin film) 2936, 1612, 1583, 1529, $1441 \mathrm{~cm}^{-1} ;{ }^{1} \mathrm{H}$ NMR (400 MHz, $\left.\mathrm{CDCl}_{3}\right) \delta 7.82(\mathrm{dd}, J=8.1,1.2 \mathrm{~Hz}, 1 \mathrm{H}), 7.73(\mathrm{dd}, J=8.1,1.2 \mathrm{~Hz}, 1 \mathrm{H}), 7.443(\mathrm{t}, J=8.1 \mathrm{~Hz}, 1 \mathrm{H}), 7.36-7.23$ $(\mathrm{m}, 5 \mathrm{H}), 7.13(\mathrm{~d}, J=8.3 \mathrm{~Hz}, 1 \mathrm{H}), 6.63(\mathrm{dd}, J=8.3,2.3 \mathrm{~Hz}, 1 \mathrm{H}), 6.60(\mathrm{~d}, J=2.3 \mathrm{~Hz}, 1 \mathrm{H}), 5.05(\mathrm{~s}, 2 \mathrm{H})$, $3.85(\mathrm{~s}, 3 \mathrm{H}) ;{ }^{13} \mathrm{C}$ NMR $\left(100 \mathrm{MHz}, \mathrm{CDCl}_{3}\right) \delta 161.4,156.6,151.4,136.8,136.7,133.4,132.0,130.7,128.6$, 128.4, 127.7, 126.8, 122.2, 116.2, 105.1, 100.3, 70.3, 55.3; HRMS (FAB+) calcd. for $\mathrm{C}_{20} \mathrm{H}_{16} \mathrm{NO}_{4} \mathrm{Cl}(\mathrm{M}+)$ 369.0768 , found 369.0759 .

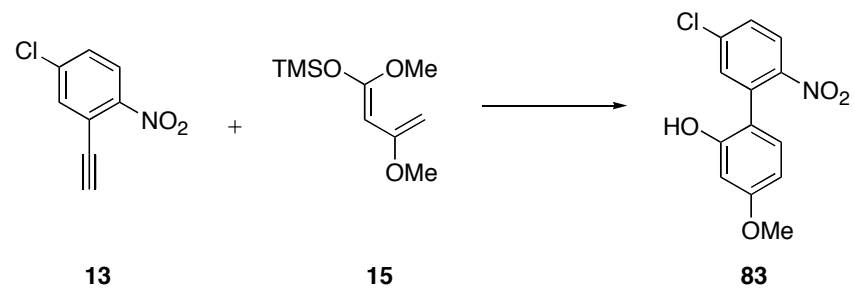

Phenol 83: To a pressure vessel containing $13(189.3 \mathrm{mg}, 1.043 \mathrm{mmol})$ and $\mathrm{PhMe}(2.0 \mathrm{~mL})$ was added diene $15^{9}(872.8 \mathrm{mg}, 4.313 \mathrm{mmol})$ at $\mathrm{rt}$. The mixture was heated at $80^{\circ} \mathrm{C}$. After $24 \mathrm{~h}$, the reaction was cooled to $0^{\circ} \mathrm{C}$ and DABCO $(670.8 \mathrm{mg}, 5.980 \mathrm{mmol})$ was added and gradually warmed to $40^{\circ} \mathrm{C}$ over 30 min. After $30 \mathrm{~min}$ at $40^{\circ} \mathrm{C}$, the brown mixture was cooled to $\mathrm{rt}$ and quenched with sat. aq. $\mathrm{NH}_{4} \mathrm{Cl}(10 \mathrm{~mL})$, diluted with EtOAc $(25 \mathrm{~mL})$, washed with $\mathrm{H}_{2} \mathrm{O}(10 \mathrm{~mL})$, and sat. aq. $\mathrm{NaCl}(2 \times 20 \mathrm{~mL})$. The dried $\left(\mathrm{Na}_{2} \mathrm{SO}_{4}\right)$ extract was concentrated in vacuo and purified via flash chromatography over silica, eluting with 0-20\% EtOAc / Hexanes to give 83 (178.9 mg, $646.6 \mu \mathrm{mol}, 62 \%$ ) as a yellow oil. IR (thin film) 3389, 2933, 1622, 1600, 1561, 1518, 865, 830, $727 \mathrm{~cm}^{-1} ;{ }^{1} \mathrm{H}$ NMR $\left(400 \mathrm{MHz}, \mathrm{CDCl}_{3}\right) \delta 7.92(\mathrm{~d}, J=8.5 \mathrm{~Hz}, 1 \mathrm{H})$, $7.46(\mathrm{dd}, J=8.5,2.3, \mathrm{~Hz}, 1 \mathrm{H}), 7.43(\mathrm{~d}, J=2.3,1 \mathrm{H}), 7.17(\mathrm{~d}, 8.5 \mathrm{~Hz}, 1 \mathrm{H}), 6.63(\mathrm{dd}, J=8.5,2.4 \mathrm{~Hz}, 1 \mathrm{H})$, $6.41(\mathrm{~d}, J=2.4 \mathrm{~Hz}, 1 \mathrm{H}), 4.94(\mathrm{~s}, 1 \mathrm{H}), 3.84(\mathrm{~s}, 3 \mathrm{H}) ;{ }^{13} \mathrm{C} \mathrm{NMR}\left(100 \mathrm{MHz}, \mathrm{CDCl}_{3}\right) \delta 161.4,153.4,147.9$, 138.8, 134.4, 132.6, 130.5, 127.9, 125.6, 116.6, 106.9, 102.0, 55.4; HRMS (EI+) calcd. for $\mathrm{C}_{13} \mathrm{H}_{10} \mathrm{NO}_{4} \mathrm{Cl}$ $(\mathrm{M}+)$ 279.0298, found 279.0290.

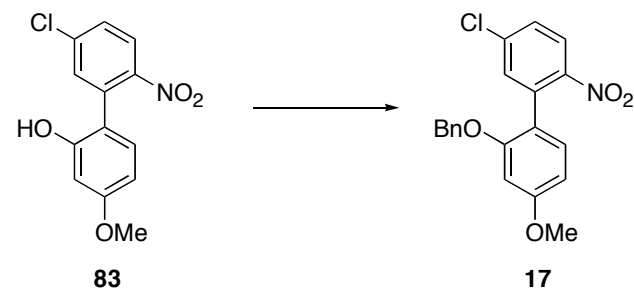

Chloride 17: To a stirred solution of $\mathbf{8 3}(100 \mathrm{mg}, 361.4 \mu \mathrm{mol})$ and dry DMF $(1.8 \mathrm{~mL})$ was added $\mathrm{NaH}\left(30.8 \mathrm{mg}, 0.77 \mathrm{mmol}, 60 \%\right.$ dispersion in mineral oil) at $0^{\circ} \mathrm{C}$. To this dark red solution was added $\mathrm{BnBr}(7.19 \mathrm{mg}, 500 \mu \mathrm{L}, 4.20 \mathrm{mmol})$. After $10 \mathrm{~min}$, the yellow solution was quenched with sat. aq. $\mathrm{NH}_{4} \mathrm{Cl}$ 
$(15 \mathrm{~mL})$, diluted with EtOAc $(20 \mathrm{~mL})$, washed with $\mathrm{H}_{2} \mathrm{O}(15 \mathrm{~mL})$, and sat. aq. $\mathrm{NaCl}(2 \times 25 \mathrm{~mL})$. The dried $\left(\mathrm{MgSO}_{4}\right)$ extract was concentrated in vacuo and purified by flash chromatography over silica gel, eluting with $0-10 \% \mathrm{Et}_{2} \mathrm{O} /$ Hexanes to give $17(124.3 \mathrm{mg}, 336.2 \mu \mathrm{mol}, 93 \%)$ as a bright yellow crystalline solid. MP $121-124^{\circ} \mathrm{C}$; IR (thin film) 2925, 2851, 1617, 1595, 1531, 1268, $1049 \mathrm{~cm}^{-1}$; ${ }^{1} \mathrm{H}$ NMR $(400 \mathrm{MHz}$, $\left.\mathrm{CDCl}_{3}\right) \delta 7.91(\mathrm{dd}, J=0.3,8.6 \mathrm{~Hz}, 1 \mathrm{H}), 7.45-7.39(\mathrm{~m}, 2 \mathrm{H}), 7.37-7.33(\mathrm{~m}, 3 \mathrm{H}), 7.27-7.22(\mathrm{~m}, 3 \mathrm{H}), 6.65$ $(\mathrm{dd}, J=8.4,2.4 \mathrm{~Hz}, 1 \mathrm{H}), 6.55(\mathrm{~d}, J=2.4 \mathrm{~Hz}, 1 \mathrm{H}), 5.00(\mathrm{~s}, 2 \mathrm{H}), 3.85(\mathrm{~s}, 3 \mathrm{H}) ;{ }^{13} \mathrm{C} \mathrm{NMR}\left(100 \mathrm{MHz}, \mathrm{CDCl}_{3}\right)$ $\delta 161.5,156.2,147.9,138.6,136.3,135.1,132.6,130.2,128.5,127.9,127.6,127.2,125.5,119.2,105.6$, 100.3, 70.7, 55.4; HRMS (EI+) calcd. for $\mathrm{C}_{20} \mathrm{H}_{16} \mathrm{NO}_{4} \mathrm{Cl}(\mathrm{M}+)$ 369.0768, found 369.0776.
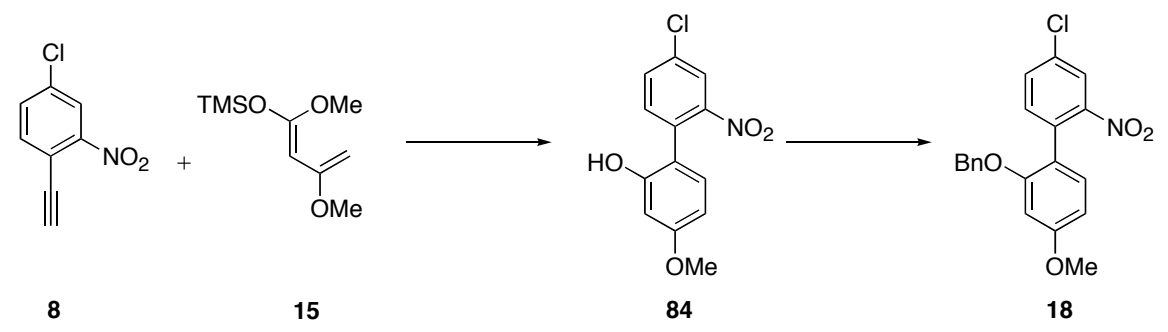

Phenol 83: To a pressure vessel containing $8(185.2 \mathrm{mg}, 1.020 \mathrm{mmol})$ and $\mathrm{PhMe}(2.0 \mathrm{~mL})$ was added diene $15^{9}(834.1 \mathrm{mg}, 4.102 \mathrm{mmol})$ at $\mathrm{rt}$. The mixture was heated at $80^{\circ} \mathrm{C}$. After $24 \mathrm{~h}$, the reaction was cooled to $0^{\circ} \mathrm{C}$ and DABCO $\left(493.6 \mathrm{mg}, 4.401 \mathrm{mmol}\right.$ ) was added and gradually warmed to $40^{\circ} \mathrm{C}$ over 30 min. After $1 \mathrm{~h}$, the brown mixture was cooled to $\mathrm{rt}$ and quenched with sat. aq. $\mathrm{NH}_{4} \mathrm{Cl}(15 \mathrm{~mL})$, diluted with EtOAc $(20 \mathrm{~mL})$, washed with $\mathrm{H}_{2} \mathrm{O}(20 \mathrm{~mL})$, and sat. aq. $\mathrm{NaCl}(2 \times 15 \mathrm{~mL})$. The dried $\left(\mathrm{Na}_{2} \mathrm{SO}_{4}\right)$ extract was concentrated in vacuo and purified via flash chromatography over silica, eluting with $0-20 \%$ EtOAc / Hexanes to give impure $84(363.0 \mathrm{mg})$ as a yellow oil and used without further purification.

Chloride 18: To a stirred solution of $84(363.0 \mathrm{mg})$ and dry DMF $(3.6 \mathrm{~mL})$ was added $\mathrm{NaH}(93.2$ $\mathrm{mg}, 2.33 \mathrm{mmol}, 60 \%$ dispersion in mineral oil) at $0^{\circ} \mathrm{C}$. To this dark red solution was added $\mathrm{BnBr}(1.22 \mathrm{~g}$, $0.85 \mathrm{~mL}, 7.15 \mathrm{mmol})$. After $10 \mathrm{~min}$, the yellow solution was quenched with sat. aq. $\mathrm{NH}_{4} \mathrm{Cl}(10 \mathrm{~mL})$, diluted with EtOAc $(30 \mathrm{~mL})$, washed with $\mathrm{H}_{2} \mathrm{O}(10 \mathrm{~mL})$, and sat. aq. $\mathrm{NaCl}(2 \times 10 \mathrm{~mL})$. The dried $\left(\mathrm{MgSO}_{4}\right)$ extract was concentrated in vacuo and purified by flash chromatography over silica gel, eluting with $0-10 \%$ $\mathrm{Et}_{2} \mathrm{O} /$ Hexanes to give $\mathbf{1 8}$ (233.9 $\mathrm{mg}, 0.632 \mathrm{mmol}, 62 \%$ over 2 steps) as a bright yellow crystalline solid. MP 126-128 ${ }^{\circ}$; IR (thin film) 3032, 2925, 1608, 1527, 1260, $1050 \mathrm{~cm}^{-1} ;{ }^{1} \mathrm{H}$ NMR (400 MHz, $\left.\mathrm{CDCl}_{3}\right) \delta$ $7.93(\mathrm{~d}, J=2.2 \mathrm{~Hz}, 1 \mathrm{H}), 7.58(\mathrm{dd}, J=8.3,2.2 \mathrm{~Hz}, 1 \mathrm{H}), 7.44-7.20(\mathrm{~m}, 7 \mathrm{H}), 6.63(\mathrm{dd}, J=8.4,2.4 \mathrm{~Hz}, 1 \mathrm{H})$, $6.54(\mathrm{~d}, J=2.4 \mathrm{~Hz}, 1 \mathrm{H}), 5.00(\mathrm{~s}, 2 \mathrm{H}), 3.84(\mathrm{~s}, 3 \mathrm{H}) ;{ }^{13} \mathrm{C} \mathrm{NMR}\left(100 \mathrm{MHz}, \mathrm{CDCl}_{3}\right) \delta 161.4,156.1,149.7$, 136.3, 133.8, 133.3, 132.6, 131.7, 130.2, 128.5, 127.9, 127.1, 124.2, 119.2, 105.6, 100.3, 70.6, 55.4; HRMS (EI+) calcd. for $\mathrm{C}_{20} \mathrm{H}_{16} \mathrm{NO}_{4} \mathrm{Cl}(\mathrm{M}+)$ 369.0768, found 369.0766.
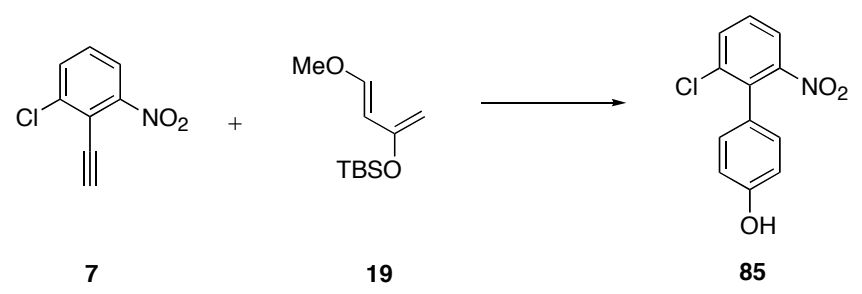

Phenol 85: To a pressure vessel containing $7(147.1 \mathrm{mg}, 810.2 \mu \mathrm{mol})$ and PhMe $(1.3 \mathrm{~mL})$ was added diene $19(630 \mathrm{mg}, 700 \mu \mathrm{L}, 2.94 \mathrm{mmol})$ at rt. The mixture was heated at $120^{\circ} \mathrm{C}$. After $24 \mathrm{~h}$, the reaction was cooled to $0^{\circ} \mathrm{C}$ and TBAF $(3.0 \mathrm{~mL}, 3.0 \mathrm{mmol}, 1.0 \mathrm{M}$ in THF) was added. After $15 \mathrm{~min}$, the brown mixture was quenched with sat. aq. $\mathrm{NH}_{4} \mathrm{Cl}(10 \mathrm{~mL})$, diluted with EtOAc $(20 \mathrm{~mL})$, washed with $\mathrm{H}_{2} \mathrm{O}$ $(10 \mathrm{~mL})$, and sat. aq. $\mathrm{NaCl}(2 \times 10 \mathrm{~mL})$. The dried $\left(\mathrm{Na}_{2} \mathrm{SO}_{4}\right)$ extract was concentrated in vacuo and purified via flash chromatography over silica, eluting with 0-20\% EtOAc / Hexanes to give 85 (161.0 mg, 644.9 $\mu \mathrm{mol}, 80 \%$ ) as a yellow solid. MP $83-84^{\circ} \mathrm{C}$; IR (thin film) $3423,1614,1529,1361,1201 \mathrm{~cm}^{-1}$; ${ }^{1} \mathrm{H}$ NMR 
$\left(400 \mathrm{MHz}, \mathrm{CDCl}_{3}\right) \delta 7.72(\mathrm{~d}, J=8.0,2 \mathrm{H}), 7.45(\mathrm{t}, J=8.0 \mathrm{~Hz}, 1 \mathrm{H}), 7.18(\mathrm{~d}, J=8.5,2 \mathrm{H}), 6.94(\mathrm{~d}, 8.5 \mathrm{~Hz}$, $2 \mathrm{H}), 5.00(\mathrm{~s}, 1 \mathrm{H}) ;{ }^{13} \mathrm{C} \mathrm{NMR}\left(75 \mathrm{MHz}, \mathrm{CDCl}_{3}\right) \delta 156.3,151.9,136.5,134.7,133.5,130.7,129.1,126.5$, 122.2, 115.9; HRMS (CI+) calcd. for $\mathrm{C}_{12} \mathrm{H}_{9} \mathrm{NO}_{3} \mathrm{Cl}(\mathrm{M}+\mathrm{H}) 250.0271$, found 250.0277.

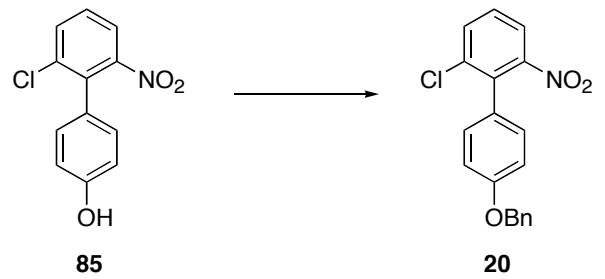

Chloride 20: To a stirred solution of $\mathbf{8 5}(111.4 \mathrm{mg}, 446.2 \mu \mathrm{mol})$ and dry DMF $(2.0 \mathrm{~mL})$ was added $\mathrm{NaH}\left(48.1 \mathrm{mg}, 1.20 \mathrm{mmol}, 60 \%\right.$ dispersion in mineral oil) at $0^{\circ} \mathrm{C}$. To this dark red solution was added $\mathrm{BnBr}(790.9 \mathrm{mg}, 550 \mu \mathrm{L}, 4.624 \mathrm{mmol})$. After $10 \mathrm{~min}$, the yellow solution was quenched with sat. aq. $\mathrm{NH}_{4} \mathrm{Cl}(20 \mathrm{~mL})$, diluted with EtOAc $(20 \mathrm{~mL})$, washed with $\mathrm{H}_{2} \mathrm{O}(10 \mathrm{~mL})$, and sat. aq. $\mathrm{NaCl}(2 \times 10 \mathrm{~mL})$. The dried $\left(\mathrm{MgSO}_{4}\right)$ extract was concentrated in vacuo and purified by flash chromatography over silica gel, eluting with $0-10 \% \mathrm{Et}_{2} \mathrm{O} /$ Hexanes to give $20(137.2 \mathrm{mg}, 403.8 \mathrm{mmol}, 90 \%)$ as a bright yellow crystalline solid. MP $85-89^{\circ} \mathrm{C}$; IR (thin film) $3088,2873,1610,1531,1244,1027 \mathrm{~cm}^{-1} ;{ }^{1} \mathrm{H}$ NMR $\left(400 \mathrm{MHz}, \mathrm{CDCl}_{3}\right)$ $\delta 7.73(\mathrm{~d}, J=8.1 \mathrm{~Hz}, 2 \mathrm{H}), 7.55-7.35(\mathrm{~m}, 6 \mathrm{H}), 7.20(\mathrm{~d}, J=8.7 \mathrm{~Hz}, 2 \mathrm{H}), 7.10(\mathrm{~d}, J=8.7 \mathrm{~Hz}, 2 \mathrm{H}), 5.14(\mathrm{~s}$, $2 \mathrm{H}) ;{ }^{13} \mathrm{C}$ NMR $\left(100 \mathrm{MHz}, \mathrm{CDCl}_{3}\right) \delta 159.2,151.6,136.7,136.1,134.4,133.2,130.2,128.7,128.7,128.1$, 127.7, 126.2, 121.9, 114.8, 70.1; HRMS (FAB+) calcd. for $\mathrm{C}_{19} \mathrm{H}_{14} \mathrm{NO}_{3} \mathrm{Cl} 339.0662$, found 339.0669.
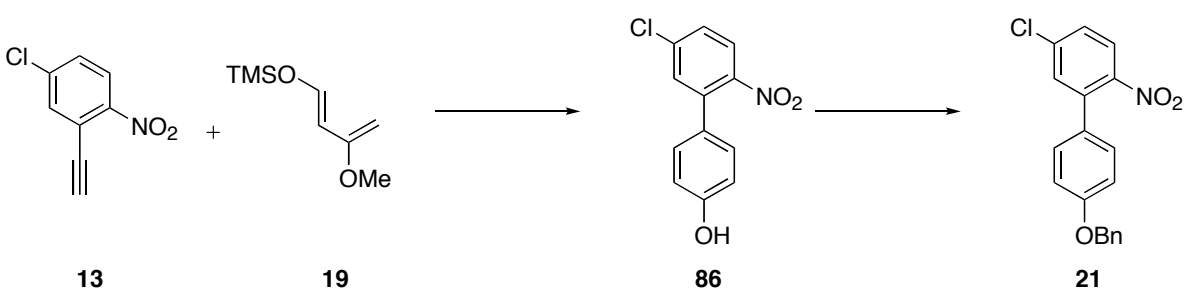

Phenol 86: To a pressure vessel containing $13(116.8 \mathrm{mg}, 643.3 \mu \mathrm{mol})$ and $\mathrm{PhMe}(1 \mathrm{~mL})$ was added diene $19(495 \mathrm{mg}, 550 \mu \mathrm{L}, 2.32 \mathrm{mmol})$ at $\mathrm{rt}$. The mixture was heated at $120^{\circ} \mathrm{C}$. After $24 \mathrm{~h}$, the reaction was cooled to $0^{\circ} \mathrm{C}$ and THF $(3.6 \mathrm{~mL}, 3.6 \mathrm{mmol}, 1.0 \mathrm{M}$ in THF) was added. After $15 \mathrm{~min}$, the brown mixture was quenched with sat. aq. $\mathrm{NH}_{4} \mathrm{Cl}(10 \mathrm{~mL})$, diluted with EtOAc $(30 \mathrm{~mL})$, washed with $\mathrm{H}_{2} \mathrm{O}$ $(15 \mathrm{~mL})$, and sat. aq. $\mathrm{NaCl}(2 \times 10 \mathrm{~mL})$. The dried $\left(\mathrm{Na}_{2} \mathrm{SO}_{4}\right)$ extract was concentrated in vacuo and purified via flash chromatography over silica, eluting with $0-20 \%$ EtOAc / Hexanes to give impure $86(171.3 \mathrm{mg})$ as a yellow oil, and was used without further purification.

Chloride 21: To a stirred solution of $86(171.3 \mathrm{mg})$ and dry DMF $(3.2 \mathrm{~mL})$ was added $\mathrm{NaH}$ (101.5 mg, $2.538 \mathrm{mmol}, 60 \%$ dispersion in mineral oil) at $0^{\circ} \mathrm{C}$. To this dark red solution was added $\mathrm{BnBr}$ $(1.44 \mathrm{~g}, 1.00 \mathrm{~mL}, 8.41 \mathrm{mmol})$. After $10 \mathrm{~min}$, the yellow solution was quenched with sat. aq. $\mathrm{NH}_{4} \mathrm{Cl}(15$ $\mathrm{mL})$, diluted with EtOAc $(30 \mathrm{~mL})$, washed with $\mathrm{H}_{2} \mathrm{O}(15 \mathrm{~mL})$, and sat. aq. $\mathrm{NaCl}(2 \times 10 \mathrm{~mL})$. The dried $\left(\mathrm{MgSO}_{4}\right)$ extract was concentrated in vacuo and purified by flash chromatography over silica gel, eluting with $0-10 \% \mathrm{Et}_{2} \mathrm{O} / \mathrm{Hexanes}$ to give 21 (170.6 mg, $502.0 \mu \mathrm{mol}, 78 \%$ over 2 steps) as a bright yellow crystalline solid. MP $144-147^{\circ} \mathrm{C}$; IR (thin film) $3087,2888,1609,1653,1249,1028 \mathrm{~cm}^{-1}$; ${ }^{1} \mathrm{H}$ NMR (400 $\left.\mathrm{MHz}, \mathrm{CDCl}_{3}\right) \delta 7.85(\mathrm{~d}, J=2.2 \mathrm{~Hz}, 1 \mathrm{H}), 7.60(\mathrm{dd}, J=8.3,2.2 \mathrm{~Hz}, 1 \mathrm{H}), 7.53-7.36(\mathrm{~m}, 6 \mathrm{H}), 7.27(\mathrm{~d}, J=8.8$ $\mathrm{Hz}, 2 \mathrm{H}), 7.08(\mathrm{~d}, J=8.8 \mathrm{~Hz}, 2 \mathrm{H}), 5.14(\mathrm{~s}, 2 \mathrm{H}) ;{ }^{13} \mathrm{C} \mathrm{NMR}\left(100 \mathrm{MHz}, \mathrm{CDCl}_{3}\right) \delta 159.2,149.5,136.7,134.3$, 133.5, 133.0, 132.3, 129.2, 128.7, 128.6, 128.2, 127.6, 124.2, 115.3, 70.1; HRMS (EI+) calcd. for $\mathrm{C}_{19} \mathrm{H}_{14} \mathrm{NO}_{3} \mathrm{Cl}(\mathrm{M}+)$ 339.0662, found 339.0660. 


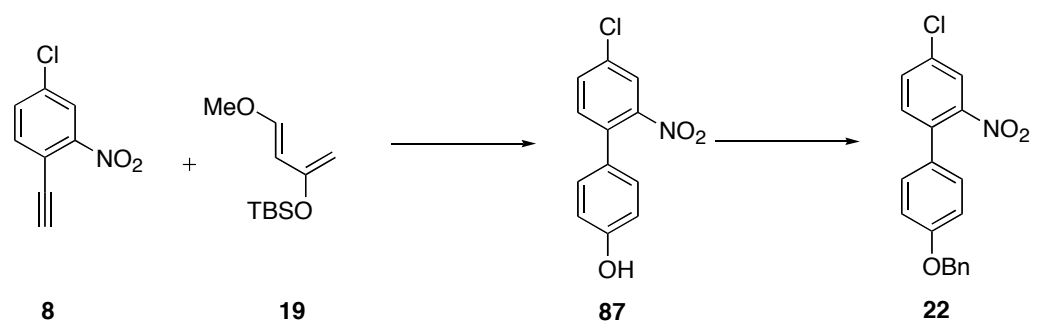

Phenol 87: To a pressure vessel containing 8 (123.7 $\mathrm{mg}, 681.3 \mu \mathrm{mol})$ and $\mathrm{PhMe}(1 \mathrm{~mL})$ was added diene 19 (495 mg, $550 \mu \mathrm{L}, 2.203 \mathrm{mmol})$ at $\mathrm{rt}$. The mixture was heated at $120^{\circ} \mathrm{C}$. After $24 \mathrm{~h}$, the reaction was cooled to $0^{\circ} \mathrm{C}$ and TBAF $(3.7 \mathrm{~mL}, 3.7 \mathrm{mmol}, 1.0 \mathrm{M}$ in THF) was added. After $10 \mathrm{~min}$, the brown mixture was quenched with sat. aq. $\mathrm{NH}_{4} \mathrm{Cl}(10 \mathrm{~mL})$, diluted with EtOAc $(30 \mathrm{~mL})$, washed with $\mathrm{H}_{2} \mathrm{O}$ $(15 \mathrm{~mL})$, and sat. aq. $\mathrm{NaCl}(2 \times 10 \mathrm{~mL})$. The dried $\left(\mathrm{Na}_{2} \mathrm{SO}_{4}\right)$ extract was concentrated in vacuo and purified via flash chromatography over silica, eluting with 0-20\% EtOAc / Hexanes to give 87 (169.4 mg) as a yellow oil, with minor impurities, and used without further purification.

Chloride 22: To a stirred solution of $87(169.4 \mathrm{mg}$ ) and dry DMF (3.0 mL) was added $\mathrm{NaH}$ (155.6 mg, $3.89 \mathrm{mmol}, 60 \%$ dispersion in mineral oil) at $0^{\circ} \mathrm{C}$. To this dark red solution was added $\mathrm{BnBr}$ $(1.44 \mathrm{~g}, 1.0 \mathrm{~mL}, 8.41 \mathrm{mmol})$. After $10 \mathrm{~min}$, the yellow solution was quenched with sat. aq. $\mathrm{NH}_{4} \mathrm{Cl}(15 \mathrm{~mL})$, diluted with EtOAc $(20 \mathrm{~mL})$, washed with $\mathrm{H}_{2} \mathrm{O}(15 \mathrm{~mL})$, and sat. aq. $\mathrm{NaCl}(2 \times 10 \mathrm{~mL})$. The dried $\left(\mathrm{MgSO}_{4}\right)$ extract was concentrated in vacuo and purified by flash chromatography over silica gel, eluting with $0-10 \% \mathrm{Et}_{2} \mathrm{O} /$ Hexanes to give 22 (175.9 mg, $517.6 \mu \mathrm{mol}, 76 \%$ over 2 steps) as a bright yellow crystalline solid. MP $147-148^{\circ} \mathrm{C}$; IR (thin film) $3067,1609,1531,1249,1028 \mathrm{~cm}^{-1} ;{ }^{1} \mathrm{H} \mathrm{NMR}(400 \mathrm{MHz}$, $\left.\mathrm{CDCl}_{3}\right) \delta 7.85(\mathrm{~d}, J=2.0 \mathrm{~Hz}, 1 \mathrm{H}), 7.60(\mathrm{dd}, J=8.3,2.0 \mathrm{~Hz}, 1 \mathrm{H}), 7.55-7.35(\mathrm{~m}, 6 \mathrm{H}), 7.27(\mathrm{~d}, J=8.6 \mathrm{~Hz}$, 2H), $7.08(\mathrm{~d}, J=8.6 \mathrm{~Hz}, 2 \mathrm{H}), 5.14(\mathrm{~s}, 2 \mathrm{H}) ;{ }^{13} \mathrm{C} \mathrm{NMR}\left(100 \mathrm{MHz}, \mathrm{CDCl}_{3}\right) \delta 159.2,149.5,136.7,134.3$, $133.5,133.0,132.3,129.2,128.7,128.6,128.2,127.6,124.2,115.3,70.1$; HRMS (EI+) calcd. for $\mathrm{C}_{19} \mathrm{H}_{14} \mathrm{NO}_{3} \mathrm{Cl}(\mathrm{M}+)$ 339.0662, found 339.0652.

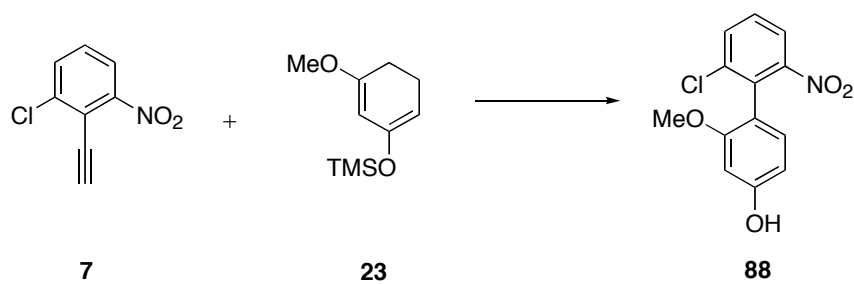

Phenol 88: To a pressure vessel containing 7 (52.6 mg, $289.7 \mu \mathrm{mol})$ was added diene 23 (269.9 $\mathrm{mg}, 1.361 \mathrm{mmol})$ at $\mathrm{rt}$. The mixture was heated at $140^{\circ} \mathrm{C}$. After $24 \mathrm{~h}$, the reaction was cooled to $0^{\circ} \mathrm{C}$ and TBAF (1.4 mL, $1.4 \mathrm{mmol}, 1 \mathrm{M}$ in THF) was added. After $10 \mathrm{~min}$, the brown mixture was quenched with sat. aq. $\mathrm{NH}_{4} \mathrm{Cl}(20 \mathrm{~mL})$, diluted with EtOAc $(30 \mathrm{~mL})$, washed with $\mathrm{H}_{2} \mathrm{O}(20 \mathrm{~mL})$, and sat. aq. $\mathrm{NaCl}(2 \times 20$ $\mathrm{mL})$. The dried $\left(\mathrm{Na}_{2} \mathrm{SO}_{4}\right)$ extract was concentrated in vacuo and purified via flash chromatography over silica, eluting with 0-20\% EtOAc / Hexanes to give 88 (53.6 mg, $191.6 \mu \mathrm{mol}, 66 \%)$ as a bright yellow solid. MP $136-138^{\circ} \mathrm{C}$; IR (thin film) 3432, 3080, 2929, 1613, 1587, 1531, 1355, $1303 \mathrm{~cm}^{-1} ;{ }^{1} \mathrm{H}$ NMR (300 $\left.\mathrm{MHz}_{,} \mathrm{CDCl}_{3}\right) \delta 7.84(\mathrm{dd}, J=8.1,1.2 \mathrm{~Hz}, 1 \mathrm{H}), 7.73(\mathrm{dd}, J=8.1,1.2, \mathrm{~Hz}, 1 \mathrm{H}), 7.44(\mathrm{t}, J=8.1,1 \mathrm{H}), 7.05(\mathrm{~d}$, $8.8 \mathrm{~Hz}, 1 \mathrm{H}), 6.56-6.50(\mathrm{~m}, 2 \mathrm{H}), 3.74(\mathrm{~s}, 3 \mathrm{H}) ;{ }^{13} \mathrm{C}$ NMR $\left(75 \mathrm{MHz}, \mathrm{CDCl}_{3}\right) \delta$ 157.8, 157.6, 151.5, 136.7, $133.5,131.8,130.9,128.5,122.1,115.3,107.4$, 99.4, 55.6; HRMS (EI+) calcd. for $\mathrm{C}_{13} \mathrm{H}_{10} \mathrm{NO}_{4} \mathrm{Cl}(\mathrm{M}+\mathrm{H})$ 279.0298 , found 279.0293 . 


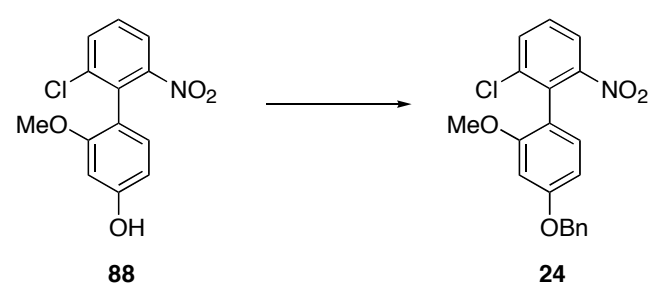

Chloride 24: To a stirred solution of $\mathbf{8 8}(26.4 \mathrm{mg}, 94.4 \mu \mathrm{mol})$ and dry DMF (50 $\mu \mathrm{L})$ was added $\mathrm{NaH}\left(8.2 \mathrm{mg}, 0.205 \mathrm{mmol}, 60 \%\right.$ dispersion in mineral oil) at $0^{\circ} \mathrm{C}$. To this dark red solution was added $\mathrm{BnBr}(187 \mathrm{mg}, 130 \mu \mathrm{L}, 1.07 \mathrm{mmol})$. After $10 \mathrm{~min}$, the yellow solution was quenched with sat. aq. $\mathrm{NH}_{4} \mathrm{Cl}$ $(10 \mathrm{~mL})$, diluted with EtOAc $(20 \mathrm{~mL})$, washed with $\mathrm{H}_{2} \mathrm{O}(10 \mathrm{~mL})$, and sat. aq. $\mathrm{NaCl}(2 \times 10 \mathrm{~mL})$. The dried $\left(\mathrm{MgSO}_{4}\right)$ extract was concentrated in vacuo and purified by flash chromatography over silica gel, eluting with $0-10 \% \mathrm{Et}_{2} \mathrm{O} /$ Hexanes to give $24(18.1 \mathrm{mg}, 48.9 \mu \mathrm{mol}, 96 \%)$ as a bright yellow crystalline solid. MP 104-106 ${ }^{\circ}$; IR (thin film) 2959, 1614, 1583, 1530, 1245, $1037 \mathrm{~cm}^{-1} ;{ }^{1} \mathrm{H}$ NMR $(300 \mathrm{MHz}$, $\left.\mathrm{CDCl}_{3}\right) \delta 7.80(\mathrm{dd}, J=8.1,1.3 \mathrm{~Hz}, 1 \mathrm{H}), 7.72(\mathrm{dd}, J=8.1,1.3 \mathrm{~Hz}, 1 \mathrm{H}), 7.53-7.34(\mathrm{~m}, 6 \mathrm{H}), 7.12(\mathrm{~d}, J=8.3$ $\mathrm{Hz}, 1 \mathrm{H}), 6.69$ (dd, $J=8.3,2.3 \mathrm{~Hz}, 1 \mathrm{H}), 6.65(\mathrm{~d}, J=2.3 \mathrm{~Hz}, 1 \mathrm{H}), 5.11(\mathrm{~s}, 2 \mathrm{H}), 3.73(\mathrm{~s}, 3 \mathrm{H}) ;{ }^{13} \mathrm{C}$ NMR $(100$ $\left.\mathrm{MHz}, \mathrm{CDCl}_{3}\right) \delta 160.9,157.5,151.5,136.7,136.7,133.5,131.8,130.8,128.7,128.5,128.2,127.8,122.2$, 115.9, 105.4, 99.6, 70.3, 55.6; HRMS (EI+) calcd. for $\mathrm{C}_{20} \mathrm{H}_{16} \mathrm{NO}_{4} \mathrm{Cl}(\mathrm{M}+)$ 369.0768, found 369.0760.

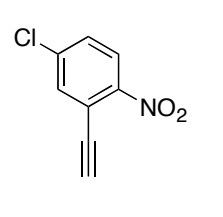

13<smiles>COc1cccc(OC)c1</smiles>

23

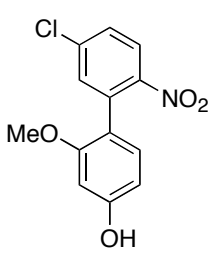

89

Phenol 89: To a pressure vessel containing 7 (106.8 mg, $588.2 \mu \mathrm{mol})$ was added diene 23 (364.7 $\mathrm{mg}, 1.839 \mathrm{mmol})$ at $\mathrm{rt}$. The mixture was heated at $140^{\circ} \mathrm{C}$. After $24 \mathrm{~h}$, the reaction was cooled to $0^{\circ} \mathrm{C}$ and TBAF (1.8 mL, $1.8 \mathrm{mmol}, 1 \mathrm{M}$ in THF) was added. After $10 \mathrm{~min}$, the brown mixture was quenched with sat. aq. $\mathrm{NH}_{4} \mathrm{Cl}(20 \mathrm{~mL})$, diluted with EtOAc $(30 \mathrm{~mL})$, washed with $\mathrm{H}_{2} \mathrm{O}(20 \mathrm{~mL})$, and sat. aq. $\mathrm{NaCl}(2 \mathrm{x} 20$ $\mathrm{mL})$. The dried $\left(\mathrm{Na}_{2} \mathrm{SO}_{4}\right)$ extract was concentrated in vacuo and purified via flash chromatography over silica, eluting with 0-20\% EtOAc / Hexanes to give 89 (124.6 mg, $445.5 \mu \mathrm{mol}, 76 \%)$ as a bright yellow solid. MP $178-181^{\circ} \mathrm{C}$; IR (thin film) 3458, 1613, 1596, 1523, 1350, $1037 \mathrm{~cm}^{-1} ;{ }^{1} \mathrm{H}$ NMR $(400 \mathrm{MHz}$, DMSO- $\left._{6}\right) \delta 9.83(\mathrm{~s}, 1 \mathrm{H}), 7.95(\mathrm{dd}, J=8.4, \mathrm{~Hz}, 1 \mathrm{H}), 7.61(\mathrm{dd}, J=8.4,2.4,1 \mathrm{H}), 7.51(\mathrm{~d}, 2.4 \mathrm{~Hz}, 1 \mathrm{H}), 7.19$ $(\mathrm{d}, J=8.4 \mathrm{~Hz}, 1 \mathrm{H}), 6.50(\mathrm{dd}, J=8.4,2.4 \mathrm{~Hz}, 1 \mathrm{H}), 6.45(\mathrm{~d}, J=2.0,1 \mathrm{H}), 3.58(\mathrm{~s}, 3 \mathrm{H}) ;{ }^{13} \mathrm{C} \mathrm{NMR}(100 \mathrm{MHz}$, DMSO- $\left.d_{6}\right) \delta 160.2,157.1,148.3,137.8,134.8,132.3,130.9,128.1,126.2,116.1,108.4,99.5,55.4 ;$ HRMS $(\mathrm{EI}+)$ calcd. for $\mathrm{C}_{13} \mathrm{H}_{10} \mathrm{NO}_{4} \mathrm{Cl}(\mathrm{M}+)$ 279.0298, found 279.0303 .

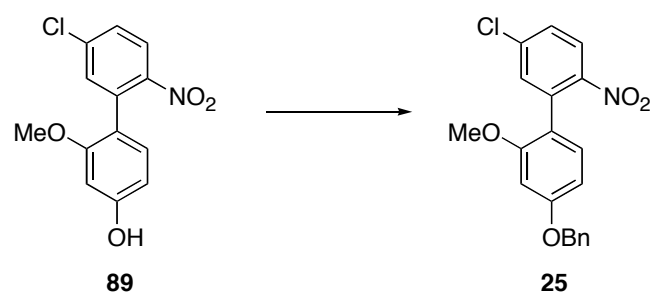

Chloride 25: To a stirred solution of $89(28.9 \mathrm{mg}, 103.3 \mu \mathrm{mol})$ and dry DMF $(50 \mu \mathrm{L})$ was added $\mathrm{NaH}\left(12.0 \mathrm{mg}, 300 \mu \mathrm{mol}, 60 \%\right.$ dispersion in mineral oil) at $0^{\circ} \mathrm{C}$. To this dark red solution was added $\mathrm{BnBr}$ (186.9 mg, $130 \mu \mathrm{L}, 1.07 \mathrm{mmol})$. After $10 \mathrm{~min}$, the yellow solution was quenched with sat. aq. $\mathrm{NH}_{4} \mathrm{Cl}(10$ $\mathrm{mL})$, diluted with EtOAc $(30 \mathrm{~mL})$, washed with $\mathrm{H}_{2} \mathrm{O}(10 \mathrm{~mL})$, and sat. aq. $\mathrm{NaCl}(2 \times 10 \mathrm{~mL})$. The dried $\left(\mathrm{MgSO}_{4}\right)$ extract was concentrated in vacuo and purified by flash chromatography over silica gel, eluting 
with $0-10 \% \mathrm{Et}_{2} \mathrm{O} / \mathrm{Hexanes}$ to give $25(36.1 \mathrm{mg}, 97.6 \mu \mathrm{mol}, 94 \%)$ as a bright yellow crystalline solid. MP $98-99^{\circ} \mathrm{C}$; IR (thin film) $3062,2941,1612,1582,1526,1273,1040 \mathrm{~cm}^{-1} ;{ }^{1} \mathrm{H}$ NMR $\left(400 \mathrm{MHz}, \mathrm{CDCl}_{3}\right) \delta$ $7.89(\mathrm{~d}, J=8.4 \mathrm{~Hz}, 1 \mathrm{H}), 7.58-7.34(\mathrm{~m}, 7 \mathrm{H}), 7.25(\mathrm{~d}, J=8.4 \mathrm{~Hz}, 1 \mathrm{H}), 6.72(\mathrm{dd}, J=8.4,2.3 \mathrm{~Hz}, 1 \mathrm{H}), 6.60$ (d, $J=2.3 \mathrm{~Hz}, 1 \mathrm{H}), 5.14$ (s, 2H), $3.70(\mathrm{~s}, 3 \mathrm{H}) ;{ }^{13} \mathrm{C}$ NMR $\left(100 \mathrm{MHz}, \mathrm{CDCl}_{3}\right) \delta 160.93,157.0,148.0,138.6$, 136.6, 134.7, 132.4, 130.1, 128.7, 128.2, 127.7, 127.6, 125.4, 118.8, 106.0, 99.5, 70.3, 55.2; HRMS (EI+) calcd. for $\mathrm{C}_{20} \mathrm{H}_{16} \mathrm{NO}_{4} \mathrm{Cl}(\mathrm{M}+)$ 369.0768, found 369.0762 .

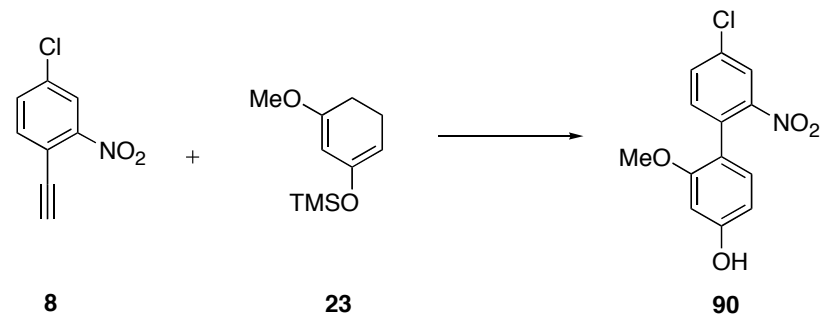

Phenol 90: To a pressure vessel containing 7 (103.0 mg, $567.3 \mu \mathrm{mol})$ was added diene 23 (353.4 $\mathrm{mg}, 1.782 \mathrm{mmol})$ at $\mathrm{rt}$. The mixture was heated at $140^{\circ} \mathrm{C}$. After $24 \mathrm{~h}$, the reaction was cooled to $0^{\circ} \mathrm{C}$ and TBAF (1.8 mL, $1.8 \mathrm{mmol}, 1 \mathrm{M}$ in THF) was added. After $10 \mathrm{~min}$, the brown mixture was quenched with sat. aq. $\mathrm{NH}_{4} \mathrm{Cl}(20 \mathrm{~mL})$, diluted with EtOAc $(30 \mathrm{~mL})$, washed with $\mathrm{H}_{2} \mathrm{O}(20 \mathrm{~mL})$, and sat. aq. $\mathrm{NaCl}(2 \times 20$ $\mathrm{mL})$. The dried $\left(\mathrm{Na}_{2} \mathrm{SO}_{4}\right)$ extract was concentrated in vacuo and purified via flash chromatography over silica, eluting with 0-20\% EtOAc / Hexanes to give 90 (115.8 mg, $414.0 \mu \mathrm{mol}, 73 \%)$ as a bright yellow solid. MP 90-92 ${ }^{\circ} \mathrm{C}$; IR (thin film) $3385,1617,1531,1359,1265,1037 \mathrm{~cm}^{-1} ;{ }^{1} \mathrm{H}$ NMR (400 MHz, DMSO$\left.d_{6}\right) \delta 9.81(\mathrm{~s}, 1 \mathrm{H}), 8.04(\mathrm{~d}, J=2.0 \mathrm{~Hz}, 1 \mathrm{H}), 7.81(\mathrm{dd}, J=8.4,2.0,1 \mathrm{H}), 7.47(\mathrm{~d}, 8.4 \mathrm{~Hz}, 1 \mathrm{H}), 7.14(\mathrm{~d}, J=8.4$ $\mathrm{Hz}, 1 \mathrm{H}), 6.51(\mathrm{dd}, J=8.4,2.4 \mathrm{~Hz}, 1 \mathrm{H}), 6.45(\mathrm{~d}, J=2.4 \mathrm{~Hz}, 1 \mathrm{H}), 3.58(\mathrm{~s}, 3 \mathrm{H}) ;{ }^{13} \mathrm{C} \mathrm{NMR}(100 \mathrm{MHz}$, DMSO- $\left.d_{6}\right) \delta 160.1,157.0,150.1,134.4,133.2,132.2,131.5,130.8,124.1,116.2,108.4,99.5,55.3$; HRMS (EI+) calcd. for $\mathrm{C}_{13} \mathrm{H}_{10} \mathrm{NO}_{4} \mathrm{Cl}$ (M) 279.0298, found 279.0293.

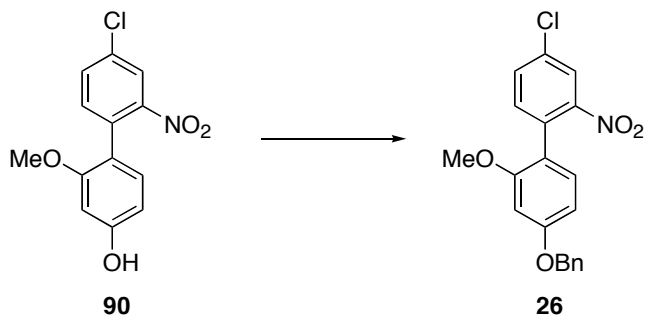

Chloride 26: To a stirred solution of $90(26.4 \mathrm{mg}, 94.4 \mu \mathrm{mol})$ and dry DMF (50 $\mu \mathrm{L})$ was added $\mathrm{NaH}\left(15.0 \mathrm{mg}, 0.375 \mathrm{mmol}, 60 \%\right.$ dispersion in mineral oil) at $0^{\circ} \mathrm{C}$. To this dark red solution was added $\mathrm{BnBr}(187 \mathrm{mg}, 130 \mu \mathrm{L}, 1.07 \mathrm{mmol})$. After $10 \mathrm{~min}$, the yellow solution was quenched with sat. aq. $\mathrm{NH}_{4} \mathrm{Cl}$ $(10 \mathrm{~mL})$, diluted with EtOAc $(30 \mathrm{~mL})$, washed with $\mathrm{H}_{2} \mathrm{O}(10 \mathrm{~mL})$, and sat. aq. $\mathrm{NaCl}(2 \times 10 \mathrm{~mL})$. The dried $\left(\mathrm{MgSO}_{4}\right)$ extract was concentrated in vacuo and purified by flash chromatography over silica gel, eluting with $0-10 \% \mathrm{Et}_{2} \mathrm{O} /$ Hexanes to give $26(32.2 \mathrm{mg}, 87.1 \mu \mathrm{mol}, 92 \%)$ as a bright yellow crystalline solid. MP 94-97 ${ }^{\circ} \mathrm{C}$; IR (thin film) 2933, 1613, 1532, 1357, 1261, $1036 \mathrm{~cm}^{-1} ;{ }^{1} \mathrm{H}$ NMR $\left(400 \mathrm{MHz}, \mathrm{CDCl}_{3}\right)$ $\delta 7.94(\mathrm{~d}, J=2.2 \mathrm{~Hz}, 1 \mathrm{H}), 7.61(\mathrm{dd}, J=8.3,2.2 \mathrm{~Hz}, 1 \mathrm{H}), 7.52-7.32(\mathrm{~m}, 6 \mathrm{H}), 7.23(\mathrm{~d}, J=8.4 \mathrm{~Hz}, 1 \mathrm{H}), 6.72$ (dd, $J=8.4,2.3 \mathrm{~Hz}, 1 \mathrm{H}), 6.60(\mathrm{~d}, J=2.3 \mathrm{~Hz}, 1 \mathrm{H}), 5.14(\mathrm{~s}, 2 \mathrm{H}), 3.70(\mathrm{~s}, 3 \mathrm{H}) ;{ }^{13} \mathrm{C} \mathrm{NMR}\left(100 \mathrm{MHz}, \mathrm{CDCl}_{3}\right)$ $\delta 160.8,156.9,149.8,136.6,133.6,133.3,132.6,131.3,130.2,128.7,128.2,127.7,124.2,118.8,106.0$, 99.5, 70.31, 55.2; HRMS (CI+) calcd. for $\mathrm{C}_{20} \mathrm{H}_{16} \mathrm{NO}_{4} \mathrm{Cl}(\mathrm{M}+)$ 369.0768, found 369.0756 . 


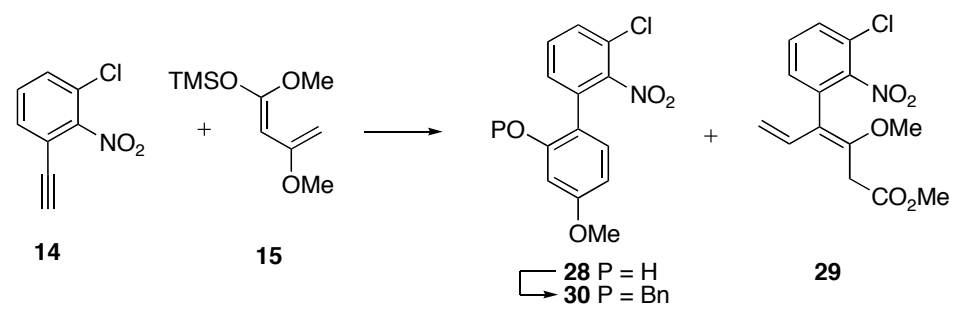

Enol Ether 29: To a pressure vessel containing 14 (144 mg, $0.790 \mathrm{mmol})$ was added diene $\mathbf{1 5}^{9}$ $(642 \mathrm{mg}, 3.17 \mathrm{mmol})$ and heated to $110^{\circ} \mathrm{C}$. After $24 \mathrm{~h}$, the reaction was cooled to $0^{\circ} \mathrm{C}$, diluted with toluene $(0.79 \mathrm{~mL})$ and DABCO $(357 \mathrm{mg}, 3.17 \mathrm{mmol})$ was added. After $2 \mathrm{~h}$, the reaction mixture was quenched with sat. aq. $\mathrm{NH}_{4} \mathrm{Cl}(10 \mathrm{~mL})$, diluted with EtOAc $(25 \mathrm{~mL})$, and washed with $\mathrm{H}_{2} \mathrm{O}(10 \mathrm{~mL})$ and sat. aq. $\mathrm{NaCl}$ $(10 \mathrm{~mL})$. The dried extract $\left(\mathrm{MgSO}_{4}\right)$ was concentrated in vacuo and purified by chromatography over silica gel, eluting with 15-35\% EtOAc / Hexanes, to sequentially give impure 28 (40.0 mg) and impure 29 (44.5 $\mathrm{mg}$ ) as a yellow oil. 29 was further purified by chromatography over silica gel containing silver nitrate, eluting with 10 - 20\% EtOAc / Hexanes. 29: IR (neat) 2915, 1735, 1537, $1027 \mathrm{~cm}^{-1} ;{ }^{1} \mathrm{H}-\mathrm{NMR}$ (400 MHz, $\left.\mathrm{CDCl}_{3}\right) \delta 7.54(\mathrm{dd}, J=1.2,8.1 \mathrm{~Hz}, 1 \mathrm{H}), 7.48(\mathrm{dd}, J=7.7,8.1 \mathrm{~Hz}, 1 \mathrm{H}), 7.30(\mathrm{dd}, J=1.2,7.7 \mathrm{~Hz}, 1 \mathrm{H}), 7.01$ $(\mathrm{ddd}, J=6.8,10.8,17.6 \mathrm{~Hz}, 1 \mathrm{H}), 5.09(\mathrm{~d}, J=10.8 \mathrm{~Hz}, 1 \mathrm{H}), 4.52(\mathrm{~d}, J=17.6 \mathrm{~Hz}, 1 \mathrm{H}), 3.73(\mathrm{~s}, 3 \mathrm{H}), 3.71(\mathrm{~s}$, $3 \mathrm{H}), 3.26(\mathrm{~d}, J=16.7 \mathrm{~Hz}, 1 \mathrm{H}), 3.03(\mathrm{~d}, J=16.7 \mathrm{~Hz}, 1 \mathrm{H}) ;{ }^{13} \mathrm{C} \mathrm{NMR}\left(100 \mathrm{MHz}, \mathrm{CDCl}_{3}\right) \delta 169.7,150.2$, $149.8,131.6,131.4,131.3,130.9,130.0,125.1,119.8,115.8,57.3,52.3,35.4$; HRMS (EI+) calcd. for $\mathrm{C}_{14} \mathrm{H}_{14} \mathrm{NO}_{5} \mathrm{Cl}(\mathrm{M}+\mathrm{H}) 311.0560$, found 311.0567 .

Biaryl 30: To a stirred solution of $28(40.0 \mathrm{mg}, 0.143 \mathrm{mmol})$ and DMF $(0.900 \mathrm{~mL})$ at $0^{\circ} \mathrm{C}$ was added $\mathrm{NaH}$ (10.6 mg, $0.265 \mathrm{mmol}, 60 \%$ in mineral oil). After bubbling ceased, $\mathrm{BnBr}(376 \mathrm{mg}, 0.263 \mathrm{~mL}$, $2.20 \mathrm{mmol}$ ) was added dropwise to the deep red solution. After $15 \mathrm{~min}$, the reaction was warmed to $\mathrm{rt}$. After $1 \mathrm{~h}$, the reaction was quenched with sat. aq. $\mathrm{NH}_{4} \mathrm{Cl}(5 \mathrm{~mL})$, diluted with EtOAc $(15 \mathrm{~mL})$, washed with $\mathrm{H}_{2} \mathrm{O}(15 \mathrm{~mL})$ and sat. aq. $\mathrm{NaCl}(15 \mathrm{~mL})$. The dried extract $\left(\mathrm{MgSO}_{4}\right)$ was concentrated in vacuo and purified by chromatography over silica gel, eluting with 3-10\% EtOAc / Hexanes, to give 30 (41.2 mg, 0.11 mmol, 14\% over two steps) as a yellow solid. MP $110-111^{\circ} \mathrm{C}$; IR (neat) $2921,1530 \mathrm{~cm}^{-1}$; ${ }^{1} \mathrm{H}$ NMR $(300$ $\left.\mathrm{MHz}_{\mathrm{CDCl}}\right) \delta 7.49(\mathrm{dd}, J=1.8,8.0 \mathrm{~Hz}, 1 \mathrm{H}), 7.43(\mathrm{dd}, J=7.6,8.0 \mathrm{~Hz}, 1 \mathrm{H}), 7.36(\mathrm{dd}, J=1.8,7.6 \mathrm{~Hz}$, $1 \mathrm{H}), 7.33-7.27(\mathrm{~m}, 5 \mathrm{H}), 7.14(\mathrm{dd}, J=1.7,7.5 \mathrm{~Hz}, 1 \mathrm{H}), 6.56(\mathrm{dd}, J=2.4,7.5 \mathrm{~Hz}, 1 \mathrm{H}), 6.54(\mathrm{dd}, J=1.7 \mathrm{~Hz}$, 1H), $5.05(\mathrm{~s}, 2 \mathrm{H}), 3.80(\mathrm{~s}, 3 \mathrm{H}) ;{ }^{13} \mathrm{C} \mathrm{NMR}\left(100 \mathrm{MHz}, \mathrm{CDCl}_{3}\right) \delta 161.5,156.7,149.6,136.6,133.4,131.0$, $130.8,130.2,129.1,128.5,127.8,126.8,125.1,117.4,105.3,100.7,70.5,55.4$; HRMS (CI+) calcd. for $\mathrm{C}_{20} \mathrm{H}_{16} \mathrm{NO}_{4} \mathrm{Cl}(\mathrm{M}+\mathrm{H}) 370.0846$, found 370.0849 .

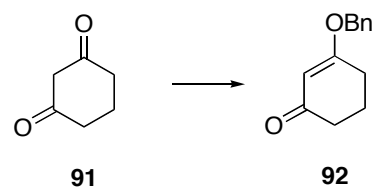

Enone 92: To a stirred solution of $91(1.07 \mathrm{~g}, 9.53 \mathrm{mmol})$ and $\mathrm{PhMe}(48.0 \mathrm{~mL})$ was added $\mathrm{BnOH}$ $(1.96 \mathrm{~mL}, 2.06 \mathrm{~g}, 19.1 \mathrm{mmol})$, and $p$-TSA $(45.4 \mathrm{mg}, 0.238 \mathrm{mmol})$. The reaction flask was equipped with a Dean Stark trap and heated at $140^{\circ} \mathrm{C}$. After $12 \mathrm{~h}$, the reaction was cooled to $\mathrm{rt}$, concentrated in vacuo and purified by chromatography over silica gel, eluting with $20-50 \%$ EtOAc / Hexanes to give known enone $\mathbf{9 2}^{10}(1.65 \mathrm{~g}, 8.16 \mathrm{mmol}, 86 \%)$ as a yellow crystalline solid. ${ }^{1} \mathrm{H}$ NMR $\left(300 \mathrm{MHz}, \mathrm{CDCl}_{3}\right) \delta 7.44-7.28(\mathrm{~m}$, $5 \mathrm{H}), 5.50(\mathrm{~s}, 1 \mathrm{H}), 4.91(\mathrm{~s}, 2 \mathrm{H}), 2.50(\mathrm{t}, J=6.3 \mathrm{~Hz}, 2 \mathrm{H}), 2.39(\mathrm{t}, J=6.3 \mathrm{~Hz}, 2 \mathrm{H}), 2.03(\mathrm{q}, J=6.3 \mathrm{~Hz}, 2 \mathrm{H})$; ${ }^{13} \mathrm{C} \mathrm{NMR}\left(75 \mathrm{MHz}, \mathrm{CDCl}_{3}\right) \delta 199.7,177.5,135.2,128.7,128.6,127.9,103.4,70.5,36.8,29.1,21.2$. 


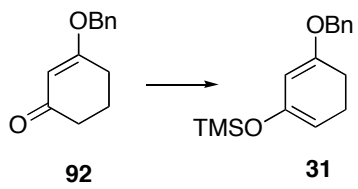

Diene 31: To a flask containing $\operatorname{LDA}^{11}(15.7 \mathrm{~mL}, 13.4 \mathrm{mmol}, 0.86 \mathrm{M}$ in $\mathrm{THF} /$ hexanes $)$ was added a solution of $92(2.56 \mathrm{~g}, 12.8 \mathrm{mmol})$ in THF $(6.7 \mathrm{~mL})$ at $-78^{\circ} \mathrm{C}$. After $10 \mathrm{~min}$, TMSCl $(1.67 \mathrm{~g}, 1.95$ $\mathrm{mL}, 15.3 \mathrm{mmol}$ ) was added. After $1 \mathrm{~h}$, the reaction was warmed to rt, poured into a cold solution of aq. $\mathrm{NaHCO}_{3}(50 \mathrm{~mL}, 5 \% \mathrm{w} / \mathrm{v})$, extracted with $\mathrm{Et}_{2} \mathrm{O}(100 \mathrm{~mL})$, and washed with $\mathrm{H}_{2} \mathrm{O}(75 \mathrm{~mL})$ and sat. aq. $\mathrm{NaCl}$ $(75 \mathrm{~mL})$. The dried extract $\left(\mathrm{MgSO}_{4}\right)$ was concentrated in vacuo to give $31(3.51 \mathrm{~g}, 12.8 \mathrm{mmol}, 99 \%)$ as a pale yellow oil. IR (neat) 2943, 1605, $1361 \mathrm{~cm}^{-1},{ }^{1} \mathrm{H}$ NMR (300 MHz, $\left.\mathrm{CDCl}_{3}\right) \delta 7.42-7.31(\mathrm{~m}, 5 \mathrm{H}), 4.88$ $(\mathrm{s}, 1 \mathrm{H}), 4.81(\mathrm{~s}, 2 \mathrm{H}), 4.61-4.59(\mathrm{~m}, 1 \mathrm{H}), 2.31-2.25(\mathrm{~m}, 4 \mathrm{H}), 0.23(\mathrm{~s}, 9 \mathrm{H}) ;{ }^{13} \mathrm{C} \mathrm{NMR}\left(100 \mathrm{MHz}, \mathrm{CDCl}_{3}\right) \delta$ $160.1,149.0,136.6,128.5,128.0,127.7,96.0,94.7,69.4,27.4,21.8,0.21$; HRMS (CI+) calcd. for $\mathrm{C}_{16} \mathrm{H}_{22} \mathrm{O}_{2} \mathrm{Si}(\mathrm{M}+\mathrm{H}) 275.1467$, found, 275.1477.

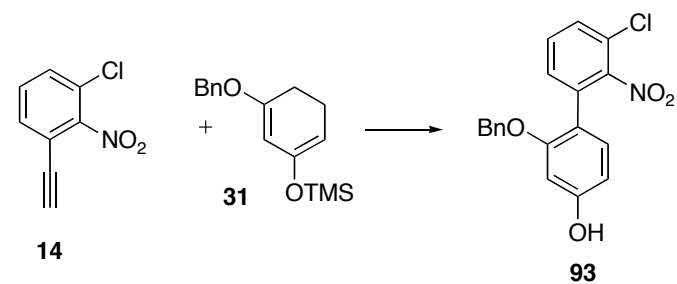

Phenol 93: To a pressure vessel containing 14 (1.88 g, $13.4 \mathrm{mmol})$ was added diene 31 (8.02 g, $29.2 \mathrm{mmol})$ and heated to $140^{\circ} \mathrm{C}$. After $5 \mathrm{~h}$, the reaction was cooled to $-30^{\circ} \mathrm{C}$, diluted with $\mathrm{THF}(20 \mathrm{~mL})$ and TBAF (31.1 mL, $31.1 \mathrm{mmol}, 1.0 \mathrm{M}$ in THF) was added. After $15 \mathrm{~min}$, the reaction was quenched with sat. aq. $\mathrm{NH}_{4} \mathrm{Cl}(30 \mathrm{~mL})$, diluted with EtOAc $(50 \mathrm{~mL})$, and washed with $\mathrm{H}_{2} \mathrm{O}(30 \mathrm{~mL})$ and sat. aq. $\mathrm{NaCl}(30$ $\mathrm{mL})$. The dried extract $\left(\mathrm{MgSO}_{4}\right)$ was concentrated in vacuo and purified by chromatography over silica gel, eluting with 15-50\% EtOAc / Hexanes, to give 93 (2.90 g, $8.16 \mathrm{mmol}, 79 \%)$ as an orange oil. MP 98$100^{\circ} \mathrm{C}$; IR (neat) $3443,1614,1537 \mathrm{~cm}^{-1} ;{ }^{1} \mathrm{H}$ NMR $\left(300 \mathrm{MHz}, \mathrm{CDCl}_{3}\right) \delta 7.48(\mathrm{dd}, J=1.5,8.0 \mathrm{~Hz}, 1 \mathrm{H}), 7.44$ $(\mathrm{dd}, J=7.7,8.0 \mathrm{~Hz}, 1 \mathrm{H}), 7.34(\mathrm{dd}, J=1.6,7.7 \mathrm{~Hz}, 1 \mathrm{H}), 7.26-7.33(\mathrm{~m}, 5 \mathrm{H}), 7.04(\mathrm{~d}, J=8.2 \mathrm{~Hz}, 1 \mathrm{H}), 6.48$ $(\mathrm{d}, J=2.3 \mathrm{~Hz}, 1 \mathrm{H}), 6.43(\mathrm{dd}, J=2.3,8.2 \mathrm{~Hz}, 1 \mathrm{H}), 5.58(\mathrm{~s}, 1 \mathrm{H}), 4.99(\mathrm{~s}, 2 \mathrm{H}) ;{ }^{13} \mathrm{C} \mathrm{NMR}\left(100 \mathrm{MHz}^{\mathrm{CDCl}}\right)_{3}$ $\delta 157.7,156.8,149.5,136.5,133.4,131.1,131.0,130.4,129.2,128.5,127.8,126.8,125.1,117.1,108.0$, 101.1, 70.4; HRMS (CI+) calcd. for $\mathrm{C}_{19} \mathrm{H}_{14} \mathrm{NO}_{4} \mathrm{Cl}(\mathrm{M}+\mathrm{H}) 355.0611$, found 355.0624 .

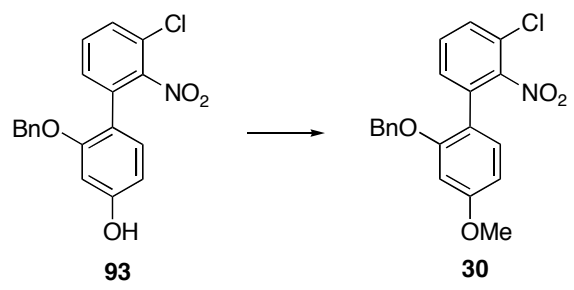

Chloride 30: To a stirred solution of $93(2.23 \mathrm{~g}, 6.27 \mathrm{mmol})$ and DMF $(31.0 \mathrm{~mL})$ at $0{ }^{\circ} \mathrm{C}$, was added $\mathrm{NaH}$ (300 mg, $7.5 \mathrm{mmol}, 60 \%$ in mineral oil). After bubbling ceased, MeI (0.780 mL, $12.5 \mathrm{mmol})$ was added dropwise to the deep red solution. After $30 \mathrm{~min}$, the reaction mixture was warmed to rt. After an additional $20 \mathrm{~min}$, the reaction was quenched with sat. aq. $\mathrm{NH}_{4} \mathrm{Cl}(20 \mathrm{~mL})$, diluted with EtOAc $(50 \mathrm{~mL})$, and washed with $\mathrm{H}_{2} \mathrm{O}(20 \mathrm{~mL})$ and sat. aq. $\mathrm{NaCl}(20 \mathrm{~mL})$. The dried extract $\left(\mathrm{MgSO}_{4}\right)$ was concentrated in vacuo and purified by recrystallization with $\mathrm{Et}_{2} \mathrm{O} /$ Hexanes $(2: 1)$ to give $\mathbf{3 0}(1.68 \mathrm{~g}, 4.55 \mathrm{mmol}, 73 \%)$ as a yellow solid. MP $110-111.5^{\circ} \mathrm{C}$; IR (neat) $2921,1530 \mathrm{~cm}^{-1} ;{ }^{1} \mathrm{H}$ NMR $\left(300 \mathrm{MHz}, \mathrm{CDCl}_{3}\right) \delta 7.49(\mathrm{dd}, J=1.8$, $8.0 \mathrm{~Hz}, 1 \mathrm{H}), 7.43(\mathrm{dd}, J=7.6,8.0 \mathrm{~Hz}, 1 \mathrm{H}), 7.36(\mathrm{dd}, J=1.8,7.6 \mathrm{~Hz}, 1 \mathrm{H}), 7.33-7.27(\mathrm{~m}, 5 \mathrm{H}), 7.14(\mathrm{dd}, J=$ $1.7,7.5 \mathrm{~Hz}, 1 \mathrm{H}), 6.56(\mathrm{dd}, J=2.4,7.5 \mathrm{~Hz}, 1 \mathrm{H}), 6.54(\mathrm{dd}, J=1.7 \mathrm{~Hz}, 1 \mathrm{H}), 5.05(\mathrm{~s}, 2 \mathrm{H}), 3.80(\mathrm{~s}, 3 \mathrm{H}) ;{ }^{13} \mathrm{C}$ NMR $\left(100 \mathrm{MHz}, \mathrm{CDCl}_{3}\right) \delta 161.5,156.7,149.6,136.6,133.4,131.0,130.8,130.2,129.1,128.5,127.8$, 
126.8, 125.1, 117.4, 105.3, 100.7, 70.5, 55.4; HRMS (CI+) calcd. for $\mathrm{C}_{20} \mathrm{H}_{16} \mathrm{NO}_{4} \mathrm{Cl}(\mathrm{M}+\mathrm{H}) 370.0846$, found 370.0849 .

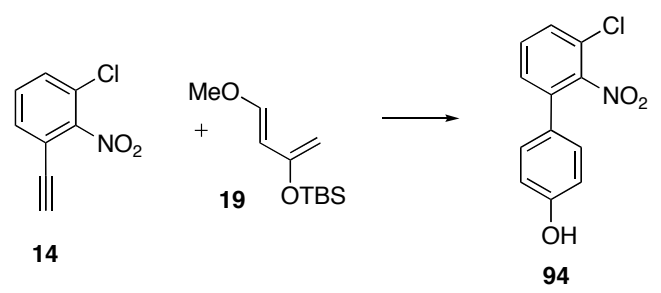

Phenol 94: To a pressure vessel containing $14(59.2 \mathrm{mg}, 0.325 \mathrm{mmol})$ and $\mathrm{PhMe}(0.650 \mathrm{~mL})$ was added diene $19(277 \mathrm{mg}, 0.308 \mathrm{~mL}, 1.30 \mathrm{mmol})$ and heated to $115^{\circ} \mathrm{C}$. After $14 \mathrm{~h}$, the reaction was cooled to $0^{\circ} \mathrm{C}$ and TBAF $(1.95 \mathrm{~mL}, 1.95 \mathrm{mmol}, 1.0 \mathrm{M}$ in THF) was added. After $15 \mathrm{~min}$, the reaction was quenched with sat. aq. $\mathrm{NH}_{4} \mathrm{Cl}(8 \mathrm{~mL})$, diluted with $\mathrm{Et}_{2} \mathrm{O}(15 \mathrm{~mL})$, and washed with $\mathrm{H}_{2} \mathrm{O}(10 \mathrm{~mL})$ and sat. aq. $\mathrm{NaCl}(10 \mathrm{~mL})$. The dried extract $\left(\mathrm{MgSO}_{4}\right)$ was concentrated in vacuo and purified by chromatography over silica gel, eluting with 20-50\% EtOAc / Hexanes, to yield 94 (64.2 $\mathrm{mg}, 0.258 \mathrm{mmol}, 78 \%)$ as a white crystalline solid. MP $132-134^{\circ} \mathrm{C}$; IR (neat) $3518,1610,1534,1459,1369,1199 \mathrm{~cm}^{-1}$; ${ }^{1} \mathrm{H} \mathrm{NMR}(400 \mathrm{MHz}$, $\left.\mathrm{CDCl}_{3}\right) \delta 7.51(\mathrm{dd}, J=2.1,8.1 \mathrm{~Hz}, 1 \mathrm{H}), 7.48(\mathrm{t}, J=8.1 \mathrm{~Hz}, 1 \mathrm{H}), 7.37(\mathrm{dd}, J=2.1,7.0 \mathrm{~Hz}, 1 \mathrm{H}), 7.27(\mathrm{dt}, J$ $=2.2,8.8 \mathrm{~Hz}, 2 \mathrm{H}), 6.90(\mathrm{dt}, J=2.2,8.8 \mathrm{~Hz}, 2 \mathrm{H}), 5.19(\mathrm{~s}, 1 \mathrm{H}) ;{ }^{13} \mathrm{C} \mathrm{NMR}\left(100 \mathrm{MHz}, \mathrm{CDCl}_{3}\right) \delta 156.8$, 149.4, 136.2, 131.1, 129.9, 129.9, 129.4, 128.2, 125.6, 116.3; HRMS $(\mathrm{CI}+)$ calcd. for $\mathrm{C}_{12} \mathrm{H}_{8} \mathrm{NO}_{3} \mathrm{Cl}(\mathrm{M}+\mathrm{H})$ 250.0271 , found 250.0269 .

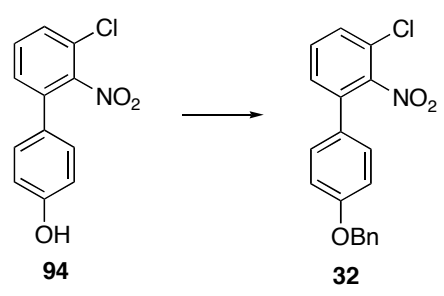

Chloride 32: To a stirred solution of $94(34.0 \mathrm{mg}, 0.140 \mathrm{mmol})$ and $\mathrm{DMF}(0.70 \mathrm{~mL})$ at $0^{\circ} \mathrm{C}$, was added $\mathrm{NaH}(6.72 \mathrm{mg}, 0.168 \mathrm{mmol}, 60 \%$ in mineral oil). After bubbling ceased, $\mathrm{BnBr}(0.170 \mathrm{~mL}, 1.40$ mmol) was added dropwise to the deep red solution. After $30 \mathrm{~min}$, the reaction mixture was warmed to $\mathrm{rt}$ and stirred for $20 \mathrm{~min}$. The reaction was quenched with sat. aq. $\mathrm{NH}_{4} \mathrm{Cl}(10 \mathrm{~mL})$, diluted with EtOAc $(20$ $\mathrm{mL})$, and washed with $\mathrm{H}_{2} \mathrm{O}(10 \mathrm{~mL})$ and sat. aq. $\mathrm{NaCl}(10 \mathrm{~mL})$. The dried extract $\left(\mathrm{MgSO}_{4}\right)$ was concentrated in vacuo and purified by chromatography over silica gel, eluting with $3-10 \%$ EtOAc / Hexanes to give $32(46.3 \mathrm{mg}, 0.136 \mathrm{mmol}, 97 \%)$ as a white crystalline solid. MP $125-127^{\circ} \mathrm{C}$; IR (neat) 2927, 1537, $1249 \mathrm{~cm}^{-1} ;{ }^{1} \mathrm{H}$ NMR $\left(300 \mathrm{MHz}, \mathrm{CDCl}_{3}\right) \delta 7.51(\mathrm{dd}, J=2.0,8.0 \mathrm{~Hz}, 1 \mathrm{H}), 7.49-7.42(\mathrm{~m}, 5 \mathrm{H})$, $7.39(\mathrm{dt}, J=1.2,7.6 \mathrm{~Hz}, 1 \mathrm{H}), 7.37(\mathrm{dd}, J=2.0,6.8 \mathrm{~Hz}, 1 \mathrm{H}), 7.33(\mathrm{dt}, J=2.0,8.8 \mathrm{~Hz}, 2 \mathrm{H}), 7.06(\mathrm{dt}, J=2.0$, $8.8 \mathrm{~Hz}, 2 \mathrm{H}), 5.13(\mathrm{~s}, 2 \mathrm{H}) ;{ }^{13} \mathrm{C} \mathrm{NMR}\left(100 \mathrm{MHz}, \mathrm{CDCl}_{3}\right) \delta 159.5,149.1,136.6,135.8,130.6,129.5,129.3$, 128.9, 128.7, 128.2, 127.9, 127.6, 125.2, 115.3, 70.1; HRMS (EI+) calcd. for $\mathrm{C}_{19} \mathrm{H}_{14} \mathrm{NO}_{3} \mathrm{Cl}(\mathrm{M}+\mathrm{H})$ 339.0662 , found 339.0670 .

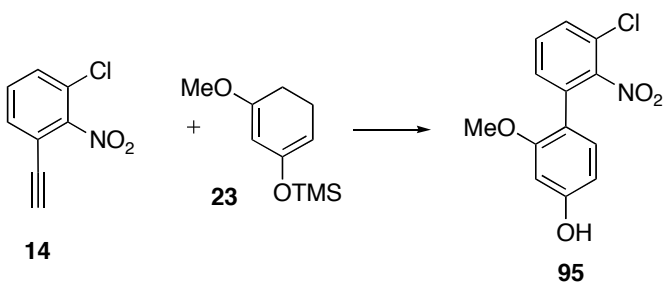

Phenol 95: To a pressure vessel containing $14(87.1 \mathrm{mg}, 0.480 \mathrm{mmol})$ was added diene $23^{12,13}$ (286 mg, $1.44 \mathrm{mmol}$ ) and heated to $140^{\circ} \mathrm{C}$. After $3.5 \mathrm{~h}$, the reaction was cooled to $\mathrm{rt}$ and the crude oil was 
purified by chromatography over silica gel, eluting with 5-40\% EtOAc / Hexanes, to give 95 (103 mg, $0.370 \mathrm{mmol}, 76 \%)$ as an orange solid. IR (neat) $3385,2924,1534 \mathrm{~cm}^{-1} ;{ }^{1} \mathrm{H}$ NMR $\left(300 \mathrm{MHz}, \mathrm{CDCl}_{3}\right) \delta$ $7.51(\mathrm{dd}, J=1.6,8.2 \mathrm{~Hz}, 1 \mathrm{H}), 7.46(\mathrm{dd}, J=7.5,8.2 \mathrm{~Hz}, 1 \mathrm{H}), 7.33$ (dd, $J=1.6,7.5 \mathrm{~Hz}, 1 \mathrm{H}), 7.08$ (dd, $J=$ 2.4, $6.5 \mathrm{~Hz}, 1 \mathrm{H}), 6.49(\mathrm{~s}, 1 \mathrm{H}), 6.48(\mathrm{dd}, J=2.4,6.5 \mathrm{~Hz}, 1 \mathrm{H}) 4.94(\mathrm{~s}, 2 \mathrm{H}), 3.79(\mathrm{~s}, 3 \mathrm{H}) ;{ }^{13} \mathrm{C}$ NMR $(100$ $\left.\mathrm{MHz}, \mathrm{CDCl}_{3}\right) \delta 157.7,150.9,133.6,131.1,130.8,130.5,129.2,125.3,124.9,115.5,107.5,99.3,55.4$; HRMS (EI+) calcd. For $\mathrm{C}_{13} \mathrm{H}_{10} \mathrm{ClNO}_{4}(\mathrm{M}+\mathrm{H}) 279.0298$, found 279.0288 .

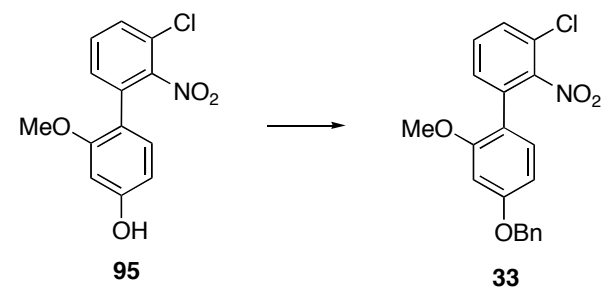

Chloride 33: To a stirred solution of $95(54.0 \mathrm{mg}, 0.190 \mathrm{mmol})$ and $\mathrm{DMF}(0.97 \mathrm{~mL})$ at $0{ }^{\circ} \mathrm{C}$, was added $\mathrm{NaH}(9.26 \mathrm{mg}, 0.232 \mathrm{mmol}, 60 \%$ in mineral oil). After bubbling ceased, $\mathrm{BnBr}(0.230 \mathrm{~mL}, 1.93$ mmol) was added dropwise to the deep red solution. After $30 \mathrm{~min}$, the reaction mixture was warmed to $\mathrm{rt}$ and stirred for $1 \mathrm{~h}$. The reaction was quenched with sat. aq. $\mathrm{NH}_{4} \mathrm{Cl}(10 \mathrm{~mL})$, diluted with EtOAc $(20 \mathrm{~mL})$, and washed with $\mathrm{H}_{2} \mathrm{O}(10 \mathrm{~mL})$ and sat. aq. $\mathrm{NaCl}(10 \mathrm{~mL})$. The dried extract $\left(\mathrm{MgSO}_{4}\right)$ was concentrated in vacuo and purified by chromatography over silica gel, eluting with 3-10\% EtOAc / Hexanes to give 33 (71.3 mg, $0.190 \mathrm{mmol}, 99 \%$ ) as a yellow solid. MP 126-127 ${ }^{\circ} \mathrm{C}$; IR (neat) $1611,1534,1200 \mathrm{~cm}^{-1}$; ${ }^{1} \mathrm{H} \mathrm{NMR}$ $\left(300 \mathrm{MHz}, \mathrm{CDCl}_{3}\right) \delta 7.51(\mathrm{dd}, J=1.5,8.1 \mathrm{~Hz}, 1 \mathrm{H}), 7.48-7.37(\mathrm{~m}, 6 \mathrm{H}), 7.34(\mathrm{dd}, J=1.5,7.6 \mathrm{~Hz}, 1 \mathrm{H}), 7.15$ $(\mathrm{d}, J=8.4 \mathrm{~Hz}, 1 \mathrm{H}), 6.65(\mathrm{dd}, J=2.2,8.4 \mathrm{~Hz}, 1 \mathrm{H}), 6.62(\mathrm{~d}, J=2.2 \mathrm{~Hz}, 1 \mathrm{H}), 5.11(\mathrm{~s}, 2 \mathrm{H}), 3.74(\mathrm{~s}, 3 \mathrm{H}) ;{ }^{13} \mathrm{C}$ NMR $\left(100 \mathrm{MHz}, \mathrm{CDCl}_{3}\right) \delta 160.9,157.5,149.4,136.6,133.6,130.9,130.8,130.5,129.2,128.7,128.2$, 127.7, 125.4, 117.4, 105.7, 99.7, 70.3, 55.4; HRMS (EI+) calcd. for $\mathrm{C}_{20} \mathrm{H}_{16} \mathrm{NO}_{4} \mathrm{Cl}(\mathrm{M}+\mathrm{H}) 369.0768$, found 369.0771 .

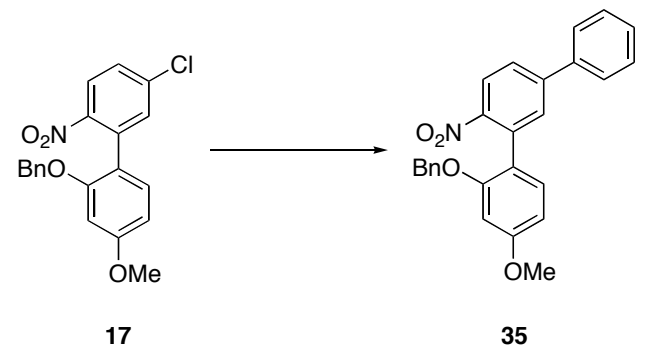

Triaryl 35: To a pressure vessel was added $17(36.7 \mathrm{mg}, 99.2 \mu \mathrm{mol}), \mathrm{PhB}(\mathrm{OH})_{2}(53.0 \mathrm{mg}, 435$ $\mu \mathrm{mol}), \mathrm{Cs}_{2} \mathrm{CO}_{3}(82.9 \mathrm{mg}, 254 \mu \mathrm{mol}), \mathrm{Pd}_{2}(\mathrm{dba})_{3}(3.4 \mathrm{mg}, 3.8 \mu \mathrm{mol}), \mathrm{PCy}_{3}(8.1 \mathrm{mg}, 29 \mu \mathrm{mol})$, and dry dioxane $(300 \mu \mathrm{L})$. The solution was sealed under Ar and heated to $80^{\circ} \mathrm{C}$. After $24 \mathrm{~h}$, the mixture was

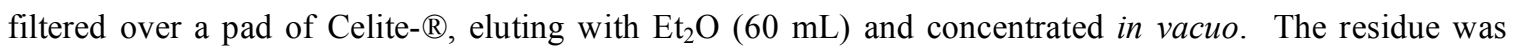
purified by flash chromatography over silica gel, eluting with $10 \% \mathrm{Et}_{2} \mathrm{O} /$ hexanes, to give 35 (37.3 mg, 96.1 $\mu \mathrm{mol}, 84 \%$ ) as a bright yellow crystalline solid. MP $127-131^{\circ} \mathrm{C}$; IR (thin film) $3067,2932,1611,1586$, $1519,1348,1050 \mathrm{~cm}^{-1} ;{ }^{1} \mathrm{H}$ NMR $\left(400 \mathrm{MHz}, \mathrm{CDCl}_{3}\right) \delta 8.06(\mathrm{~d}, J=8.4 \mathrm{~Hz}, 1 \mathrm{H}), 7.75-7.57(\mathrm{~m}, 4 \mathrm{H}), 7.57-7.4$ (m, 3H), 7.4-7.2(m, 6H), $6.67(\mathrm{dd}, J=8.3,2.0 \mathrm{~Hz}, 1 \mathrm{H}), 6.60(\mathrm{~d}, J=2.0,1 \mathrm{H}), 5.05(\mathrm{~s}, 2 \mathrm{H}), 3.86(\mathrm{~s}, 3 \mathrm{H}) ;{ }^{13} \mathrm{C}$ NMR $\left(100 \mathrm{MHz}, \mathrm{CDCl}_{3}\right) \delta 161.2,156.3,148.4,145.6,139.0,136.5,133.8,131.4,130.3,129.1,128.6$, $128.5,127.8,127.4,127.1,126.1,124.8,120.6,105.5,100.4,70.7,55.4$; HRMS (EI+) calcd. for $\mathrm{C}_{26} \mathrm{H}_{21} \mathrm{NO}_{4}(\mathrm{M}+)$ 411.1471, found 411.1475. 


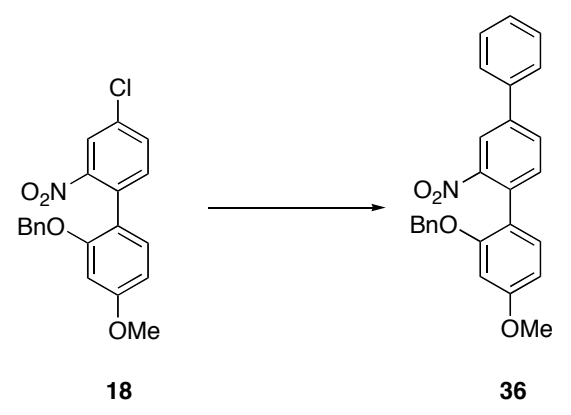

Triaryl 36: To a pressure vessel was added $18(13.2 \mathrm{mg}, 35.7 \mu \mathrm{mol}), \mathrm{PhB}(\mathrm{OH})_{2}(17.6 \mathrm{mg}, 144$ $\mu \mathrm{mol}), \mathrm{Cs}_{2} \mathrm{CO}_{3}(24.8 \mathrm{mg}, 76.1 \mu \mathrm{mol}), \mathrm{Pd}_{2}(\mathrm{dba})_{3}(0.1 \mathrm{mg}, 1.2 \mu \mathrm{mol}), \mathrm{PCy}_{3}(1.1 \mathrm{mg}, 3.9 \mu \mathrm{mol})$, and dry dioxane $(60 \mu \mathrm{L})$. The solution was sealed under $\mathrm{Ar}$ and heated to $80^{\circ} \mathrm{C}$. After $24 \mathrm{~h}$, the mixture was

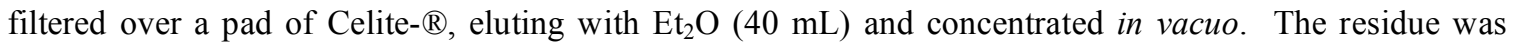
purified by flash chromatography over silica gel, eluting with $0-10 \% \mathrm{Et}_{2} \mathrm{O} /$ hexanes, to give $\mathbf{3 6}(12.2 \mathrm{mg}$, $31.5 \mu \mathrm{mol}, 88 \%$ ) as a bright yellow crystalline solid. MP $130-2^{\circ} \mathrm{C}$; IR (thin film) $3054,2925,1610,1520$, 1356, 1091, $1024 \mathrm{~cm}^{-1}$; ${ }^{1} \mathrm{H}$ NMR $\left(400 \mathrm{MHz}, \mathrm{CDCl}_{3}\right) \delta 8.18(\mathrm{~d}, J=1.9 \mathrm{~Hz}, 1 \mathrm{H}), 7.86(\mathrm{dd}, J=8.0,1.9 \mathrm{~Hz}$, $1 \mathrm{H}), 7.74-7.63(\mathrm{~m}, 2 \mathrm{H}), 7.58-7.42(\mathrm{~m}, 4 \mathrm{H}), 7.38-7.23(\mathrm{~m}, 6 \mathrm{H}), 6.67(\mathrm{dd}, J=8.4,2.3 \mathrm{~Hz}, 1 \mathrm{H}), 6.58(\mathrm{~d}, J=$ $2.3 \mathrm{~Hz}, 1 \mathrm{H}), 5.04(\mathrm{~s}, 2 \mathrm{H}), 3.85,(\mathrm{~s}, 3 \mathrm{H}) ;{ }^{13} \mathrm{C}$ NMR $\left(100 \mathrm{MHz}, \mathrm{CDCl}_{3}\right) \delta 161.1,156.3,149.9,140.9,138.6$, $136.5,133.2,131.8,130.8,130.3,129.1,128.5,128.3,127.8,127.1,127.0,122.5,120.1,105.5,100.4$, 70.7, 55.4; HRMS (EI+) calcd. for $\mathrm{C}_{26} \mathrm{H}_{21} \mathrm{NO}_{4}(\mathrm{M}+)$ 411.1471, found 411.1455.

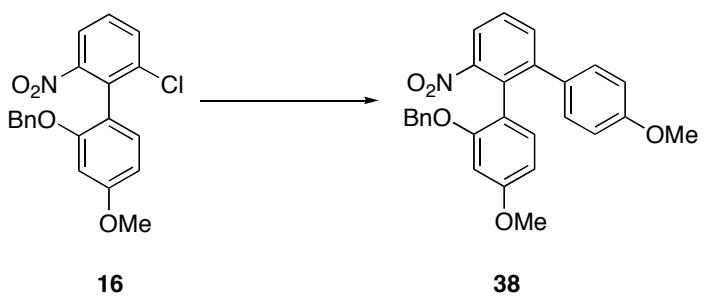

Triaryl 38: To a pressure vessel was added 16 (43.8 mg, $118 \mu \mathrm{mol}), p-\mathrm{MeO}-\mathrm{C}_{6} \mathrm{H}_{4}-\mathrm{B}(\mathrm{OH})_{2}(68.9$ $\mathrm{mg}, 453 \mu \mathrm{mol}), \mathrm{Cs}_{2} \mathrm{CO}_{3}(69.6 \mathrm{mg}, 214 \mu \mathrm{mol}), \mathrm{Pd}_{2}(\mathrm{dba})_{3}(2.3 \mathrm{mg}, 2.5 \mu \mathrm{mol}), \mathrm{PCy}_{3}(4.3 \mathrm{mg}, 15 \mu \mathrm{mol})$, and dry dioxane $(250 \mu \mathrm{L})$. The solution was sealed under Ar and heated to $80^{\circ} \mathrm{C}$. After $24 \mathrm{~h}$, the mixture was

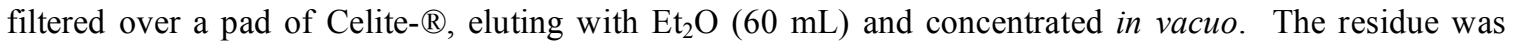
purified by flash chromatography over silica gel, eluting with $10 \% \mathrm{Et}_{2} \mathrm{O} /$ hexanes, to give 38 (47.0 $\mathrm{mg}, 107$ $\mu \mathrm{mol}, 90 \%$ ) as a bright yellow crystalline solid. MP $131-133^{\circ} \mathrm{C}$; IR (thin film) $2957,2923,2853,1610$, 1581, 1527, 1514, 1356, $1246 \mathrm{~cm}^{-1} ;{ }^{1} \mathrm{H}$ NMR $\left(400 \mathrm{MHz}, \mathrm{CDCl}_{3}\right) \delta 7.83$ (dd, $\left.J=8.0,1.4 \mathrm{~Hz}, 1 \mathrm{H}\right), 7.61$ (dd, $J=7.7,1.4 \mathrm{~Hz}, 1 \mathrm{H}), 7.51(\mathrm{t}, J=8.0 \mathrm{~Hz}, 1 \mathrm{H}), 7.40-7.24(\mathrm{~m}, 3 \mathrm{H}), 7.18(\mathrm{~d}, J=6.3 \mathrm{~Hz}, 2 \mathrm{H}), 6.98(\mathrm{~d}, J=8.9$ $\mathrm{Hz}, 2 \mathrm{H}), 6.84(\mathrm{~d}, J=8.3 \mathrm{~Hz}, 1 \mathrm{H}), 6.73(\mathrm{~d}, J=8.9 \mathrm{~Hz}, 2 \mathrm{H}), 6.41(\mathrm{~d}, J=2.3 \mathrm{~Hz}, 1 \mathrm{H}), 6.39(\mathrm{dd}, J=8.3,2.4$ $\mathrm{Hz}, 1 \mathrm{H}), 4.98(\mathrm{~d}, J=12.6 \mathrm{~Hz}, 1 \mathrm{H}), 4.88(\mathrm{~d}, J=12.5 \mathrm{~Hz}, 1 \mathrm{H}), 3.80(\mathrm{~s}, 3 \mathrm{H}), 3.76(\mathrm{~s}, 3 \mathrm{H}) ;{ }^{13} \mathrm{C} \mathrm{NMR}(100$ $\left.\mathrm{MHz}, \mathrm{CDCl}_{3}\right) \delta 160.6,158.6,156.8,151.3,144.3,137.0,133.9,132.5,131.5,130.9,130.4,128.4,127.7$, 127.6, 126.7, 122.2, 117.7, 113.3, 104.9, 99.9, 70.0, 55.2, 55.2; HRMS (CI+) calcd. for $\mathrm{C}_{27} \mathrm{H}_{24} \mathrm{NO}_{5}(\mathrm{M}+\mathrm{H})$ 442.1654 , found 442.1668 . 


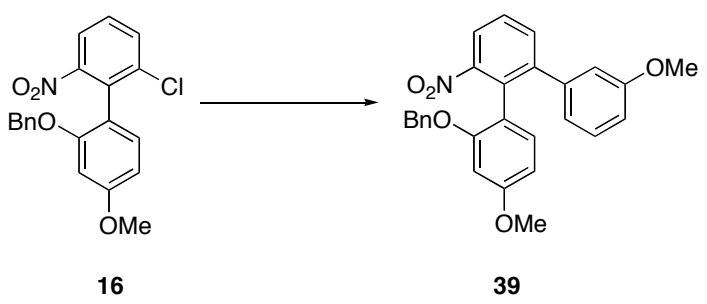

Triaryl 39: To a pressure vessel was added $16(47.3 \mathrm{mg}, 128 \mu \mathrm{mol}), m-\mathrm{MeO}-\mathrm{C}_{6} \mathrm{H}_{4}-\mathrm{B}(\mathrm{OH})_{2}(65.5$ $\mathrm{mg}, 431 \mu \mathrm{mol}), \mathrm{Cs}_{2} \mathrm{CO}_{3}(92.0 \mathrm{mg}, 282 \mu \mathrm{mol}), \mathrm{Pd}_{2}(\mathrm{dba})_{3}(2.9 \mathrm{mg}, 3.2 \mu \mathrm{mol}), \mathrm{PCy}_{3}(1.8 \mathrm{mg}, 6.4 \mu \mathrm{mol})$, and dry dioxane $(300 \mu \mathrm{L})$. The solution was sealed under Ar and heated to $80^{\circ} \mathrm{C}$. After $24 \mathrm{~h}$, the mixture was

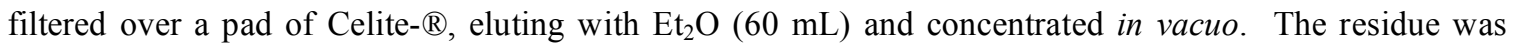
purified by flash chromatography over silica gel, eluting with $10 \% \mathrm{Et}_{2} \mathrm{O} /$ hexanes, to give 39 (51.4 mg, 116 $\mu \mathrm{mol}, 91 \%$ ) as a crystalline yellow, $1: 1$ mixture of atropisomers. MP $127-129^{\circ} \mathrm{C}$; IR (thin film) 2929,1612 , $1583,1528,1512,1360,1227,1042,753 \mathrm{~cm}^{-1} ;{ }^{1} \mathrm{H}$ NMR $\left(400 \mathrm{MHz}, \mathrm{CDCl}_{3}\right) \delta$ 7.91-7.85 (m, 1H), 7.69-7.63 (m, $1 \mathrm{H}), 7.57-7.50(\mathrm{~m}, 1 \mathrm{H}), 7.39-7.19(\mathrm{~m}, 5 \mathrm{H}), 7.13(\mathrm{t}, J=7.6 \mathrm{~Hz}, 1 \mathrm{H}), 6.89-6.84(\mathrm{~m}, 1 \mathrm{H}), 6.80-6.76(\mathrm{~m}$, $1 \mathrm{H}), 7.64-6.68(\mathrm{~m}, 1 \mathrm{H}), 6.63-6.58(\mathrm{~m}, 1 \mathrm{H}), 6.47-6.38(\mathrm{~m}, 2 \mathrm{H}), 4.99(\mathrm{~d}, J=12.4 \mathrm{~Hz}, 1 \mathrm{H}), 4.87(\mathrm{~d}, J=12.4$ $\mathrm{Hz}, 1 \mathrm{H}), 3.75(\mathrm{~s}, 3 \mathrm{H}), 3.60(\mathrm{~s}, 3 \mathrm{H}) ;{ }^{13} \mathrm{C}$ NMR $\left(100 \mathrm{MHz}, \mathrm{CDCl}_{3}\right) \delta 160.8,158.9,156.8,151.2,144.4$, $141.4,137.0,133.8,131.4,131.0,128.8,128.4,127.8,127.6,126.7,122.6,121.8,117.6,114.4,113.4$, 104.9, 99.9, 70.1, 55.3, 55.0; HRMS (CI+) calcd. for $\mathrm{C}_{27} \mathrm{H}_{23} \mathrm{NO}_{5} 441.1576$, found 441.1577.

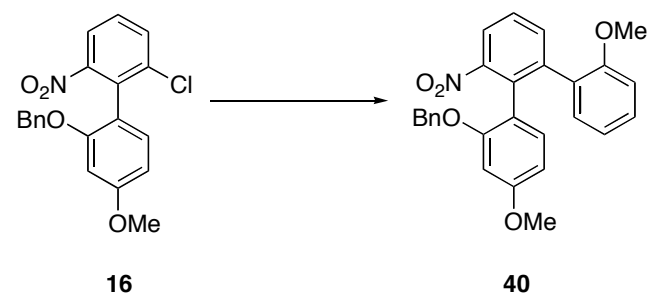

Triaryl 40: To a pressure vessel was added $16(42.3 \mathrm{mg}, 114 \mu \mathrm{mol}), o-\mathrm{MeO}-\mathrm{C}_{6} \mathrm{H}_{4}-\mathrm{B}(\mathrm{OH})_{2}(64.4$ $\mathrm{mg}, 432 \mu \mathrm{mol}), \mathrm{Cs}_{2} \mathrm{CO}_{3}(74.3 \mathrm{mg}, 228 \mu \mathrm{mol}), \mathrm{Pd}_{2}(\mathrm{dba})_{3}(2.5 \mathrm{mg}, 2.7 \mu \mathrm{mol}), \mathrm{PCy}_{3}(3.3 \mathrm{mg}, 12 \mu \mathrm{mol})$, and dry dioxane $(230 \mu \mathrm{L})$. The solution was sealed under Ar and heated to $80^{\circ} \mathrm{C}$. After $24 \mathrm{~h}$, the mixture was

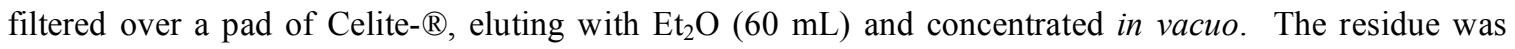
purified by flash chromatography over silica gel, eluting with $10 \% \mathrm{Et}_{2} \mathrm{O} /$ hexanes, to give $\mathbf{4 0}$ (40.4 mg, 91.5 $\mu \mathrm{mol}, 80 \%$ ) as a bright yellow crystalline solid. MP $123-124^{\circ} \mathrm{C}$; IR (thin film) $3003,2954,1613,1582$, $1527,1512,1358,1274,1242,1039,1026,755 \mathrm{~cm}^{-1} ;{ }^{1} \mathrm{H}$ NMR $\left(400 \mathrm{MHz}, \mathrm{CDCl}_{3}\right) \delta 7.90(\mathrm{dd}, J=8.0,1.3$ $\mathrm{Hz}, 1 \mathrm{H}), 7.63-7.55(\mathrm{br}, 1 \mathrm{H}), 7.50,(\mathrm{t}, J=8.0 \mathrm{~Hz}, 1 \mathrm{H}), 7.39-7.16(\mathrm{~m}, 6 \mathrm{H}), 7.04-6.59(\mathrm{br}, 4 \mathrm{H}), 6.48-6.21(\mathrm{br}$, $2 \mathrm{H}), 4.98,(\mathrm{~d}, J=12.4 \mathrm{~Hz}, 1 \mathrm{H}), 4.92(\mathrm{~d}, J=12.4 \mathrm{~Hz}, 1 \mathrm{H}), 3.719(\mathrm{~s}, 3 \mathrm{H}), 3.5-3.2(\mathrm{br}, 3 \mathrm{H}) ;{ }^{13} \mathrm{C} \mathrm{NMR}(100$ $\left.\mathrm{MHz}, \mathrm{CDCl}_{3}\right) \delta 160.4,156.5,156.1,150.7,141.7,137.0,134.8,132.3,131.0,130.9,128.9,128.4,127.8$, 127.6, 127.3, 126.7, 122.7, 120.0, 118.1, 110.3, 104.2, 99.5, 70.0, 55.2, 55.0; HRMS (FAB+) calcd. for $\mathrm{C}_{27} \mathrm{H}_{23} \mathrm{NO}_{5} 441.1576$, found 441.1595 .

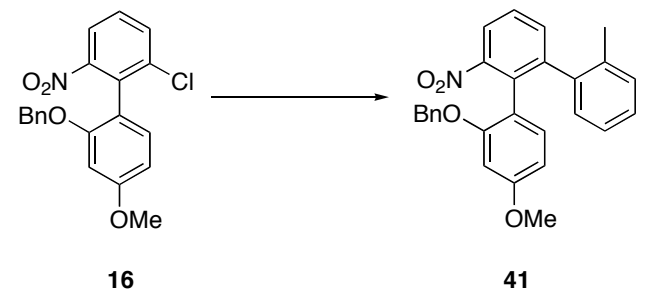

Triaryl 41: To a pressure vessel was added $16(39.0 \mathrm{mg}, 105 \mu \mathrm{mol}), o-\mathrm{Me}_{-} \mathrm{C}_{6} \mathrm{H}_{4}-\mathrm{B}(\mathrm{OH})_{2}(69.5$ $\mathrm{mg}, 511 \mu \mathrm{mol}), \mathrm{Cs}_{2} \mathrm{CO}_{3}(112.3 \mathrm{mg}, 344.7 \mu \mathrm{mol}), \mathrm{Pd}_{2}(\mathrm{dba})_{3}(2.4 \mathrm{mg}, 2.6 \mu \mathrm{mol})$ and dry dioxane $(300 \mu \mathrm{L})$. The solution was sealed under Ar and heated to $80^{\circ} \mathrm{C}$. After $24 \mathrm{~h}$, the mixture was filtered over a pad of 


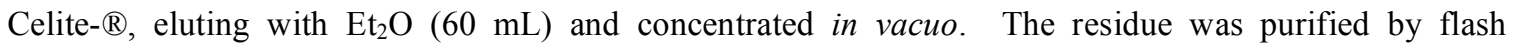
chromatography over silica gel, eluting with $10 \% \mathrm{Et}_{2} \mathrm{O} / \mathrm{h}$ exanes, to give $41(40.0 \mathrm{mg}, 93.9 \mu \mathrm{mol}, 89 \%)$ as a crystalline yellow, 1:1 mixture of atropisomers. MP $72-75^{\circ} \mathrm{C}$; IR (thin film) $3062,2924,1613,1578,1528$, $1512,1269,1049,757 \mathrm{~cm}^{-1} ;{ }^{1} \mathrm{H}$ NMR $\left(400 \mathrm{MHz}, \mathrm{CDCl}_{3}\right) \delta$ 7.95-7.87 (m, 1H), 7.57-7.45 (m, 2H), 7.39$7.10(\mathrm{~m}, 8 \mathrm{H}), 7.06-6.89(\mathrm{~m}, 1 \mathrm{H}), 6.83-6.72(\mathrm{~m}, 1 \mathrm{H}), 6.37(\mathrm{dd}, J=10.0,2.4 \mathrm{~Hz}, 1 \mathrm{H}), 6.28(\mathrm{dt}, J=8.5,2.3$ $\mathrm{Hz}, 1 \mathrm{H}), 5.05-4.85(\mathrm{~m}, 2 \mathrm{H}), 3.71(\mathrm{~s}, 3 \mathrm{H}), 2.19(\mathrm{~s}, 1.3 \mathrm{H}), 1.80(\mathrm{~s}, 1.7 \mathrm{H}) ;{ }^{13} \mathrm{C} \mathrm{NMR}\left(100 \mathrm{MHz}, \mathrm{CDCl}_{3}\right) \delta$ $160.5,160.4,156.6,156.3,151.2,151.1,144.4,144.4,139.5,139.4,137.0,136.8,136.1,135.1,134.5$, $134.3,132.2,131.8,131.5,130.4,130.1,129.7,129.6,128.5,128.4,127.7,127.6,127.4,127.4,127.3$, 126.8, 126.7, 125.1, 125.0, 122.7, 122.6, 117.8, 117.0, 104.6, 104.4, 99.5, 70.1, 70.0, 55.1, 20.4, 19.3; HRMS (EI+) calcd. for $\mathrm{C}_{27} \mathrm{H}_{23} \mathrm{NO}_{4} 425.1627$, found 425.1612 .

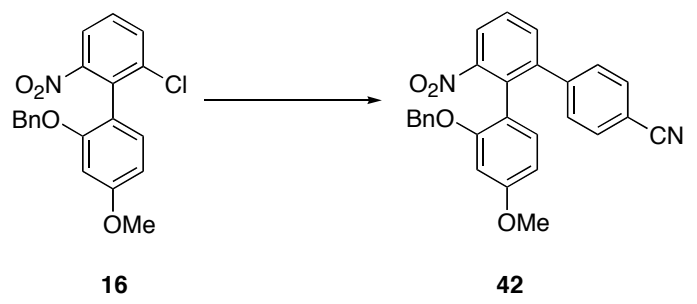

Triaryl 42: To a pressure vessel was added $16(41.0 \mathrm{mg}, 111 \mu \mathrm{mol}), p-\mathrm{CN}-\mathrm{C}_{6} \mathrm{H}_{4}-\mathrm{B}(\mathrm{OH})_{2}(64.2$ $\left.\mathrm{mg}, 437 \mu \mathrm{mol}), \mathrm{KF}(58.4 \mathrm{mg}, 1.00 \mathrm{mmol}), \mathrm{Pd}^{t} \mathrm{Bu}_{3} \mathrm{P}\right]_{2}(4.0 \mathrm{mg}, 7.8 \mu \mathrm{mol})$ and NMP (300 $\left.\mu \mathrm{L}\right)$. The solution

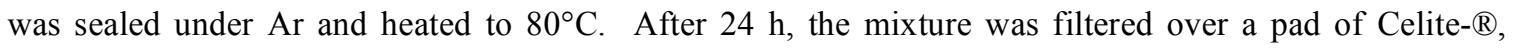
eluting with $\mathrm{Et}_{2} \mathrm{O}(60 \mathrm{~mL})$ and concentrated in vacuo. The residue was purified by flash chromatography over silica gel, eluting with $10 \% \mathrm{Et}_{2} \mathrm{O} /$ hexanes, to give $\mathbf{4 2}(40.0 \mathrm{mg}, 91.5 \mu \mathrm{mol}, 80 \%)$ as a bright yellow crystalline solid. MP $142-144^{\circ} \mathrm{C}$; IR (thin film) $2950,2918,2228,1610,15821531,1513,1272,1242$, 1048, $737 \mathrm{~cm}^{-1}$; ${ }^{1} \mathrm{H}$ NMR $\left(400 \mathrm{MHz}, \mathrm{CDCl}_{3}\right) \delta 7.93(\mathrm{t}, J=4.8 \mathrm{~Hz}, 1 \mathrm{H}), 7.85-7.78(\mathrm{~m}, 1 \mathrm{H}), 7.75-7.70(\mathrm{~m}$, $1 \mathrm{H}), 7.60-7.54(\mathrm{~m}, 2 \mathrm{H}), 7.50-7.45(\mathrm{~m}, 2 \mathrm{H}), 7.37-7.28(\mathrm{~m}, 1 \mathrm{H}), 7.19-7.10(\mathrm{~m}, 4 \mathrm{H}), 6.80(\mathrm{~d}, J=8.4 \mathrm{~Hz}, 1 \mathrm{H})$, $6.42(\mathrm{~d}, J=2.3 \mathrm{~Hz}, 1 \mathrm{H}), 6.39(\mathrm{dd}, J=8.4,2.3 \mathrm{~Hz}, 1 \mathrm{H}), 4.96(\mathrm{~d}, J=12.4 \mathrm{~Hz}, 1 \mathrm{H}), 4.84(\mathrm{~d}, J=12.4 \mathrm{~Hz}$, $1 \mathrm{H}), 3.77(\mathrm{~s}, 3 \mathrm{H}) ;{ }^{13} \mathrm{C} \mathrm{NMR}\left(100 \mathrm{MHz}, \mathrm{CDCl}_{3}\right) \delta 161.1,156.6,151.2,144.9,142.7,136.6,133.3,132.9$, 131.6, 131.3, 130.0, 128.5, 128.2, 127.8, 126.8, 123.5, 118.7, 116.6, 110.9, 105.1, 100.0, 70.1, 55.3; HRMS $(\mathrm{CI}+)$ calcd. for $\mathrm{C}_{27} \mathrm{H}_{20} \mathrm{~N}_{2} \mathrm{O}_{4} 436.2423$, found 436.1426 .

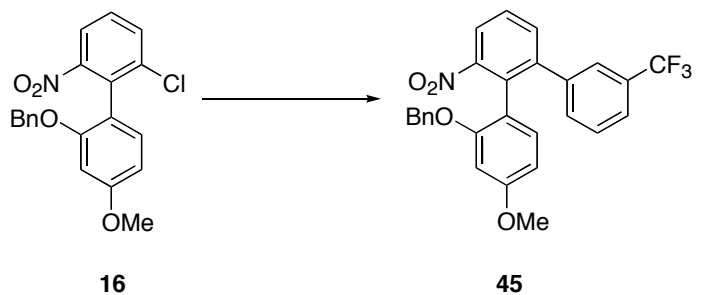

Triaryl 45: To a pressure vessel was added $16(110.3 \mathrm{mg}, 298.2 \mu \mathrm{mol}), m-\mathrm{CF}_{3}-\mathrm{C}_{6} \mathrm{H}_{4}-\mathrm{B}(\mathrm{OH})_{2}$ (235.8 mg, $1.241 \mathrm{mmol}), \mathrm{KF}(155.5 \mathrm{mg}, 2.676 \mathrm{mmol}), \operatorname{Pd}\left[{ }^{t} \mathrm{Bu}_{3} \mathrm{P}\right]_{2}(9.0 \mathrm{mg}, 18 \mu \mathrm{mol})$ and NMP $(600 \mu \mathrm{L})$. The solution was sealed under Ar and heated to $80^{\circ} \mathrm{C}$. After $48 \mathrm{~h}$, the mixture was filtered over a pad of

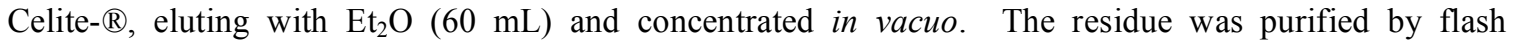
chromatography over silica gel, eluting with 50-75\% PhMe/hexanes, to give 45 (100.2 $\mathrm{mg}, 229.6 \mu \mathrm{mol}$, $77 \%$ ) as a bright yellow crystalline solid. MP $121-124^{\circ} \mathrm{C}$; IR (thin film) $3067,2938,1613,1582,1531$, $1513,1359,1335,1271,1061,756 \mathrm{~cm}^{-1} ;{ }^{1} \mathrm{H}$ NMR $\left(400 \mathrm{MHz}, \mathrm{CDCl}_{3}\right) \delta 7.93,(\mathrm{dd}, J=8.0,1.4 \mathrm{~Hz}, 1 \mathrm{H})$, $7.63(\mathrm{dd}, J=8.0,1.4 \mathrm{~Hz}, 1 \mathrm{H}), 7.57(\mathrm{t}, J=7.8,1 \mathrm{H}), 7.49(\mathrm{~d}, J=7.7 \mathrm{~Hz}, 1 \mathrm{H}), 7.36-7.20(\mathrm{~m}, 8 \mathrm{H}), 6.83(\mathrm{~d}, J$ $=8.3 \mathrm{~Hz}, 1 \mathrm{H}), 6.42(\mathrm{~d}, J=2.2 \mathrm{~Hz}, 1 \mathrm{H}), 6.39(\mathrm{dd}, J=8.3,2.2 \mathrm{~Hz}, 1 \mathrm{H}), 4.97(\mathrm{~d}, J=12.4 \mathrm{~Hz}, 1 \mathrm{H}), 4.86(\mathrm{~d}, J$ $=12.4 \mathrm{~Hz}, 1 \mathrm{H}), 3.74(\mathrm{~s}, 3 \mathrm{H}) ;{ }^{13} \mathrm{C}$ NMR $\left(100 \mathrm{MHz}, \mathrm{CDCl}_{3}\right) \delta 161.1,156.7,151.2,143.1,140.7,136.7$, $133.5,132.5,131.4,131.3,130.0\left(\mathrm{q}, J_{(\mathrm{C}-\mathrm{F})}=32 \mathrm{~Hz}\right), 128.4,128.2,128.1,127.7,126.7,126.1\left(\mathrm{q}, J_{(\mathrm{C}-\mathrm{F})}=4\right.$ 
$\mathrm{Hz}), 123.9\left(\mathrm{q}, J_{(\mathrm{C}-\mathrm{F})}=273 \mathrm{~Hz}\right), 123.9\left(\mathrm{q}, J_{(\mathrm{C}-\mathrm{F})}=4 \mathrm{~Hz}\right), 123.2,122.6,119.9,116.9,105.1,99.9,70.1,55.3$; HRMS (EI+) calcd. for $\mathrm{C}_{27} \mathrm{H}_{20} \mathrm{~F}_{3} \mathrm{NO}_{4} 479.1344$, found 479.1334 .
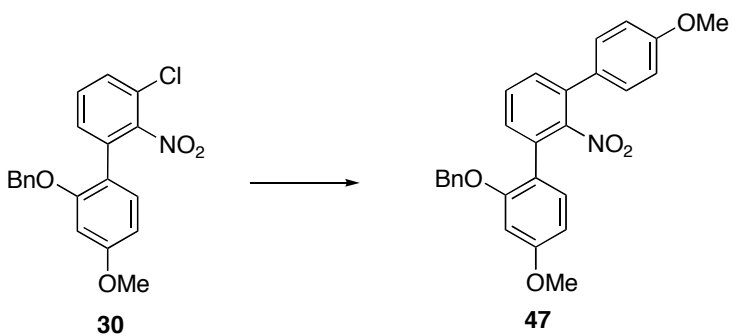

Triaryl 47: To a pressure vessel containing $30(41.9 \mathrm{mg}, 0.110 \mathrm{mmol})$, was sequentially added $\mathrm{KF}(57.4 \mathrm{mg}, 0.990 \mathrm{mmol}), p-\mathrm{OMe}-\mathrm{C}_{6} \mathrm{H}_{4}-\mathrm{B}(\mathrm{OH})_{2}(68.9 \mathrm{mg}, 0.450 \mathrm{mmol}),\left(t-\mathrm{Bu}_{3} \mathrm{P}\right)_{2} \mathrm{Pd}(2.8 \mathrm{mg}, 0.0060$ $\mathrm{mmol})$, and NMP $(1.10 \mathrm{~mL})$. The solution was sealed under $\mathrm{Ar}$ and heated to $80^{\circ} \mathrm{C}$. After $48 \mathrm{~h}$, the reaction was quenched with sat. aq. $\mathrm{NH}_{4} \mathrm{Cl}(10 \mathrm{~mL})$, diluted with EtOAc $(25 \mathrm{~mL})$, and washed with $\mathrm{H}_{2} \mathrm{O}$ $(20 \mathrm{~mL})$ and sat. aq. $\mathrm{NaCl}(20 \mathrm{~mL})$. The dried extract $\left(\mathrm{MgSO}_{4}\right)$ was concentrated in vacuo and purified by chromatography over silica gel, eluting with 5-20\% EtOAc / Hexanes to give 47 (42.0 mg, $0.0950 \mathrm{mmol}$, $86 \%$ ) as a yellow crystalline solid. MP $102-103^{\circ} \mathrm{C}$; IR (neat) $2927,1608,1530,1246 \mathrm{~cm}^{-1}$; ${ }^{1} \mathrm{H}$ NMR (400 $\left.\mathrm{MHz}, \mathrm{CDCl}_{3}\right) \delta 7.54(\mathrm{t}, J=7.6 \mathrm{~Hz}, 1 \mathrm{H}), 7.41(\mathrm{~d}, J=7.6 \mathrm{~Hz}, 2 \mathrm{H}), 7.36(\mathrm{dt}, J=2.0,3.2,8.4 \mathrm{~Hz}, 2 \mathrm{H}), 7.36-$ $7.27(\mathrm{~m}, 5 \mathrm{H}), 7.20(\mathrm{~d}, J=8.4 \mathrm{~Hz}, 1 \mathrm{H}), 6.98(\mathrm{dt}, J=1.6,3.2,8.4 \mathrm{~Hz}, 2 \mathrm{H}), 6.57(\mathrm{dd}, J=2.4,8.4 \mathrm{~Hz}, 1 \mathrm{H})$, $6.56(\mathrm{~d}, J=2.4 \mathrm{~Hz}, 1 \mathrm{H}), 5.08(\mathrm{~s}, 2 \mathrm{H}), 3.87(\mathrm{~s}, 3 \mathrm{H}), 3.81(\mathrm{~s}, 3 \mathrm{H}) ;{ }^{13} \mathrm{C} \mathrm{NMR}\left(100 \mathrm{MHz}, \mathrm{CDCl}_{3}\right) \delta 161.2$, $159.7,156.8,150.4,137.0,134.2,131.7,131.1,130.9,130.0,129.5,129.4,129.3,128.4,127.6,126.8$, 118.6, 114.2, 105.2, 100.8, 70.5, 55.4, 55.3; HRMS (TOF-MS/ES+) calcd. for $\mathrm{C}_{27} \mathrm{H}_{23} \mathrm{NO}_{5}(\mathrm{M}+\mathrm{Na})$ 464.1474, found 464.1460 .
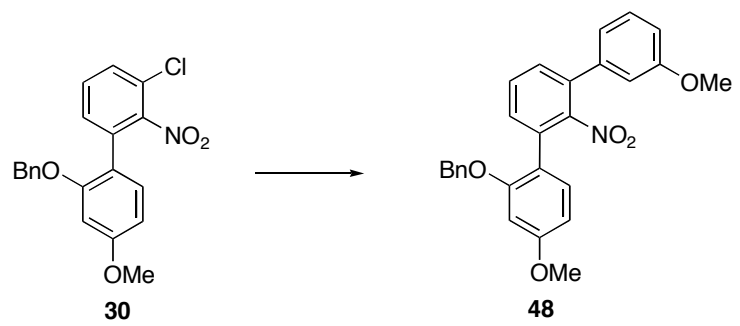

Triaryl 48: To a pressure vessel containing $30(23.4 \mathrm{mg}, 0.0630 \mathrm{mmol})$, was sequentially added $\mathrm{KF}(32.9 \mathrm{mg}, 0.570 \mathrm{mmol}), m-\mathrm{OMe}-\mathrm{C}_{6} \mathrm{H}_{4}-\mathrm{B}(\mathrm{OH})_{2}(38.3 \mathrm{mg}, 0.250 \mathrm{mmol}),\left(t-\mathrm{Bu}_{3} \mathrm{P}\right)_{2} \mathrm{Pd}(1.6 \mathrm{mg}, 0.0030$ $\mathrm{mmol})$, and NMP $(0.63 \mathrm{~mL})$. The solution was sealed under Ar and heated to $80^{\circ} \mathrm{C}$. After $48 \mathrm{~h}$, the reaction was quenched with sat. aq. $\mathrm{NH}_{4} \mathrm{Cl}(10 \mathrm{~mL})$, diluted with EtOAc $(25 \mathrm{~mL})$, and washed with $\mathrm{H}_{2} \mathrm{O}$ $(20 \mathrm{~mL})$ and sat. aq. $\mathrm{NaCl}(20 \mathrm{~mL})$. The dried extract $\left(\mathrm{MgSO}_{4}\right)$ was concentrated in vacuo and purified by chromatography over silica gel, eluting with 5-20\% EtOAc / Hexanes to give 48 (17.9 mg, $0.0410 \mathrm{mmol}$, $64 \%$ ) as a yellow crystalline solid. MP $107-108^{\circ} \mathrm{C}$; IR (neat) $3063,2930,1608,1534 \mathrm{~cm}^{-1}$; ${ }^{1} \mathrm{H}$ NMR (400 $\left.\mathrm{MHz}, \mathrm{CDCl}_{3}\right) \delta 7.56(\mathrm{dd}, J=7.6,7.7 \mathrm{~Hz}, 1 \mathrm{H}), 7.45(\mathrm{dd}, J=1.4,5.2 \mathrm{~Hz}, 1 \mathrm{H}), 7.43(\mathrm{dd}, J=1.4,5.2 \mathrm{~Hz}$, $1 \mathrm{H}), 7.38-7.27(\mathrm{~m}, 6 \mathrm{H}), 7.21(\mathrm{~d}, J=8.4 \mathrm{~Hz}, 1 \mathrm{H}), 7.00(\mathrm{~d}, J=7.6 \mathrm{~Hz}, 1 \mathrm{H}), 6.97(\mathrm{dd}, J=2.0,4.0 \mathrm{~Hz}, 2 \mathrm{H})$, $6.58(\mathrm{dd}, J=2.4,8.4 \mathrm{~Hz}, 1 \mathrm{H}), 6.56(\mathrm{~d}, J=2.4 \mathrm{~Hz}, 1 \mathrm{H}), 5.07(\mathrm{~s}, 2 \mathrm{H}), 3.85(\mathrm{~s}, 3 \mathrm{H}), 3.82(\mathrm{~s}, 3 \mathrm{H}) ;{ }^{13} \mathrm{C} \mathrm{NMR}$ $\left(100 \mathrm{MHz}, \mathrm{CDCl}_{3}\right) \delta 161.2,159.6,156.8,150.3,138.4,136.9,134.4,131.7,131.6,130.9,129.8,129.7$, 129.6, 128.4, 127.6, 126.8, 120.5, 118.6, 114.2, 113.6, 105.2, 100.8, 70.5, 55.4, 55.3; HRMS (EI+) calcd. for $\mathrm{C}_{27} \mathrm{H}_{23} \mathrm{NO}_{5}(\mathrm{M}+\mathrm{H})$ 441.1576, found 441.1569. 


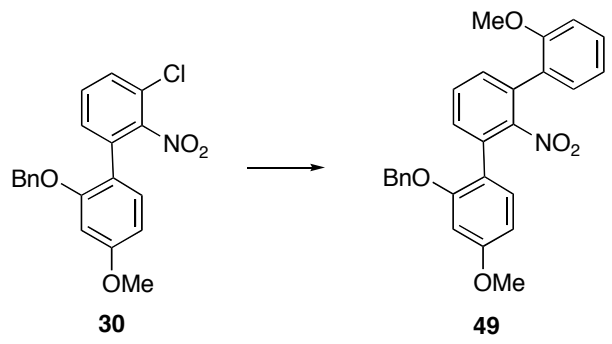

Triaryl 49: To a pressure vessel containing $30(36.2 \mathrm{mg}, 0.0980 \mathrm{mmol})$ was sequentially added $\mathrm{KF}(51.2 \mathrm{mg}, 0.880 \mathrm{mmol}), o-\mathrm{OMe}-\mathrm{C}_{6} \mathrm{H}_{4}-\mathrm{B}(\mathrm{OH})_{2}(62.3 \mathrm{mg}, 0.390 \mathrm{mmol})$, and $\left(t-\mathrm{Bu}{ }_{3} \mathrm{P}\right)_{2} \mathrm{Pd}(2.5 \mathrm{mg}, 0.0050$ mmol), and NMP $(0.98 \mathrm{~mL})$. The solution was sealed under Ar and heated to $80^{\circ} \mathrm{C}$. After $24 \mathrm{~h}$, the reaction was quenched with sat. aq. $\mathrm{NH}_{4} \mathrm{Cl}(5 \mathrm{~mL})$, diluted with EtOAc $(15 \mathrm{~mL})$, and washed with $\mathrm{H}_{2} \mathrm{O}(5$ $\mathrm{mL})$ and sat. aq. $\mathrm{NaCl}(5 \mathrm{~mL})$. The dried extract $\left(\mathrm{MgSO}_{4}\right)$ was concentrated in vacuo and purified by chromatography over silica gel, eluting with 3-10\% EtOAc / Hexanes to give 49 (19.1 mg, $0.0430 \mathrm{mmol}$, $44 \%$ ) as a pale yellow solid. MP $156-157^{\circ} \mathrm{C}$; IR (neat) $2924,1610,1530 \mathrm{~cm}^{-1} ;{ }^{1} \mathrm{H} \mathrm{NMR} \mathrm{(400} \mathrm{MHz,}$ $\left.\mathrm{CDCl}_{3}\right) \delta 7.57(\mathrm{dd}, J=7.6,8.0 \mathrm{~Hz}, 1 \mathrm{H}), 7.41(\mathrm{dd}, J=7.6,8.0 \mathrm{~Hz}, 3 \mathrm{H}), 7.34-7.25(\mathrm{~m}, 7 \mathrm{H}), 7.08(\mathrm{t}, J=7.6$ $\mathrm{Hz}, 1 \mathrm{H}), 6.96(\mathrm{~d}, J=8.4 \mathrm{~Hz}, 1 \mathrm{H}), 6.61(\mathrm{dd}, J=2.0,8.4 \mathrm{~Hz}, 1 \mathrm{H}), 6.53(\mathrm{~d}, J=2.0 \mathrm{~Hz}, 1 \mathrm{H}), 5.04(\mathrm{~s}, 2 \mathrm{H}), 3.81$ $(\mathrm{s}, 3 \mathrm{H}), 3.72(\mathrm{~s}, 3 \mathrm{H}) ;{ }^{13} \mathrm{C}$ NMR $\left(100 \mathrm{MHz}, \mathrm{CDCl}_{3}\right) \delta 161.0,156.7,156.4,150.4,137.0,132.3,132.2,131.5$, $130.9,130.8,130.7,130.4,130.1,129.7,128.4,127.5,126.7,120.9,119.8,111.0,105.4,100.7,70.5,55.4$, 55.3; HRMS (FAB+) calcd. for $\mathrm{C}_{27} \mathrm{H}_{23} \mathrm{NO}_{5}(\mathrm{M}+\mathrm{H}) 441.1576$, found 441.1613 .

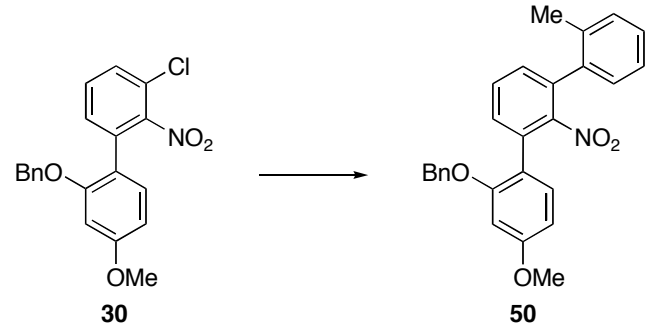

Triaryl 50: To a pressure vessel containing $30(59.5 \mathrm{mg}, 0.160 \mathrm{mmol})$ was sequentially added $\mathrm{KF}$ (83.5 mg, $1.44 \mathrm{mmol}), o-\mathrm{Me}-\mathrm{C}_{6} \mathrm{H}_{4}-\mathrm{B}(\mathrm{OH})_{2}(87.0 \mathrm{mg}, 0.640 \mathrm{mmol}),\left(t-\mathrm{Bu}_{3} \mathrm{P}\right)_{2} \mathrm{Pd}(4.1 \mathrm{mg}, 0.0080 \mathrm{mmol})$, and NMP $(1.60 \mathrm{~mL})$. The solution was sealed under $\mathrm{Ar}$ and heated to $80^{\circ} \mathrm{C}$. After $48 \mathrm{~h}$, the reaction was quenched with sat. aq. $\mathrm{NH}_{4} \mathrm{Cl}(5 \mathrm{~mL})$, diluted with EtOAc $(20 \mathrm{~mL})$, and washed with $\mathrm{H}_{2} \mathrm{O}(10 \mathrm{~mL})$ and sat. aq. $\mathrm{NaCl}(10 \mathrm{~mL})$. The dried extract $\left(\mathrm{MgSO}_{4}\right)$ was concentrated in vacuo and purified by chromatography over silica gel, eluting with 3-10\% EtOAc / Hexanes followed by recrystallization with $\mathrm{Et}_{2} \mathrm{O} / \mathrm{Hexanes}$ (1:2) to give $\mathbf{5 0}(22.8 \mathrm{mg}, 0.0540 \mathrm{mmol}, 34 \%)$ as a pale yellow solid. MP $126-127^{\circ} \mathrm{C}$; IR (neat) 3062 , 2860, 1617, $1531 \mathrm{~cm}^{-1} ;{ }^{1} \mathrm{H}$ NMR $\left(400 \mathrm{MHz} \mathrm{CDCl}_{3}\right) \delta 7.53(\mathrm{t}, J=7.6 \mathrm{~Hz}, 1 \mathrm{H}), 7.42(\mathrm{dd}, J=1.6,8.0 \mathrm{~Hz}$, $1 \mathrm{H}), 7.32-7.26(\mathrm{~m}, 8 \mathrm{H}), 7.24(\mathrm{~d}, J=8.0 \mathrm{~Hz}, 1 \mathrm{H}), 7.19(\mathrm{dd}, J=2.0,6.8 \mathrm{~Hz}, 1 \mathrm{H}), 7.16(\mathrm{dd}, J=1.6,8.0 \mathrm{~Hz}$, $1 \mathrm{H}), 6.58(\mathrm{dd}, J=2.4,8.4 \mathrm{~Hz}, 1 \mathrm{H}), 6.56(\mathrm{~d}, J=2.4 \mathrm{~Hz}, 1 \mathrm{H}), 5.02(\mathrm{~s}, 2 \mathrm{H}), 3.82(\mathrm{~s}, 3 \mathrm{H}), 2.16(\mathrm{~s}, 3 \mathrm{H}) ;{ }^{13} \mathrm{C}$ NMR $\left(100 \mathrm{MHz}, \mathrm{CDCl}_{3}\right) \delta 161.2,156.6,150.6,136.8,136.5,134.5,131.7,131.4,131.0,130.0,129.8$, $129.5,128.8,128.5,128.4,128.3,127.7,127.0,125.5,118.9,105.3,100.5,70.4,55.4,20.1$; HRMS (TOF/ES+) calcd. for $\mathrm{C}_{27} \mathrm{H}_{23} \mathrm{NO}_{4}(\mathrm{M}+\mathrm{Na}) 448.1525$, found 448.1512 . 


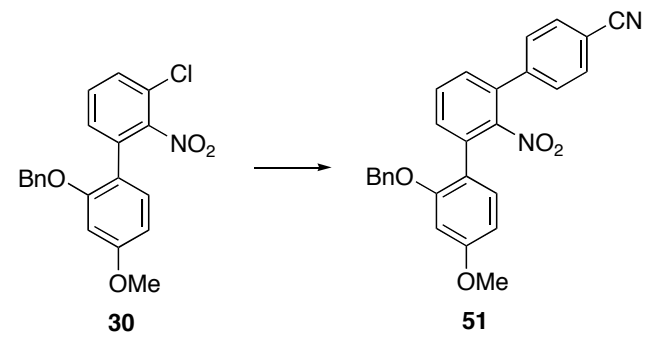

Triaryl 51: To a pressure vessel containing $30(48.6 \mathrm{mg}, 0.130 \mathrm{mmol})$, was sequentially added $\mathrm{KF}(68.4 \mathrm{mg}, 1.18 \mathrm{mmol}), p-\mathrm{CN}-\mathrm{C}_{6} \mathrm{H}_{4}-\mathrm{B}(\mathrm{OH})_{2}(76.1 \mathrm{mg}, 0.520 \mathrm{mmol}),\left(t-\mathrm{Bu}_{3} \mathrm{P}\right)_{2} \mathrm{Pd}(3.4 \mathrm{mg}, 0.0070$ $\mathrm{mmol})$, and NMP $(1.30 \mathrm{~mL})$. The solution was sealed under $\mathrm{Ar}$ and heated to $80^{\circ} \mathrm{C}$. After $24 \mathrm{~h}$, the reaction was quenched with sat. aq. $\mathrm{NH}_{4} \mathrm{Cl}(5 \mathrm{~mL})$, diluted with EtOAc $(15 \mathrm{~mL})$, and washed with $\mathrm{H}_{2} \mathrm{O}(5$ $\mathrm{mL})$ and sat. aq. $\mathrm{NaCl}(5 \mathrm{~mL})$. The dried extract $\left(\mathrm{MgSO}_{4}\right)$ was concentrated in vacuo and purified by chromatography over silica gel, eluting with 5-20\% EtOAc / Hexanes to give 51 (34.8 mg, 0.0800 mmol, $61 \%$ ) as a pale yellow solid. MP $178-179.5^{\circ} \mathrm{C}$; IR (neat) $2921,2223,1610,1530 \mathrm{~cm}^{-1} ;{ }^{1} \mathrm{H} \mathrm{NMR}(400 \mathrm{MHz}$, $\left.\mathrm{CDCl}_{3}\right) \delta 7.75(\mathrm{~d}, J=8.0 \mathrm{~Hz}, 2 \mathrm{H}), 7.61(\mathrm{dd}, J=8.0,7.6 \mathrm{~Hz}, 1 \mathrm{H}), 7.52(\mathrm{~d}, J=8.0 \mathrm{~Hz}, 2 \mathrm{H}), 7.51(\mathrm{~d}, J=7.6$ $\mathrm{Hz}, 1 \mathrm{H}), 7.38(\mathrm{dd}, J=1.2,7.6 \mathrm{~Hz}, 1 \mathrm{H}), 7.34-7.28(\mathrm{~m}, 5 \mathrm{H}), 7.20(\mathrm{~d}, J=8.4 \mathrm{~Hz}, 1 \mathrm{H}), 6.60(\mathrm{dd}, J=2.4,8.4$ $\mathrm{Hz}, 1 \mathrm{H}), 6.57(\mathrm{~d}, J=2.4 \mathrm{~Hz}, 1 \mathrm{H}), 5.06(\mathrm{~s}, 2 \mathrm{H}), 3.82(\mathrm{~s}, 3 \mathrm{H}) ;{ }^{13} \mathrm{C} \mathrm{NMR}\left(100 \mathrm{MHz}, \mathrm{CDCl}_{3}\right) \delta 161.4,156.6$, $149.9,141.9,136.8,132.9,132.7,132.5,132.4,130.8,130.1,129.4,128.9,128.5,127.7,126.8,118.5$, 118.1, 112.4, 105.4, 100.6, 70.4, 55.4; HRMS (FAB+) calcd. for $\mathrm{C}_{27} \mathrm{H}_{20} \mathrm{~N}_{2} \mathrm{O}_{4}(\mathrm{M}+)$ 436.1423, found 436.1440 .

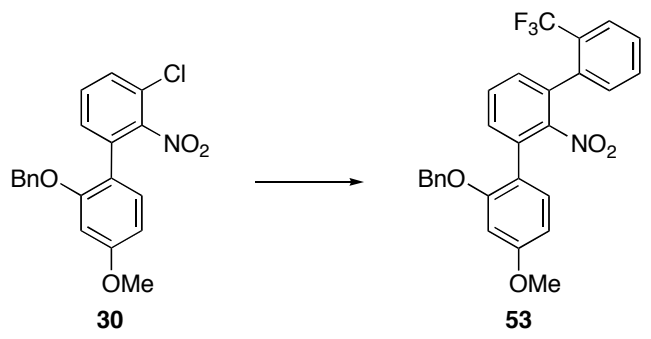

Triaryl 53: To a pressure vessel containing 30 (36.2 $\mathrm{mg}, 0.0980 \mathrm{mmol})$, was sequentially added $\mathrm{KF}(51.2 \mathrm{mg}, 0.880 \mathrm{mmol}), o-\mathrm{CF}_{3}-\mathrm{C}_{6} \mathrm{H}_{4}-\mathrm{B}(\mathrm{OH})_{2}(74.5 \mathrm{mg}, 0.390 \mathrm{mmol}),\left(t-\mathrm{Bu}_{3} \mathrm{P}\right)_{2} \mathrm{Pd}(2.5 \mathrm{mg}, 0.0050$ mmol), and NMP $(0.98 \mathrm{~mL})$. The solution was sealed under Ar and heated to $80^{\circ} \mathrm{C}$. After $24 \mathrm{~h}$, the reaction was quenched with sat. aq. $\mathrm{NH}_{4} \mathrm{Cl}(5 \mathrm{~mL})$, diluted with EtOAc $(15 \mathrm{~mL})$, and washed with $\mathrm{H}_{2} \mathrm{O}(10$ $\mathrm{mL})$ and sat. aq. $\mathrm{NaCl}(10 \mathrm{~mL})$. The dried extract $\left(\mathrm{MgSO}_{4}\right)$ was concentrated in vacuo and purified by chromatography over silica gel, eluting with 3-5\% EtOAc / Hexanes followed by recrystallization with $\mathrm{Et}_{2} \mathrm{O} /$ Hexanes $(2: 1)$ to give $55(10.1 \mathrm{mg}, 0.0210 \mathrm{mmol}, 22 \%)$ as a yellow crystalline solid. MP 102$104^{\circ} \mathrm{C}$; IR (neat) 3063, 2933, $1530 \mathrm{~cm}^{-1} ;{ }^{1} \mathrm{H} \mathrm{NMR}\left(300 \mathrm{MHz}, \mathrm{CDCl}_{3}\right) \delta 7.78(\mathrm{dd}, J=2.4,7.2 \mathrm{~Hz}, 1 \mathrm{H})$, 7.57-7.52 (m, 2H), $7.47(\mathrm{dd}, J=1.8,7.8 \mathrm{~Hz}, 1 \mathrm{H}), 7.34-7.28(\mathrm{~m}, 5 \mathrm{H}), 7.24(\mathrm{~d}, J=8.4 \mathrm{~Hz}, 1 \mathrm{H}), 6.59(\mathrm{dd}, J=$ $2.4,8.4 \mathrm{~Hz}, 1 \mathrm{H}), 6.55(\mathrm{~d}, J=2.4 \mathrm{~Hz}, 1 \mathrm{H}), 5.01(\mathrm{~s}, 2 \mathrm{H}), 3.82(\mathrm{~s}, 3 \mathrm{H}) ;{ }^{13} \mathrm{C} \mathrm{NMR}\left(100 \mathrm{MHz}, \mathrm{CDCl}_{3}\right) \delta 161.2$, $156.6,150.1,136.7,135.4,132.3,132.1,131.3,131.2,131.1,130.9,129.9,129.8,129.3,128.5,128.4$, 127.6, 126.9, 126.4, 126.3, 119.0, 105.4, 100.5, 70.5, 55.4; HRMS (EI+) calcd. for $\mathrm{C}_{27} \mathrm{H}_{20} \mathrm{~F}_{3} \mathrm{NO}_{4}(\mathrm{M}+)$ 479.1344 , found 479.1323 . 


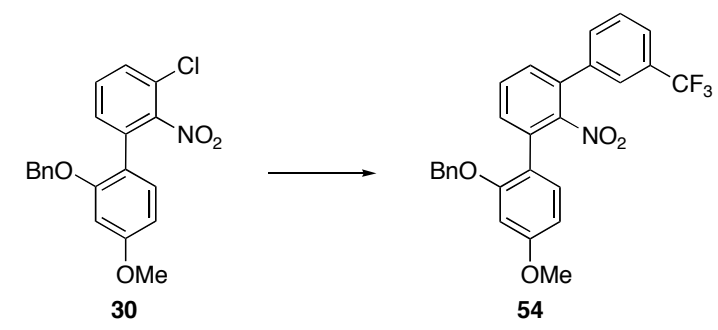

Triaryl 54: To a pressure vessel containing $30(39.4 \mathrm{mg}, 0.107 \mathrm{mmol})$, was sequentially added $\mathrm{KF}(55.9 \mathrm{mg}, 0.960 \mathrm{mmol}), m-\mathrm{CF}_{3}-\mathrm{C}_{6} \mathrm{H}_{4}-\mathrm{B}(\mathrm{OH})_{2}(81.3 \mathrm{mg}, 0.430 \mathrm{mmol}),\left(t-\mathrm{Bu}{ }_{3} \mathrm{P}\right)_{2} \mathrm{Pd}(2.7 \mathrm{mg}, 0.0050$ mmol), and NMP $(1.07 \mathrm{~mL})$. The solution was sealed under $\mathrm{Ar}$ and heated to $80^{\circ} \mathrm{C}$. After $48 \mathrm{~h}$, the reaction was quenched with sat. aq. $\mathrm{NH}_{4} \mathrm{Cl}(5 \mathrm{~mL})$, diluted with EtOAc $(15 \mathrm{~mL})$, and washed with $\mathrm{H}_{2} \mathrm{O}(5$ $\mathrm{mL})$ and sat. aq. $\mathrm{NaCl}(5 \mathrm{~mL})$. The dried extract $\left(\mathrm{MgSO}_{4}\right)$ was concentrated in vacuo and purified by chromatography over silica gel, eluting with 3-5\% EtOAc / Hexanes to give 54 (36.3 mg, $0.0800 \mathrm{mmol}$, $71 \%$ ) as a pale yellow oil. IR (neat) $2921,1527,1339 \mathrm{~cm}^{-1} ;{ }^{1} \mathrm{H}$ NMR $\left(400 \mathrm{MHz}, \mathrm{CDCl}_{3}\right) \delta 7.69-7.67(\mathrm{~m}$, $2 \mathrm{H}), 7.58(\mathrm{t}, J=7.5 \mathrm{~Hz}, 1 \mathrm{H}), 7.56(\mathrm{t}, J=5.7 \mathrm{~Hz}, 1 \mathrm{H}), 7.48(\mathrm{dd}, J=1.5,7.8 \mathrm{~Hz}, 1 \mathrm{H}), 7.39(\mathrm{dd}, J=1.2,7.5$ $\mathrm{Hz}, 1 \mathrm{H}), 7.35-7.25(\mathrm{~m}, 6 \mathrm{H}), 7.20(\mathrm{~d}, J=8.4 \mathrm{~Hz}, 1 \mathrm{H}), 6.58(\mathrm{dd}, J=2.4,8.4 \mathrm{~Hz}, 1 \mathrm{H}), 6.55(\mathrm{~d}, J=2.4 \mathrm{~Hz}$, $1 \mathrm{H}), 5.05(\mathrm{~s}, 2 \mathrm{H}), 3.81(\mathrm{~s}, 3 \mathrm{H}) ;{ }^{13} \mathrm{C} \mathrm{NMR}\left(75 \mathrm{MHz}, \mathrm{CDCl}_{3}\right) \delta 161.3,156.8,150.2,137.9,136.8,133.2$, $132.3,132.2,131.4,131.3,130.9,130.2,129.9,129.8,129.1,128.4,127.7,126.9,125.3,125.2(\mathrm{q}, J=3.8$ $\mathrm{Hz}, 1 \mathrm{C}), 118.3,105.3,100.6,70.5,55.4$; HRMS (EI+) calcd. for $\mathrm{C}_{27} \mathrm{H}_{20} \mathrm{~F}_{3} \mathrm{NO}_{4}(\mathrm{M}+)$ 479.1344, found 479.1324 .

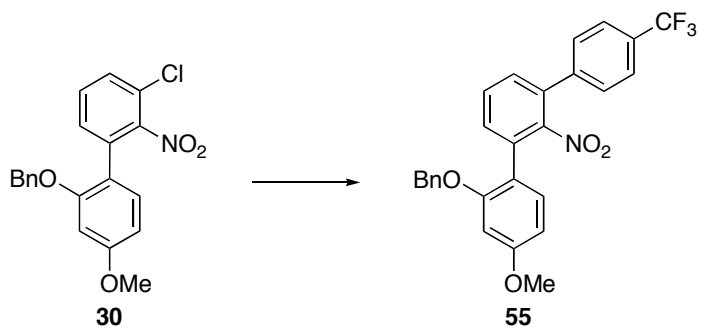

Triaryl 55: To a pressure vessel containing $30(48.5 \mathrm{mg}, 0.130 \mathrm{mmol})$, was sequentially added $\mathrm{KF}(68.4 \mathrm{mg}, 1.18 \mathrm{mmol}), p-\mathrm{CF}_{3}-\mathrm{C}_{6} \mathrm{H}_{4}-\mathrm{B}(\mathrm{OH})_{2}(99.5 \mathrm{mg}, 0.520 \mathrm{mmol}),\left(t-\mathrm{Bu}_{3} \mathrm{P}\right)_{2} \mathrm{Pd}(3.4 \mathrm{mg}, 0.0070$ mmol), and NMP $(1.31 \mathrm{~mL})$. The solution was sealed under Ar and heated to $80^{\circ} \mathrm{C}$. After $24 \mathrm{~h}$, the reaction was quenched with sat. aq. $\mathrm{NH}_{4} \mathrm{Cl}(5 \mathrm{~mL})$, diluted with EtOAc $(15 \mathrm{~mL})$, and washed with $\mathrm{H}_{2} \mathrm{O}(5$ $\mathrm{mL})$ and sat. aq. $\mathrm{NaCl}(5 \mathrm{~mL})$. The dried extract $\left(\mathrm{MgSO}_{4}\right)$ was concentrated in vacuo and purified by chromatography over silica gel, eluting with 5-20\% EtOAc / Hexanes to give 55 (37.5 mg, 0.0780 mmol, $60 \%$ ) as a yellow crystalline solid. MP $113-114^{\circ} \mathrm{C}$; IR (neat) $2918,1527,1323 \mathrm{~cm}^{-1}$; ${ }^{1} \mathrm{H} \mathrm{NMR}(400 \mathrm{MHz}$, $\left.\mathrm{CDCl}_{3}\right) \delta 7.70(\mathrm{~d}, J=8.2 \mathrm{~Hz}, 2 \mathrm{H}), 7.59(\mathrm{t}, J=7.7 \mathrm{~Hz}, 1 \mathrm{H}), 7.52(\mathrm{~d}, J=8.2 \mathrm{~Hz}, 2 \mathrm{H}), 7.49(\mathrm{dd}, J=1.4,7.7$ $\mathrm{Hz}, 1 \mathrm{H}), 7.39(\mathrm{dd}, J=1.4,7.7 \mathrm{~Hz}, 1 \mathrm{H}), 7.33-7.27(\mathrm{~m}, 5 \mathrm{H}), 7.20(\mathrm{~d}, J=8.3 \mathrm{~Hz}, 1 \mathrm{H}), 6.58(\mathrm{dd}, J=2.4,8.3$ $\mathrm{Hz}, 1 \mathrm{H}), 6.55(\mathrm{~d}, J=2.4 \mathrm{~Hz}, 1 \mathrm{H}), 5.06(\mathrm{~s}, 2 \mathrm{H}), 3.81(\mathrm{~s}, 3 \mathrm{H}) ;{ }^{13} \mathrm{C} \mathrm{NMR}\left(100 \mathrm{MHz}, \mathrm{CDCl}_{3}\right) \delta 161.3,156.7$, $150.2,140.8,136.8,133.3,132.4,132.2,130.8,130.3,129.9,129.6,128.6,128.5,127.7,126.8,125.7$, 125.6, 118.3, 105.3, 100.7, 70.5, 55.4; HRMS (EI+) calcd. for $\mathrm{C}_{27} \mathrm{H}_{20} \mathrm{NO}_{4} \mathrm{~F}_{3}(\mathrm{M}+)$ 479.1344, found 479.1353. 


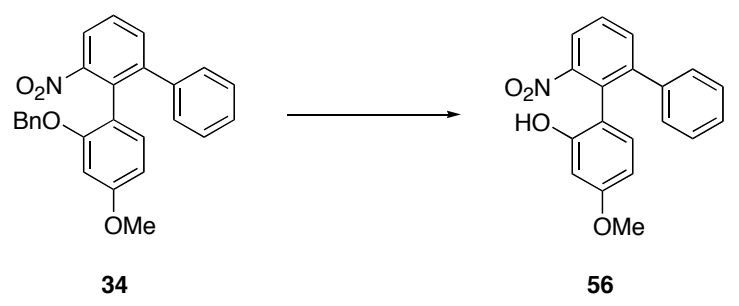

Phenol 56: To a stirred solution of $34(45.3 \mathrm{mg}, 110 \mu \mathrm{mol})$ in $\mathrm{CH}_{2} \mathrm{Cl}_{2}(98 \mu \mathrm{L})$ was added $\mathrm{BCl}_{3}$ $\left(600 \mu \mathrm{L}, 600 \mu \mathrm{mol}, 1.0 \mathrm{M}\right.$ in heptane) at $0^{\circ} \mathrm{C}$. After $4 \mathrm{~h}$, the reaction was quenched with $\mathrm{MeOH}(2.0 \mathrm{~mL})$, concentrated in vacuo, and purified via flash chromatography over silica gel, eluting with 10-30\% EtOAc / hexanes to give 56 (32.9 mg, $102 \mu \mathrm{mol}, 92 \%$ ) as a bright yellow oil. IR (neat) 3522, 1620, 1592, 1526, 1360, 1264, 1040, 877, $764 \mathrm{~cm}^{-1}$; ${ }^{1} \mathrm{H}$ NMR (400 MHz, $\left.\mathrm{CDCl}_{3}\right) \delta 7.85(\mathrm{dd}, J=8.0,1.4 \mathrm{~Hz}, 1 \mathrm{H}), 7.68(\mathrm{dd}, J$ $=8.0,1.4 \mathrm{~Hz}, 1 \mathrm{H}), 7.60(\mathrm{t}, J=8.0 \mathrm{~Hz}, 1 \mathrm{H}), 7.28-7.21(\mathrm{~m}, 3 \mathrm{H}), 7.19-7.12(\mathrm{~m}, 2 \mathrm{H}), 6.77(\mathrm{~d}, J=8.0 \mathrm{~Hz}, 1 \mathrm{H})$, 6.41-6.32 (m, 2H), $4.95(\mathrm{br}, 1 \mathrm{H}), 3.65(\mathrm{~s}, 3 \mathrm{H}) ;{ }^{13} \mathrm{C} \mathrm{NMR}\left(100 \mathrm{MHz}, \mathrm{CDCl}_{3}\right) \delta 160.8,154.0,151.7,145.2$, $139.5,134.1,131.5,129.7,129.1,128.5,128.0,127.4,122.6,115.0,106.7,101.7,55.2$; HRMS (EI+) calcd. for $\mathrm{C}_{19} \mathrm{H}_{15} \mathrm{NO}_{4} 321.1001$, found 321.0999 .

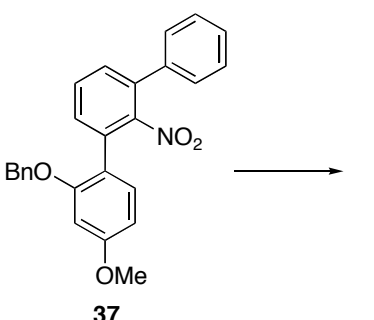

37

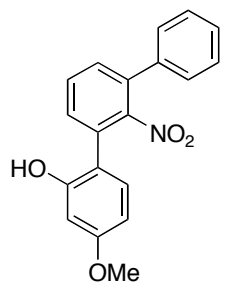

57

Phenol 57: To a stirred solution of $37(45.2 \mathrm{mg}, 0.110 \mathrm{mmol})$ in $\mathrm{CH}_{2} \mathrm{Cl}_{2}(1.10 \mathrm{~mL})$ was added $\mathrm{BCl}_{3}(0.660 \mathrm{~mL}, 0.660 \mathrm{mmol}, 1.0 \mathrm{M}$ in hexanes $)$ at $0^{\circ} \mathrm{C}$. After $4 \mathrm{~h}$, the reaction was quenched with $\mathrm{MeOH}$ $(2.0 \mathrm{~mL})$, concentrated in vacuo, and purified via recrystallization with $\mathrm{CH}_{2} \mathrm{Cl}_{2}$ to yield 57 (29.0 $\mathrm{mg}$, $0.0900 \mathrm{mmol}, 82 \%$ ) as a yellow crystalline solid. MP $166-167^{\circ} \mathrm{C}$; IR (neat) $3409,2921,1617,1530 \mathrm{~cm}^{-1}$; ${ }^{1} \mathrm{H}$ NMR (400 MHz, MeOD) $\delta 7.62(\mathrm{t}, J=7.7 \mathrm{~Hz}, 1 \mathrm{H}), 7.46-7.38(\mathrm{~m}, 7 \mathrm{H}), 7.05(\mathrm{~d}, J=8.0 \mathrm{~Hz}, 1 \mathrm{H}), 6.50-$ $6.47(\mathrm{~m}, 2 \mathrm{H}), 3.81(\mathrm{~s}, 3 \mathrm{H}) ;{ }^{13} \mathrm{C}$ NMR (100 MHz, MeOD) $\delta 161.3,155.6,152.8,150.5,137.4,134.4,132.0$, $131.5,130.5,129.5,128.2,127.9,127.8,116.6,104.7,101.0,54.3$; HRMS (EI+) calcd. for $\mathrm{C}_{19} \mathrm{H}_{15} \mathrm{NO}_{4}$ $(\mathrm{M}+\mathrm{H}) 321.1001$, found 321.1004 .

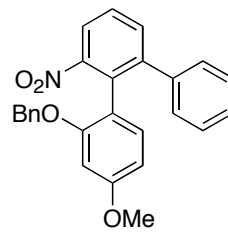

34

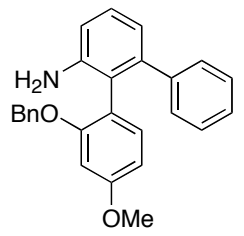

58

Aniline 58: To a stirred solution of $34(44.6 \mathrm{mg}, 101 \mu \mathrm{mol})$ in glacial HOAc $(410 \mu \mathrm{L})$ was added $\mathrm{Zn}$ dust $(41.0 \mathrm{mg}, 627 \mu \mathrm{mol})$ at rt. After $20 \mathrm{~h}$, the mixture was quenched with sat. aq. $\mathrm{NaHCO}_{3}(15 \mathrm{~mL})$, diluted with EtOAc $(20 \mathrm{~mL})$ and washed with $\mathrm{H}_{2} \mathrm{O}(20 \mathrm{~mL})$ and sat. aq. $\mathrm{NaCl}(20 \mathrm{~mL})$. The dried extract $\left(\mathrm{Na}_{2} \mathrm{SO}_{4}\right)$ was concentrated in vacuo and purified via flash chromatography over silica gel, eluting with $15-$ 25\% EtOAc / Hexanes to give 58 (34.2 mg, 90.9 umol, 90\%) as a colorless oil. IR (neat) 3471, 3379, 3058, 2835, 1609, 1580, 1266, $1044 \mathrm{~cm}^{-1}$; ${ }^{1} \mathrm{H}$ NMR (400 MHz, $\left.\mathrm{CDCl}_{3}\right) \delta 7.38-7.13(\mathrm{~m}, 11 \mathrm{H}), 7.01(\mathrm{~d}, J=9.0 \mathrm{~Hz}$, $1 \mathrm{H}), 6.87(\mathrm{dd}, J=8.0,1.1 \mathrm{~Hz}, 1 \mathrm{H}), 6.83(\mathrm{dd}, J=8.0,1.1 \mathrm{H}, 1 \mathrm{H}), 6.54-6.41(\mathrm{~m}, 2 \mathrm{H}), 5.02(\mathrm{~d}, J=12.8 \mathrm{~Hz}$, $1 \mathrm{H}), 4.92(\mathrm{~d}, J=12.8 \mathrm{~Hz}, 1 \mathrm{H}), 3.76(\mathrm{~s}, 3 \mathrm{H}), 3.52(\mathrm{br}, 2 \mathrm{H}) ;{ }^{13} \mathrm{C} \mathrm{NMR}\left(100 \mathrm{MHz}, \mathrm{CDCl}_{3}\right) \delta 160.2,157.2$, 
145.0, 143.2, 142.4, 137.4, 132.9, 129.3, 128.4, 128.1, 127.5, 127.4, 126.6, 126.0, 122.9, 120.2, 119.4, 114.3, 105.4, 100.6, 69.9, 55.3; HRMS (EI+) calcd. for $\mathrm{C}_{26} \mathrm{H}_{23} \mathrm{NO}_{2} 381.1729$, found 381.1721.

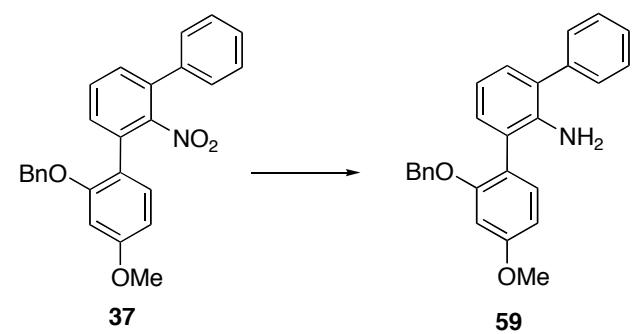

Aniline 59: To a stirred solution of $37(54.4 \mathrm{mg}, 0.132 \mathrm{mmol})$ in glacial HOAc $(0.55 \mathrm{~mL})$ was added $\mathrm{Zn}$ dust $(43.2 \mathrm{mg}, 0.660 \mathrm{mmol})$ at rt. After $20 \mathrm{~h}$, the mixture was quenched with sat. aq. $\mathrm{NaHCO}_{3}$ $(15 \mathrm{~mL})$, diluted with EtOAc $(20 \mathrm{~mL})$ and washed with $\mathrm{H}_{2} \mathrm{O}(20 \mathrm{~mL})$ and sat. aq. $\mathrm{NaCl}(20 \mathrm{~mL})$. The dried extract $\left(\mathrm{MgSO}_{4}\right)$ was concentrated in vacuo and purified by chromatography over silica gel, eluting with 15-25\% EtOAc / Hexanes to give $\mathbf{5 9}(49.0 \mathrm{mg}, 0.128 \mathrm{mmol}, \mathbf{9 7 \%})$ as a yellow oil. IR (neat) 3471,3385 , $3057,2933,1611,1503,1163 \mathrm{~cm}^{-1} ;{ }^{1} \mathrm{H}$ NMR $\left(300 \mathrm{MHz}, \mathrm{CDCl}_{3}\right) \delta$ 7.56-7.48 (m, 4H), 7.41 (dt, $J=1.5,1.5$, $7.2 \mathrm{~Hz}, 1 \mathrm{H}), 7.38-7.32(\mathrm{~m}, 6 \mathrm{H}), 7.20(\mathrm{dd}, J=1.2,7.2 \mathrm{~Hz}, 2 \mathrm{H}), 6.93(\mathrm{t}, J=7.5 \mathrm{~Hz}, 1 \mathrm{H}), 6.71-6.67(\mathrm{~m}, 2 \mathrm{H})$, $5.12(\mathrm{~s}, 2 \mathrm{H}), 3.88(\mathrm{~s}, 3 \mathrm{H}), 3.85$ (broad s, $2 \mathrm{H}) ;{ }^{13} \mathrm{C} \mathrm{NMR}\left(75 \mathrm{MHz}, \mathrm{CDCl}_{3}\right) \delta 160.5,156.9,142.0,140.2$, 137.2, 132.4, 130.7, 129.5, 129.4, 128.8, 128.5, 127.8, 127.7, 127.1, 126.9, 125.0, 122.0, 117.9, 106.0, 101.3, 70.7, 55.5; HRMS (EI+) calcd. for $\mathrm{C}_{26} \mathrm{H}_{23} \mathrm{NO}_{2}(\mathrm{M}+\mathrm{H}) 382.1729$, found 381.1728 .

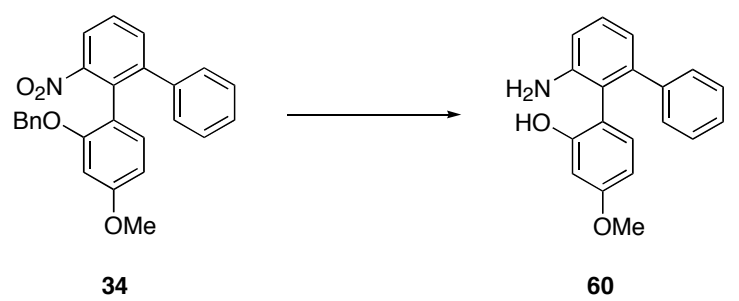

Phenol 60: To a stirred solution of $34(54.7 \mathrm{mg}, 132.3 \mu \mathrm{mol})$ and EtOH (460 $\mu \mathrm{L}$, absolute) was added $\mathrm{Pd} / \mathrm{C}(62.3 \mathrm{mg}, 10 \% \mathrm{Pd})$. After stirring under an atmosphere of $\mathrm{H}_{2}$ for $21 \mathrm{~h}$, the mixture was filtered over a pad of Celite- $\AA$ with EtOAc $(50 \mathrm{~mL})$ and concentrated in vacuo. The product was purified via flash chromatography over silica gel, eluting with 15-20\% EtOAc / Hexanes to give 60 (26.1 mg, $89.6 \mu \mathrm{mol}$, $67 \%$ ) as a colorless oil; IR (neat) $3472,3382,3187,3057,2959,1621,1573,1265,1161,1039 \mathrm{~cm}^{-1} ;{ }^{1} \mathrm{H}$ NMR $\left(400 \mathrm{MHz}, \mathrm{CDCl}_{3}\right) \delta 7.30(\mathrm{t}, J=7.9 \mathrm{~Hz}, 1 \mathrm{H}), 7.25-7.10(\mathrm{~m}, 5 \mathrm{H}), 6.95(\mathrm{dd}, J=7.6,1.0 \mathrm{~Hz}, 1 \mathrm{H}), 6.86$ $(\mathrm{dd}, J=8.0,1.0 \mathrm{~Hz}, 1 \mathrm{H}), 6.80(\mathrm{~d}, J=8.5 \mathrm{~Hz}, 1 \mathrm{H}), 6.54(\mathrm{~d}, J=2.5 \mathrm{~Hz}, 1 \mathrm{H}), 6.38(\mathrm{dd}, 8.5,2.5 \mathrm{~Hz}, 1 \mathrm{H})$, 3.78 (s, 3H), 4.70-3.40 (br, 3H); ${ }^{13} \mathrm{C}$ NMR (100 MHz, $\left.\mathrm{CDCl}_{3}\right) \delta 160.7,154.7,144.7,144.0,141.3,132.6$, $129.1,129.1,127.7,126.5,121.4,120.6,115.9,114.9,107.3,101.6,55.2$; HRMS (EI+) calcd. for $\mathrm{C}_{19} \mathrm{H}_{17} \mathrm{NO}_{2} 291.1259$, found 291.1251 .

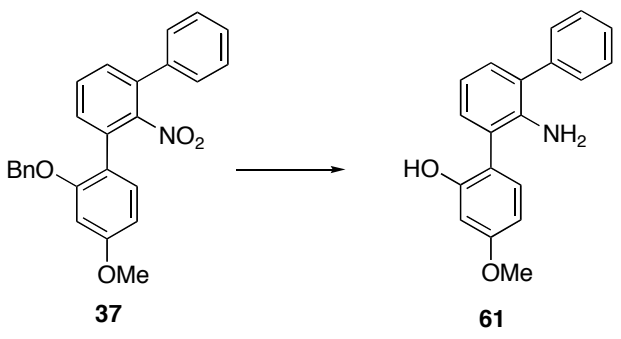

Phenol 61: To a stirred solution of $37(25.6 \mathrm{mg}, 0.0620 \mathrm{mmol})$ and EtOH $(0.31 \mathrm{~mL})$ was added $\mathrm{Pd} / \mathrm{C}(29.9 \mathrm{mg}, 10 \% \mathrm{Pd})$. After stirring under an atmosphere of $\mathrm{H}_{2}$ for $21 \mathrm{~h}$, the mixture was filtered over a 
pad of celite- $($ with EtOAc $(50 \mathrm{~mL})$ and concentrated in vacuo. The product was purified by chromatography over silica gel, eluting with 15-20\% EtOAc / Hexanes to give 61 (15.3 mg, $0.0530 \mathrm{mmol}$, $85 \%$ ) as a white solid. MP $87-89^{\circ} \mathrm{C}$; IR (neat) $3394,3301,2921,1731,1617,1160 \mathrm{~cm}^{-1}$; ${ }^{1} \mathrm{H}$ NMR (400 $\left.\mathrm{MHz}, \mathrm{CDCl}_{3}\right) \delta 7.55-7.50(\mathrm{~m}, 4 \mathrm{H}), 7.45(\mathrm{~m}, 1 \mathrm{H}), 7.29(\mathrm{~d}, J=2.0 \mathrm{~Hz}, 1 \mathrm{H}), 7.26(\mathrm{dd}, J=1.6,7.6 \mathrm{~Hz}, 1 \mathrm{H})$, $7.23(\mathrm{dd}, J=1.6,8.4 \mathrm{~Hz}, 1 \mathrm{H}), 7.05(\mathrm{t}, J=7.6 \mathrm{~Hz}, 1 \mathrm{H}), 6.69(\mathrm{~m}, 2 \mathrm{H}), 3.87(\mathrm{~s}, 3 \mathrm{H}) ;{ }^{13} \mathrm{C} \mathrm{NMR}(100 \mathrm{MHz}$, $\left.\mathrm{CDCl}_{3}\right) \delta 161.1,154.9,139.0,138.9,131.9,131.1,129.9,129.8,129.3,129.1,127.7,126.3,120.6,118.8$, 107.9, 103.1 55.4; HRMS (EI+) calcd. for $\mathrm{C}_{19} \mathrm{H}_{17} \mathrm{NO}_{2}(\mathrm{M}+\mathrm{H}) 291.1259$, found 291.126.

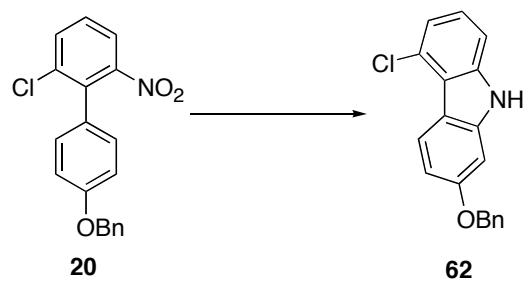

Carbazole 62: To a pressure vessel containing $20(38.7 \mathrm{mg}, 114 \mu \mathrm{mol})$ and $o-\mathrm{C}_{6} \mathrm{H}_{4} \mathrm{Cl}_{2}(230 \mu \mathrm{L})$ was added $\mathrm{PPh}_{3}(75.5 \mathrm{mg}, 289 \mu \mathrm{mol})$ at rt. The mixture was heated to $180^{\circ} \mathrm{C}$. After $24 \mathrm{~h}$, the reaction was cooled to rt and purified via flash chromatography over silica gel, eluting with 10-30\% EtOAc / Hexanes to give impure $62(40.2 \mathrm{mg})$ as a brown solid. Recrystallization from $\mathrm{CHCl}_{3} /$ Pentane afforded $\mathbf{6 1}(26.3 \mathrm{mg}$, $85.5 \mu \mathrm{mol}, 75 \%$ ) as an off-white solid. MP $158-160^{\circ} \mathrm{C}$; IR (thin film) $3387,1177 \mathrm{~cm}^{-1} ;{ }^{1} \mathrm{H}$ NMR (400 $\left.\mathrm{MHz}, \mathrm{CDCl}_{3}\right) \delta 8.48(\mathrm{~d}, J=8.7 \mathrm{~Hz}, 1 \mathrm{H}), 8.02$ (br s, $\left.1 \mathrm{H}\right), 7.52$ (d, $\left.J=7.2 \mathrm{~Hz}, 2 \mathrm{H}\right), 7.45$ (t, $\left.J=7.2 \mathrm{~Hz}, 2 \mathrm{H}\right)$, $7.38(\mathrm{t}, J=7.2 \mathrm{~Hz}, 1 \mathrm{H}), 7.33-7.18(\mathrm{~m}, 3 \mathrm{H}), 7.03(\mathrm{dd}, J=8.7,2.2 \mathrm{~Hz}, 1 \mathrm{H}), 6.97(\mathrm{~d}, J=0.9 \mathrm{~Hz}, 1 \mathrm{H}), 5.19(\mathrm{~s}$, $2 \mathrm{H}) ;{ }^{13} \mathrm{C}$ NMR $\left(100 \mathrm{MHz}, \mathrm{CDCl}_{3}\right) \delta 158.5,140.8,140.6,137.0,128.7,128.0,127.8,127.5,125.0,123.9$, 120.9, 120.3, 116.4, 109.3, 108.6, 95.7, 70.4; HRMS (EI+) calcd. for $\mathrm{C}_{19} \mathrm{H}_{14} \mathrm{NOCl}(\mathrm{M}+)$ 307.0764, found 307.0775 .

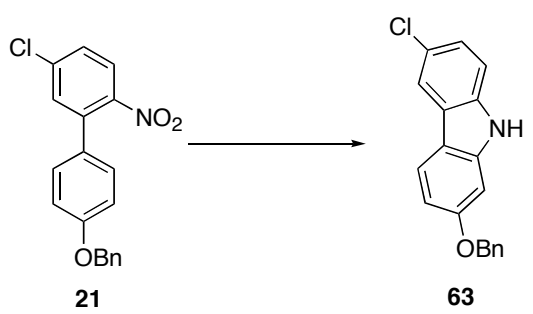

Carbazole 63: To a pressure vessel containing $21(49.9 \mathrm{mg}, 147 \mu \mathrm{mol})$ and $o-\mathrm{C}_{6} \mathrm{H}_{4} \mathrm{Cl}_{2}(300 \mu \mathrm{L})$ was added $\mathrm{PPh}_{3}(119.4 \mathrm{mg}, 455 \mu \mathrm{mol})$ at $\mathrm{rt}$. The mixture was heated to $180^{\circ} \mathrm{C}$. After $24 \mathrm{~h}$, the reaction was cooled to $\mathrm{rt}$ and purified via flash chromatography over silica gel, eluting with 10-30\% EtOAc / Hexanes to give impure $\mathbf{6 3}(50.4 \mathrm{mg})$ as a brown solid. Recrystallization from $\mathrm{CHCl}_{3} /$ Pentane afforded $\mathbf{6 3}$ (43.7 mg, $142 \mu \mathrm{mol}, 89 \%$ ) as an off-white solid. MP 222-224 ${ }^{\circ} \mathrm{C}$; IR (KBr) 3390, 2916, 1624, 1225, 1176, 1027, 816, $728 \mathrm{~cm}^{-1} ;{ }^{1} \mathrm{H}$ NMR (400 MHz, $d_{6}$-DMSO) $\delta 11.30(\mathrm{~s}, 1 \mathrm{H}), 8.11(\mathrm{~s}, 1 \mathrm{H}), 8.04(\mathrm{~d}, J=7.8 \mathrm{~Hz}, 1 \mathrm{H})$, 7.68-7.19 (m, 7H), $7.08(\mathrm{~s}, 1 \mathrm{H}), 6.89(\mathrm{~d}, J=7.8 \mathrm{~Hz}, 1 \mathrm{H}), 5.22(\mathrm{~s}, 2 \mathrm{H}) ;{ }^{13} \mathrm{C}$ NMR $\left(100 \mathrm{MHz}, d_{6}\right.$-DMSO) $\delta 158.5,142.2,138.7,137.7,128.9,128.3,128.2,124.5,124.3,123.4,122.0,119.4,116.0,112.5,109.4$, 96.2, 70.0; HRMS (EI+) calcd. for $\mathrm{C}_{19} \mathrm{H}_{14} \mathrm{NOCl}(\mathrm{M}+)$ 307.0764, found 307.0764. 


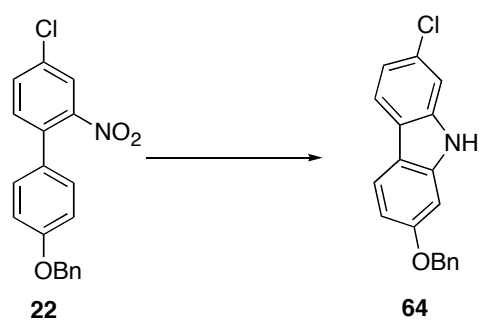

Carbazole 64: To a pressure vessel containing $22(18.7 \mathrm{mg}, 55.0 \mathrm{mmol})$ and $o-\mathrm{C}_{6} \mathrm{H}_{4} \mathrm{Cl}_{2}(150 \mu \mathrm{L})$ was added $\mathrm{PPh}_{3}(44.1 \mathrm{mg}, 168 \mu \mathrm{mol})$ at $\mathrm{rt}$. The mixture was heated to $180^{\circ} \mathrm{C}$. After $24 \mathrm{~h}$, the reaction was cooled to rt and purified via flash chromatography over silica gel, eluting with 10-30\% EtOAc/ Hexanes to give impure $64(17.6 \mathrm{mg})$ as a brown solid. Recrystallization from $\mathrm{CHCl}_{3} /$ Pentane afforded 64 (14.2 mg, $46.1 \mu \mathrm{mol}, 84 \%)$ as an off-white solid. MP 235-238 ${ }^{\circ} \mathrm{C}$; IR (KBr) 3396, 2923, 1605, 1016, $797 \mathrm{~cm}^{-1} ;{ }^{1} \mathrm{H}$ NMR (400 MHz, $d_{6}$-DMSO) $11.29(\mathrm{~s}, 1 \mathrm{H}), 8.02(\mathrm{~d}, J=3.3 \mathrm{~Hz}, 1 \mathrm{H}), 8.00(\mathrm{~d}, J=3.7 \mathrm{~Hz}, 1 \mathrm{H}), 7.52$ (d, $J=$ $7.2 \mathrm{~Hz}, 2 \mathrm{H}), 7.46(\mathrm{~d}, J=1.8 \mathrm{~Hz}, 1 \mathrm{H}), 7.43(\mathrm{t}, J=7.1 \mathrm{~Hz}, 2 \mathrm{H}), 7.35(\mathrm{t}, J=7.3 \mathrm{~Hz}, 1 \mathrm{H}), 7.14(\mathrm{dd}, J=8.3$, $1.9 \mathrm{~Hz}, 1 \mathrm{H}), 7.09(\mathrm{~d}, J=2.3 \mathrm{~Hz}, 1 \mathrm{H}), 6.90(\mathrm{dd}, J=8.6,2.3 \mathrm{~Hz}, 1 \mathrm{H}), 5.21(\mathrm{~s}, 2 \mathrm{H}) ;{ }^{13} \mathrm{C} \mathrm{NMR}\left(100 \mathrm{MHz}, d_{6^{-}}\right.$ DMSO) $\delta 158.3,141.9,140.9,137.7,129.0,128.9,128.3,128.2,122.0,121.6,121.1,119.1,116.2,110.8$, 109.4, 96.4, 70.0; HRMS (EI+) calcd. for $\mathrm{C}_{19} \mathrm{H}_{14} \mathrm{NOCl}(\mathrm{M}+)$ 307.0764, found 307.0772.

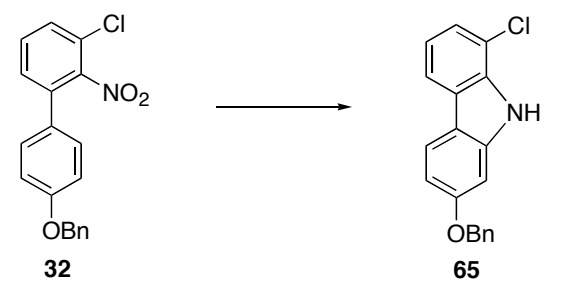

Carbazole 65: To a pressure vessel containing $32(17.2 \mathrm{mg}, 0.0510 \mathrm{mmol})$ and $o$-dichlorobenzene $(100 \mu \mathrm{L})$ was added $\mathrm{PPh}_{3}(66.4 \mathrm{mg}, 0.254 \mathrm{mmol})$ at $\mathrm{rt}$. The mixture was heated at $180^{\circ} \mathrm{C}$. After $48 \mathrm{~h}$, the reaction was purified via flash chromatography over silica gel, eluting with 0-20\% EtOAc / Hexanes to give 65 (10.2 mg, $0.033 \mathrm{mmol}, 65 \%)$ as a white solid. MP $145-146{ }^{\circ} \mathrm{C}$; IR $3419,2911,1419,735 \mathrm{~cm}^{-1} ;{ }^{1} \mathrm{H}$ NMR (400 MHz, CDCl $)_{3} \delta .21(\mathrm{bs}, 1 \mathrm{H}), 7.96(\mathrm{~d}, J=8.6 \mathrm{~Hz}, 1 \mathrm{H}), 7.89(\mathrm{~d}, J=7.8 \mathrm{~Hz}, 1 \mathrm{H}), 7.52(\mathrm{~d}, J=7.2$ $\mathrm{Hz}, 2 \mathrm{H}), 7.45(\mathrm{t}, J=7.1,7.6 \mathrm{~Hz}, 2 \mathrm{H}), 7.38(\mathrm{t}, J=7.2,7.8 \mathrm{~Hz}, 2 \mathrm{H}), 7.18(\mathrm{t}, J=7.8 \mathrm{~Hz}, 1 \mathrm{H}), 7.07(\mathrm{~d}, J=2.0$ $\mathrm{Hz}, 1 \mathrm{H}), 7.00(\mathrm{dd}, J=2.2 \mathrm{~Hz}, 8.6 \mathrm{~Hz}, 1 \mathrm{H}) ;{ }^{13} \mathrm{C} \mathrm{NMR}\left(100 \mathrm{MHz}, \mathrm{CDCl}_{3}\right) \delta 158.7,140.5,137.0,136.7$, 128.7, 128.1, 127.5, 125.0, 123.9, 121.6, 120.4, 117.9, 117.6, 115.8, 109.8, 96.2, 70.5; HRMS (FAB+) calcd. For $\mathrm{C}_{19} \mathrm{H}_{14} \mathrm{ClNO}(\mathrm{M}+\mathrm{H}) 308.0842$, found 308.0846 .
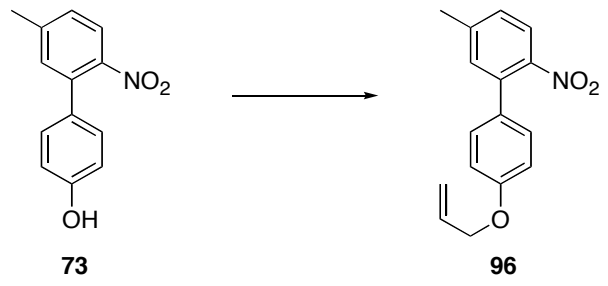

Allyl ether 96: To a stirred solution of $73(843.0 \mathrm{mg}, 3.677 \mathrm{mmol})$ and dry DMF (18.0 mL) was added $\mathrm{NaH}$ (320.9 mg, $8.022 \mathrm{mmol}, 60 \%$ dispersion in mineral oil) at $0^{\circ} \mathrm{C}$. To this dark red solution was added allyl iodide $(3.12 \mathrm{~g}, 1.70 \mathrm{~mL}, 18.59 \mathrm{mmol})$. After $10 \mathrm{~min}$, the yellow solution was quenched with sat. aq. $\mathrm{NH}_{4} \mathrm{Cl}(20 \mathrm{~mL})$, diluted with EtOAc $(100 \mathrm{~mL})$, washed with $\mathrm{H}_{2} \mathrm{O}(10 \mathrm{~mL})$, and sat. aq. $\mathrm{NaCl}(2 \times 10$ $\mathrm{mL})$. The dried $\left(\mathrm{Na}_{2} \mathrm{SO}_{4}\right)$ extract was concentrated in vacuo and purified by flash chromatography over silica gel, eluting with PhMe to give 96 (990 mg, $3.68 \mathrm{mmol}, 99 \%$ ) as a bright yellow oil. IR (neat) 1610 , 1516, 1353, $734 \mathrm{~cm}^{-1} ;{ }^{1} \mathrm{H}$ NMR (400 MHz, $\left.\mathrm{CDCl}_{3}\right) \delta 7.782(\mathrm{~d}, J=8.9,1 \mathrm{H}), 7.31-7.22(\mathrm{~m}, 4 \mathrm{H}), 7.03-6.97$ $(\mathrm{m}, 2 \mathrm{H}), 6.18-6.05(\mathrm{~m}, 1 \mathrm{H}), 5.48(\mathrm{dq}, J=17.2, J=1.5 \mathrm{~Hz}, 1 \mathrm{H}), 5.34(\mathrm{dq}, J=10.5,1.3 \mathrm{~Hz}, 1 \mathrm{H}), 4.60(\mathrm{dt}, J=$ 5.3, $1.5 \mathrm{~Hz}, 2 \mathrm{H}), 2.47(\mathrm{~s}, 3 \mathrm{H}) ;{ }^{13} \mathrm{C} \mathrm{NMR}\left(100 \mathrm{MHz}, \mathrm{CDCl}_{3}\right) \delta 158.6,147.1,143.3,136.1,133.2,132.6$, 
130.1, 129.1, 128.3, 124.3, 117.8, 114.9, 68.9, 21.4; HRMS (EI+) calcd. for $\mathrm{C}_{16} \mathrm{H}_{15} \mathrm{NO}_{3}(\mathrm{M}+)$ 269.1052, found 269.1042 .

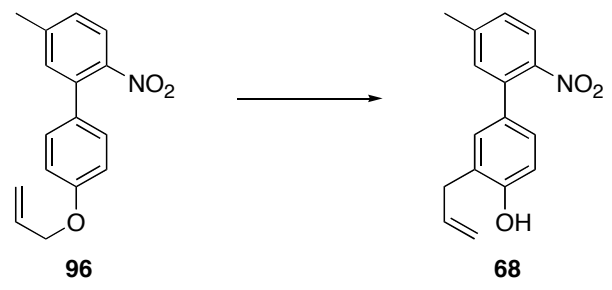

Phenol 68: To a stirred solution of 96 (990 mg, $3.68 \mathrm{mmol})$ in $\mathrm{CH}_{2} \mathrm{Cl}_{2}(37.0 \mathrm{~mL})$ was added $\mathrm{BCl}_{3}$ $\left(11.1 \mathrm{~mL}, 11.1 \mathrm{mmol}, 1.0 \mathrm{M}\right.$ in hexanes) at $-78^{\circ} \mathrm{C}$. After $2 \mathrm{~h}$, the reaction was quenched with $\mathrm{MeOH}(2.0$ $\mathrm{mL})$ at $-78^{\circ} \mathrm{C}$ and warmed to rt. The solution was diluted with $\mathrm{CH}_{2} \mathrm{Cl}_{2}(45 \mathrm{~mL})$ and washed with $\mathrm{H}_{2} \mathrm{O}(2 \mathrm{x}$ $20 \mathrm{~mL})$ and sat. aq. $\mathrm{NaCl}(2 \times 20 \mathrm{~mL})$. The dried $\left(\mathrm{Na}_{2} \mathrm{SO}_{4}\right)$ extract was concentrated in vacuo and purified via flash chromatography over silica gel, eluting with $10-30 \% \mathrm{Et}_{2} \mathrm{O} / \mathrm{PhMe}$ to give $\mathbf{6 8}$ (845.7 mg, 3.141 mmol, $85 \%$ ) as a yellow crystalline solid. MP $82-83^{\circ} \mathrm{C}$; IR (thin film) $3486,1609,1520,1351,1215,758$ $\mathrm{cm}^{-1} ;{ }^{1} \mathrm{H}$ NMR $\left(400 \mathrm{MHz}, \mathrm{CDCl}_{3}\right) \delta 7.78(\mathrm{~d}, J=8.1 \mathrm{~Hz}, 1 \mathrm{H}), 7.28-7.22(\mathrm{~m}, 2 \mathrm{H}), 7.14-7.08(\mathrm{~m}, 2 \mathrm{H}), 6.88$ $(\mathrm{d}, J=8.0 \mathrm{~Hz}, 1 \mathrm{H}), 6.06(\mathrm{~m}, 1 \mathrm{H}), 5.24(\mathrm{dq}, J=5.25,1.5 \mathrm{~Hz}, 1 \mathrm{H}), 5.21(\mathrm{t}, J=1.6 \mathrm{~Hz}, 2 \mathrm{H}), ;{ }^{13} \mathrm{C} \mathrm{NMR}(100$ $\left.\mathrm{MHz}, \mathrm{CDCl}_{3}\right) \delta$; HRMS (EI+) calcd. for $\mathrm{C}_{19} \mathrm{H}_{15} \mathrm{NO}_{4}(\mathrm{M}+)$ 269.1052, found 269.1053 .

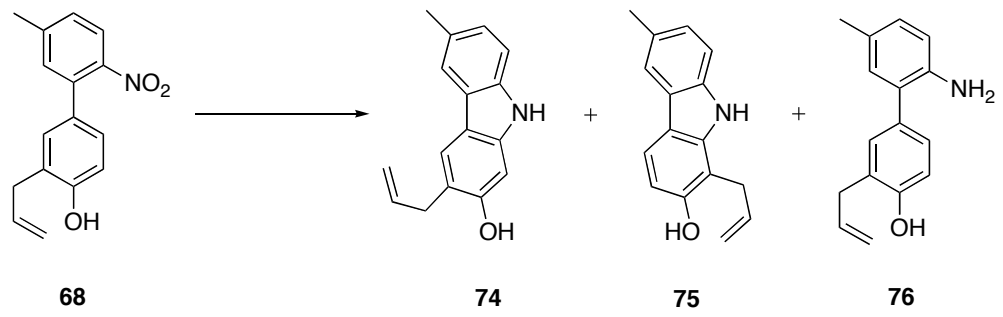

Carbazoles 74 and 75 and Aniline 76: METHOD A - To a pressure vessel containing 68 (51.6 mg, $191.6 \mu \mathrm{mol})$ and $o-\mathrm{C}_{6} \mathrm{H}_{4} \mathrm{Cl}_{2}(2.00 \mathrm{~mL})$ was added $\mathrm{PPh}_{3}(205 \mathrm{mg}, 782 \mu \mathrm{mol})$ at rt. The mixture was heated at $180^{\circ} \mathrm{C}$. After $30 \mathrm{~h}$ at $180^{\circ} \mathrm{C}$, the reaction was cooled to $\mathrm{rt}$ and passes trough a silica plug. Purification via flash chromatography over silica gel, eluting with 10-15\% EtOAc / Hexanes gave sequentially 75 (23.2 mg, $97.8 \mu \mathrm{mol}, 51 \%), 76(5.3 \mathrm{mg}, 22.1 \mu \mathrm{mol}, 11 \%)$, and $74(14.5 \mathrm{mg}, 61.1 \mu \mathrm{mol}, 32 \%)$ as off-white solids. MethOD B - To a pressure vessel containing $68(26.6 \mathrm{mg}, 98.8 \mu \mathrm{mol})$ and $o-\mathrm{C}_{6} \mathrm{H}_{4} \mathrm{Cl}_{2}(1.00 \mathrm{~mL})$ was added $\mathrm{P}^{n} \mathrm{Bu}_{3}(81 \mathrm{mg}, 100 \mu \mathrm{L}, 400 \mu \mathrm{mol})$ at $\mathrm{rt}$. The mixture was heated at $180^{\circ} \mathrm{C}$. After $12 \mathrm{~h}$ at $180^{\circ} \mathrm{C}$, the reaction was cooled to $\mathrm{rt}$ and purified via flash chromatography over silica gel, eluting with 10-25\% EtOAc / Hexanes to give sequentially 75 (5.6 mg, $24 \mu \mathrm{mol}, 23 \%), 76$ (9.4 mg, $39 \mu \mathrm{mol}, 38 \%)$, and 74 (6.5 mg, 27 $\mu \mathrm{mol}, 27 \%)$ as off-white solids.

74: MP $131-133^{\circ} \mathrm{C}$; IR (thin film) $3412,3212,2920,2851,1639,1615,1211,909,802 \mathrm{~cm}^{-1} ;{ }^{1} \mathrm{H}$ NMR $\left(400 \mathrm{MHz}, \mathrm{CDCl}_{3}\right) \delta 7.78(\mathrm{~d}, J=4.9 \mathrm{~Hz}, 3 \mathrm{H}), 7.27(\mathrm{~d}, J=8.2 \mathrm{~Hz}, 1 \mathrm{H}), 7.18(\mathrm{dd}, J=8.2,1.1 \mathrm{~Hz}$, $1 \mathrm{H}), 6.86(\mathrm{~s}, 1 \mathrm{H}), 6.15(\mathrm{ddt}, J=16.5,10.1,6.3 \mathrm{~Hz}, 1 \mathrm{H}), 5.26(\mathrm{dq}, J=12.2,1.6 \mathrm{~Hz}, 1 \mathrm{H}), 5.23(\mathrm{dt}, J=4.9,1.7$ $\mathrm{Hz}, 1 \mathrm{H}), 5.19$ (br s, $1 \mathrm{H}), 3.61(\mathrm{~d}, J=3.6 \mathrm{~Hz}, 2 \mathrm{H}), 2.54(\mathrm{~s}, 3 \mathrm{H}) ;{ }^{13} \mathrm{C} \mathrm{NMR}\left(100 \mathrm{MHz}, \mathrm{CDCl}_{3}\right) \delta 153.4$, 140.1, 137.8, 137.3, 128.7, 125.8, 123.7, 121.5, 119.5, 117.9, 117.4, 116.4, 110.0, 97.4, 35.7, 21.5; HRMS $(\mathrm{EI}+)$ calcd. for $\mathrm{C}_{16} \mathrm{H}_{15} \mathrm{NO} 237.1154(\mathrm{M}+)$, found 237.1149 .

75: MP 154-156 ${ }^{\circ} \mathrm{C}$; IR (thin film) 3459, 3356, 2918, 2850, 1614, 1211, 912, $804 \mathrm{~cm}^{-1} ;{ }^{1} \mathrm{H}$ NMR $\left(400 \mathrm{MHz}, \mathrm{CDCl}_{3}\right) \delta 7.91(\mathrm{br} \mathrm{s}, 1 \mathrm{H}), 7.80(\mathrm{~d}, J=8.1 \mathrm{~Hz}, 1 \mathrm{H}), 7.79(\mathrm{~s}, 1 \mathrm{H}), 7.32(\mathrm{~d}, J=8.2 \mathrm{~Hz}, 1 \mathrm{H}), 7.19$ (dd, $J=8.2,1.3 \mathrm{~Hz}, 1 \mathrm{H}), 6.76(\mathrm{~d}, J=8.3 \mathrm{~Hz}, 1 \mathrm{H}), 6.13$ (ddt, $J=16.0,10.1,6.0 \mathrm{~Hz}, 1 \mathrm{H}), 5.29-5.19(\mathrm{~m}, 2 \mathrm{H})$, $4.96(\mathrm{br} \mathrm{s}, 1 \mathrm{H}), 3.72(\mathrm{dt}, J=5.9,1.6 \mathrm{~Hz}, 2 \mathrm{H}), 2.54(\mathrm{~s}, 3 \mathrm{H}) ;{ }^{13} \mathrm{C} \mathrm{NMR}\left(100 \mathrm{MHz}, \mathrm{CDCl}_{3}\right) \delta 152.0,140.8$, $137.9,135.6,128.9,125.9,124.1,119.5,119.0,117.5,116.3,110.2,108.9,106.5,29.4,21.5$; HRMS (EI+) calcd. for $\mathrm{C}_{16} \mathrm{H}_{15} \mathrm{NO} 237.1154(\mathrm{M}+)$, found 237.1149 . 
76: MP 136-138 ${ }^{\circ}$; IR (thin film) 3376, 3311, 1607, $1270 \mathrm{~cm}^{-1}$; ${ }^{1} \mathrm{H}$ NMR (400 $\mathrm{MHz}, \mathrm{CDCl}_{3}$ ) $\delta$ 7.29-7.18 (m, 2H), 7.06-6.97 (m, 2H), $6.85(\mathrm{~d}, J=8.0 \mathrm{~Hz}, 1 \mathrm{H}), 6.76(\mathrm{~d}, J=7.8 \mathrm{~Hz}, 1 \mathrm{H}), 6.09(\mathrm{~m}, 1 \mathrm{H}), 5.29-$ $5.17(\mathrm{~m}, 2 \mathrm{H}), 3.92(\mathrm{br} \mathrm{s}, 1 \mathrm{H}), 3.49(\mathrm{~d}, J=6.4 \mathrm{~Hz}, 2), 2.34$ (s, $3 \mathrm{H}) ;{ }^{13} \mathrm{C} \mathrm{NMR}\left(100 \mathrm{MHz}, \mathrm{CDCl}_{3}\right) \delta 153.4$, 140.6, 136.4, 131.9, 131.1, 131.1, 128.7, 128.4, 128.4, 128.1, 126.1, 116.6, 116.1, 116.0, 35.1, 20.5. HRMS (EI+) calcd. for $\mathrm{C}_{16} \mathrm{H}_{17} \mathrm{NO} 239.1310(\mathrm{M}+)$, found 239.1321 .

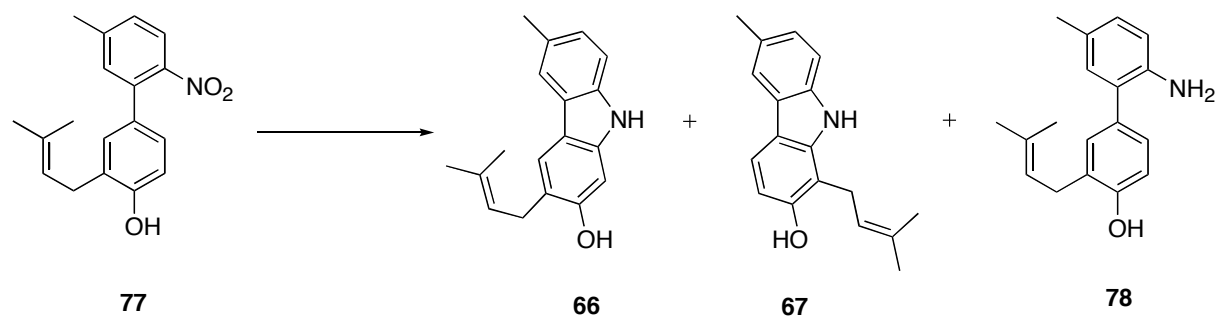

Siamenol 66, Carbazole 67 and Amine 78: To a pressure vessel containing 77 (50.4 mg, 169 $\mu \mathrm{mol})$ and $o-\mathrm{C}_{6} \mathrm{H}_{4} \mathrm{Cl}_{2}(400 \mu \mathrm{L})$ was added $\mathrm{P}^{n} \mathrm{Bu}_{3}(138 \mathrm{mg}, 170 \mu \mathrm{L}, 681 \mu \mathrm{mol})$ at rt. The mixture was heated at $100^{\circ} \mathrm{C}$. After $12 \mathrm{~h}$ at $100^{\circ} \mathrm{C}$, the reaction was cooled to $\mathrm{rt}$ and purified via flash chromatography over silica gel, eluting with 10-25\% EtOAc / Hexanes to give sequentially 67 (19.2 mg, $72.3 \mu \mathrm{mol}, 43 \%), 78$ (10.8 mg, $40.4 \mu \mathrm{mol}, 24 \%$ ), and $\mathbf{6 6}(12.4 \mathrm{mg}, 46.7 \mu \mathrm{mol}, 28 \%)$ as white solids.

66: MP $140-143^{\circ} \mathrm{C}$; IR (thin film) $3406,3252,2920,2852,1636,1617,1465,1319,1210,1014$, $802 \mathrm{~cm}^{-1}$; ${ }^{1} \mathrm{H}$ NMR $\left(400 \mathrm{MHz}, \mathrm{CDCl}_{3}\right) \delta 7.77(\mathrm{~m}, 3 \mathrm{H}), 7.27(\mathrm{~d}, J=8.0 \mathrm{~Hz}, 1 \mathrm{H}), 7.17(\mathrm{~d}, J=8.0 \mathrm{~Hz}, 1 \mathrm{H})$, $6.86(\mathrm{~s}, 1 \mathrm{H}), 5.44(\mathrm{tt}, J=7.2,1.2 \mathrm{H}, 1 \mathrm{H}), 5.30(\mathrm{~s}, 1 \mathrm{H}), 3.55(\mathrm{~d}, J=7.2 \mathrm{~Hz}, 2 \mathrm{H}), 2.54(\mathrm{~s}, 3 \mathrm{H}), 1.88(\mathrm{~s}, 3 \mathrm{H})$, $1.85(\mathrm{~s}, 3 \mathrm{H}) ;{ }^{1} \mathrm{H}$ NMR $\left(400 \mathrm{MHz}, d_{4}\right.$-MeOD) $\delta 7.64(\mathrm{dd}, J=1.6,0.8 \mathrm{~Hz}, 1 \mathrm{H}), 7.60(\mathrm{~s}, 1 \mathrm{H}), 7.19(\mathrm{~d}, J=8.2$ $\mathrm{Hz}, 1 \mathrm{H}), 7.04$ (dd, $J=8.1,1.0 \mathrm{~Hz}, 1 \mathrm{H}), 6.79$ (s, 1H), 5.43 (t-sept, $J=7.3,1.4 \mathrm{~Hz}, 1 \mathrm{H}), 3.41$ (d, $J=7.3 \mathrm{~Hz}$, 2H), 2.45 (s, 3H), $1.78(\mathrm{~s}, 6 \mathrm{H}) ;{ }^{13} \mathrm{C} \mathrm{NMR}\left(100 \mathrm{MHz}, \mathrm{CDCl}_{3}\right) \delta$ 153.7, 139.9, 137.7, 134.7, 128.6, 125.7, $123.7,122.6,120.8,119.4,117.2,109.9,97.2,30.5,25.8,21.4,17.9 ;{ }^{13} \mathrm{C} \mathrm{NMR}\left(100 \mathrm{MHz}, \mathrm{CDCl}_{3}\right) \delta$ 154.16, 140.4, 138.5, 131.1, 127.3, 124.7, 124.0, 123.9, 120.5, 119.7, 118.5, 116.1, 109.7, 95.9, 28.5, 24.9, 20.4, 16.7 HRMS (EI+) calcd. for $\mathrm{C}_{18} \mathrm{H}_{19} \mathrm{NO} 265.1467(\mathrm{M}+)$, found 265.1471.

67: MP 126- $128^{\circ} \mathrm{C}$; IR (thin film) 3524, 3424, 3261,2919, 2853, 1614, 1227, 1211, 1032, $802 \mathrm{~cm}^{-}$ ${ }^{1} ;{ }^{1} \mathrm{H}$ NMR $\left(400 \mathrm{MHz}, \mathrm{CDCl}_{3}\right) \delta 7.85(\mathrm{br} \mathrm{s}, 1 \mathrm{H}), 7.78(\mathrm{~d}, J=1.0 \mathrm{~Hz}, 1 \mathrm{H}), 7.76(\mathrm{~d}, J=3.6 \mathrm{~Hz}, 1 \mathrm{H}), 7.31(\mathrm{~d}$, $J=8.2 \mathrm{~Hz}, 1 \mathrm{H}), 7.18(\mathrm{dd}, J=8.4,1.1 \mathrm{~Hz}, 1 \mathrm{H}), 6.76(\mathrm{~d}, J=8.3 \mathrm{~Hz}, 1 \mathrm{H}), 5.41$ (d-quint, $J=6.9,1.4 \mathrm{~Hz}, 1 \mathrm{H}$ ), $5.11(\mathrm{br} \mathrm{s}, 1 \mathrm{H}), 3.64(\mathrm{~d}, J=6.9 \mathrm{~Hz}, 2 \mathrm{H}), 2.54(\mathrm{~s}, 3 \mathrm{H}), 1.94(\mathrm{~s}, 3 \mathrm{H}), 1.82(\mathrm{~d}, J=1.2 \mathrm{~Hz}, 3 \mathrm{H}) ;{ }^{13} \mathrm{C} \mathrm{NMR}(100$ $\left.\mathrm{MHz}, \mathrm{CDCl}_{3}\right) \delta 152.2,140.4,137.8,134.9,128.8,125.8,124.2,121.5,119.5,118.6,117.4,110.1,109.0$, 108.3, 25.8, 24.4, 21.5, 18.1; HRMS (EI+) calcd. for $\mathrm{C}_{16} \mathrm{H}_{15} \mathrm{NO} 237.1154(\mathrm{M}+)$, found 237.1155.

78: MP $126-132^{\circ} \mathrm{C}$; IR (thin film) $3363,3276,2920,1604,1431,1279,1233 \mathrm{~cm}^{-1} ;{ }^{1} \mathrm{H}$ NMR (400 $\left.\mathrm{MHz}, \mathrm{CDCl}_{3}\right) \delta 7.23(\mathrm{~d}, J=2.0 \mathrm{~Hz}, 1 \mathrm{H}), 7.21(\mathrm{dd}, J=8.3,2.1 \mathrm{~Hz}, 1 \mathrm{H}), 7.00(\mathrm{~d}, J=9.1 \mathrm{~Hz}, 2 \mathrm{H}), 6.87(\mathrm{~d}, J$ $=8.0 \mathrm{~Hz}, 1 \mathrm{H}), 6.74(\mathrm{~d}, J=7.8 \mathrm{~Hz}, 1 \mathrm{H}), 5.40(\mathrm{tt}, J=5.9,1.3 \mathrm{~Hz}, 1 \mathrm{H}), 4.18(\mathrm{br} \mathrm{s}, 1 \mathrm{H}), 3.44(\mathrm{~d}, J=7.2 \mathrm{~Hz}$, $2 \mathrm{H}), 2.32(\mathrm{~s}, 3 \mathrm{H}), 1.83(\mathrm{~s}, 3 \mathrm{H}), 1.82(\mathrm{~s}, 3 \mathrm{H}) ;{ }^{13} \mathrm{C}$ NMR $\left(100 \mathrm{MHz}, \mathrm{CDCl}_{3}\right) \delta 153.6,140.9,134.8,131.9$, 131.1, 130.7, 128.6, 128.1, 128.0, 128.0, 127.4, 121.7, 115.9, 115.9, 29.8, 25.9, 20.5, 17.9; HRMS (EI+) calcd. for $\mathrm{C}_{18} \mathrm{H}_{21} \mathrm{NO}(\mathrm{M}+)$ 267.1623, found 267.162

\section{References}

1. Sigma-Aldrich Catalog \# 106,046.

2. Vetlino, M. G.; Coe, J. W. Tetrahedron Lett. 1994, 35, 219-22. (b) Caron, S.; Vazquez, E.; Stevens, R. W.; Nahao, K.; Koike, H.; Murata, Y. J. Org. Chem. 2003, 68, 4104-07.

3. Sigma-Aldrich Catalog \# C4753.

4. (a) Ohira, S. Synth. Commun. 1989, 19, 561-4. (b) S. Müller, S.; Liepold, B.; Roth, G. J.; Bestmann, J. SYNLETT 1996, 521-22. For preparation of 6, see also: (c) Goundry, W. R. F.; Baldwin, J. E.; 
Lee, V. Tetrehedron 2003, 59, 1719-29. (d) Kitamura, M.; Tokynaga, M.; Noyori, R. J. Am. Chem. Soc. 1995, 117, 2931-2.

5. Sigma-Aldrich Catalog \# 579,823.

6. Sigma-Aldrich Catalog \# C58,800.

7. Liu, B.; Moffett, K. K.; Joseph, R. W.; Dorsey, B. D. Tetrahedron Lett. 2005, 46, 1779-1782.

8. Kataoka, T.; Watanabe, S.; Mori, E.; Kadomoto, R.; Tanimura, S.; Kohno, M. Bioorg. Med. Chem. 2004, 12, 2397.

9. Savard, J.; Brassard, P. Tetrahedron 1984, 40, 3455-64.

10. (a) Murugan, R.; Kamakshi, R.; Reddy, B. S. R. Aust. J. Chem. 2005, 58, 228-30. (b) Chandrasekhar, S.; Rao, Y. S.; Reddy, N. R. SYNLETT 2005, 1471-73. (c) Bhosale, R. S.; Bhosale, S. V.; Bhosale, S. V.; Wang, T.; Zubaidha, P. K. Tetrahedron Lett. 2004, 45, 7187-88.

11. To a stirred solution of $\mathrm{i}-\mathrm{Pr}_{2} \mathrm{NH}(1.42 \mathrm{~g}, 1.97 \mathrm{~mL}, 14.1 \mathrm{mmol})$ in $\mathrm{THF}(7.78 \mathrm{~mL})$ at $-78^{\circ} \mathrm{C}$ was added dropwise $n$-BuLi $(5.59 \mathrm{~mL}, 13.2 \mathrm{mmol}, 2.4 \mathrm{M}$ in hexanes). After $10 \mathrm{~min}$ a white precipitate appeared and the solution was warmed to $0^{\circ} \mathrm{C}$. After $5 \mathrm{~min}$, the solution was recooled to $-78^{\circ} \mathrm{C}$ and ready for use.

12. Nicolaou, K. C.; Montagnon, T.; Vassilikogiznnakis, G.; Mathison, C. J. N. J. Am.

Chem. Soc. 2005, 127, 8872-88.

13. Freskos, J. N.; Morrow, G. W.; Swenton, J. S. J. Org. Chem. 1985, 50, 805-10. 